\title{
WestVirginiaUniversity
}

THE RESEARCH REPOSITORY @ WVU

Graduate Theses, Dissertations, and Problem Reports

2010

\section{Social Worlds of Rock Climbers at Seneca Rocks, West Virginia}

Katherine A. Thompson

West Virginia University

Follow this and additional works at: https://researchrepository.wvu.edu/etd

\section{Recommended Citation}

Thompson, Katherine A., "Social Worlds of Rock Climbers at Seneca Rocks, West Virginia" (2010).

Graduate Theses, Dissertations, and Problem Reports. 3175.

https://researchrepository.wvu.edu/etd/3175

This Dissertation is protected by copyright and/or related rights. It has been brought to you by the The Research Repository @ WVU with permission from the rights-holder(s). You are free to use this Dissertation in any way that is permitted by the copyright and related rights legislation that applies to your use. For other uses you must obtain permission from the rights-holder(s) directly, unless additional rights are indicated by a Creative Commons license in the record and/ or on the work itself. This Dissertation has been accepted for inclusion in WVU Graduate Theses, Dissertations, and Problem Reports collection by an authorized administrator of The Research Repository @ WVU.

For more information, please contact researchrepository@mail.wvu.edu. 
Social Worlds of Rock Climbers at Seneca Rocks, West Virginia

Katherine A. Thompson

Dissertation submitted to the Davis College of Agriculture, Natural Resources and Design at West Virginia University in partial fulfillment of the requirements for the degree of

Doctor of Philosophy

in

Forest Resources Science

Chad D. Pierskalla, Ph.D., Chair

Steve W. Selin, Ph.D.

David A. Smaldone, Ph.D.

Jinyang Deng, Ph.D.

Recreation, Parks, and Tourism Resources Program, West Virginia University

Jaci Webb-Dempsey, Ph.D.

Department of Education, Fairmont State University

Morgantown, West Virginia

2010

Keywords: Rock climbing, recreation management, traditional climbing, qualitative research, grounded theory, risk, safety, conflict, recreation planning

Copyright 2010 Katherine A. Thompson 


\section{ABSTRACT \\ Social Worlds of Rock Climbers at Seneca Rocks, West Virginia}

Katherine A. Thompson

The purpose of this study was to provide management at Spruce Knob-Seneca Rocks National Recreation Area, West Virginia, with an understanding of the social worlds of rock climbers at Seneca Rocks, to ascertain any management interventions that can improve access to climbing areas at Seneca Rocks, and to determine how permitted group sizes among guided and/or unguided climbers would affect the social worlds of climbers at Seneca Rocks. Between the fall of 2009 and spring of 201017 interviews with rock climbers of varying experience climbing at Seneca Rocks were conducted, then analyzed along with accident reports, internet forum discussions, academic literature, "grey" literature, and artifacts, using a constructivist grounded theory method. The social subworlds of climbers at Seneca Rocks were found to be highly fragmented among infrequent users of the area as well as social insiders, whereas frequent users were the most cohesive social subworld. This fragmentation led to challenges communicating safety information between more- and less experienced climbers. Social fragmentation among insiders led to incomplete information being passed on to area management, meaning that management decisions may be informed by the group of insiders that partnered with them but not by the group that distrusted the US Forest Service. It is recommended that area management attempt to cultivate trust with the latter group of insiders in order to ensure that future decision making is fully informed, especially with respect to issues that are complex and nuanced among climbers, like bolting. Further, it is necessary to exploit new information channels and reconsider current communication approaches to ensure that climbers with little information about the area can make safe climbing decisions while climbing at Seneca Rocks. 


\section{ACKNOWLEDGEMENTS}

I would be remiss if I did not start out by thanking Jo Tynon, Bruce Shindler, and Royal Jackson at Oregon State University, without whose encouragement I never would have considered graduate school or my current career path. To my committee: words will never express the gratitude I feel for experiencing this journey with you. I couldn't have asked for better people to share it with. To Julie Fosbender and Steve Kickert: thank you for your wisdom, and for providing so many incredible opportunities to give back to one of my favorite places on the planet. To the many graduate students and faculty both at West Virginia University and around the world with whom I have been blessed to cross paths, thank you for your support, humor, curiosity, and encouragement. To Karen Robinson, I miss you terribly every day. To all my online friends, including but definitely not limited to Bob, Brooke, Cheryl, Clarity, Jeff, Jen, Margaret, Melanie, Paul, Rejoyce, the various Sues and Susans, Trent, and too many others of you to possibly mention in this brief space (but you know I mean you), for supporting me, putting up with me, and generally propping me up when I needed it, through the best and the worst of it. I cannot thank you enough. To Brandy and Deb: thank you for making me take breaks, keeping me sane, feeding the family, and all of the other incredible things you do just by being you. To my folks: thank you for trying to understand this crazy graduate school thing I've been doing for so long now. Finally, to Ben and Logan: I could not have done this without your support, love, and general silliness - thank you ever so much for following me around and putting up with me during my less-than-pleasant moments. You are the best family I could ever ask for. 


\section{TABLE OF CONTENTS}

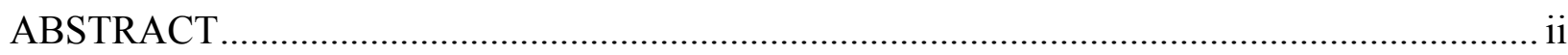

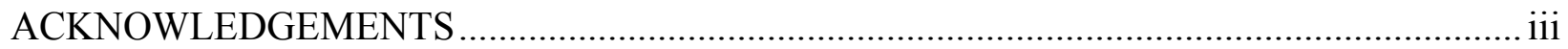

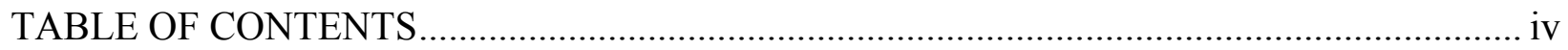

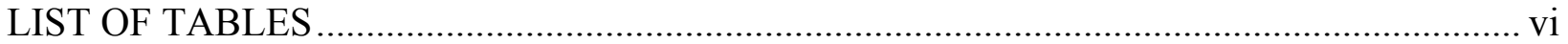

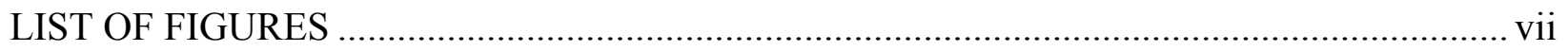

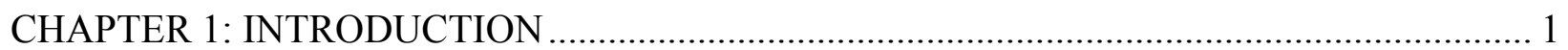

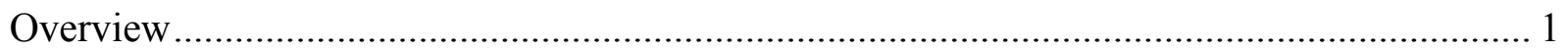

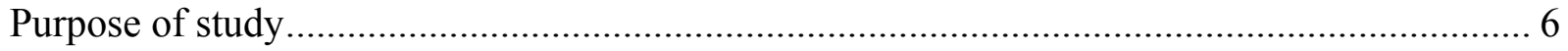

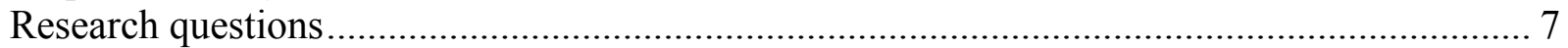

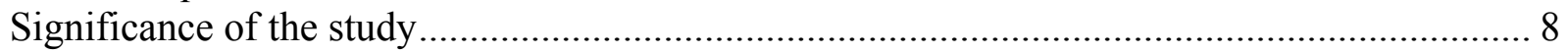

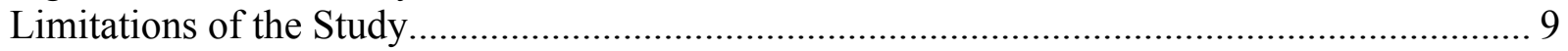

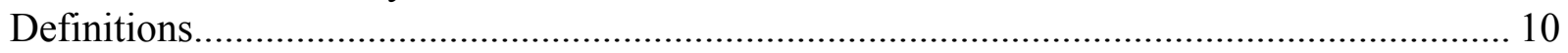

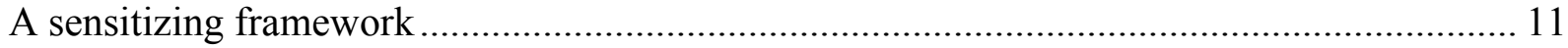

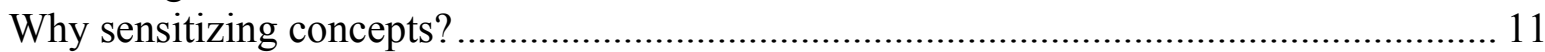

Social worlds and symbolic interactionism .................................................................. 12

Rock climbing: safety, etiquette, and group sizes................................................................ 16

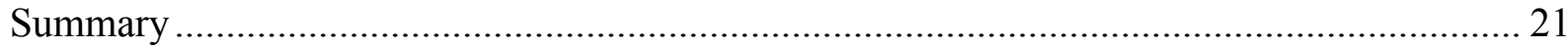

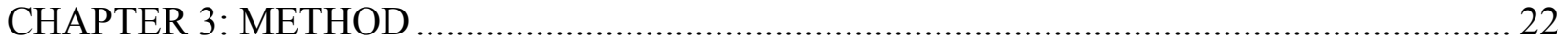

Dealing with complex social situations - constructivist grounded theory ............................... 23

Situational, project, and positional mapping ..................................................................... 27

The Importance of Nonhuman Actors/Actants ...................................................................... 28

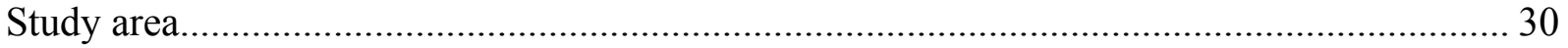

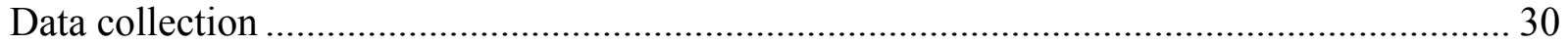

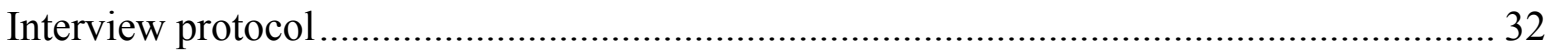

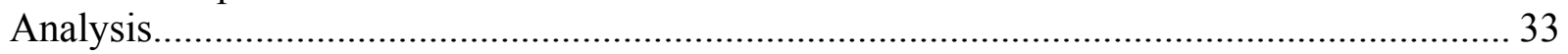

Constructivist grounded theory .................................................................................. 33

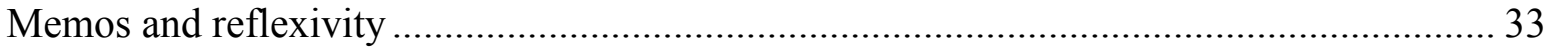

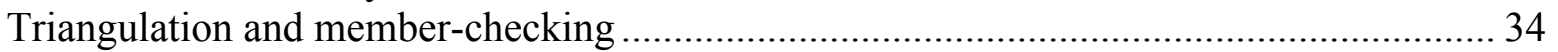

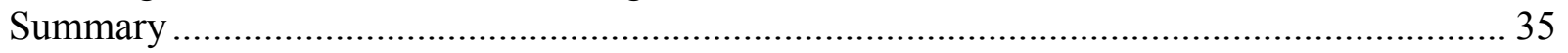

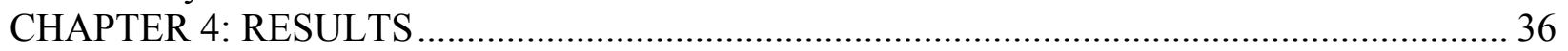

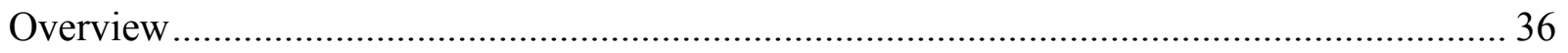

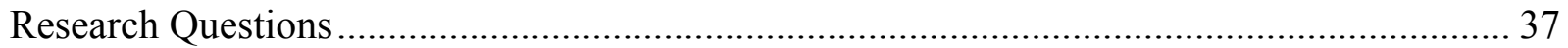

What are the social worlds of climbers at Seneca Rocks? How can they be described?...... 37

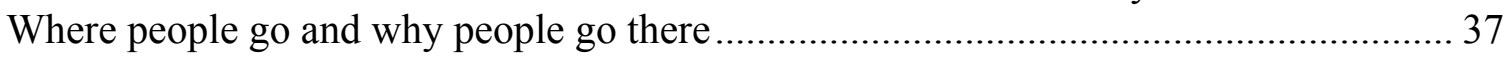

Defining Seneca Rocks by what it is not .................................................................... 46

Does how an individual learned to climb affect their membership in a particular social world at Seneca Rocks? ................................................................................................ 52 What practices exist in the social worlds of climbers at Seneca Rocks with regard to safety practices? To climbing etiquette? ………………………............................................... 55 What practices exist in the social worlds of climbers at Seneca Rocks with regard to group sizes? What perceptions do climbers have of current SKSR group size regulations for both guided and unguided climbing? 
What practices exist in the social worlds of climbers at Seneca Rocks with regard to the use of climbing equipment, including but not limited to removable protection and bolting? .... 71

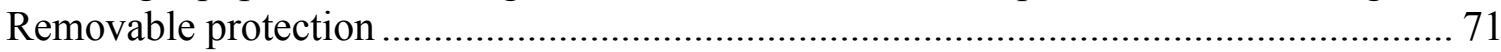

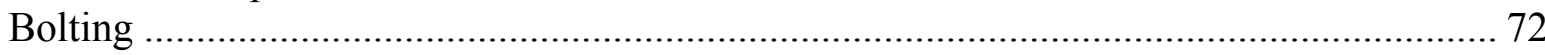

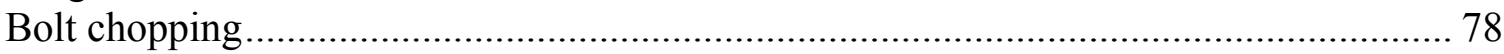

How are acceptable practices communicated and enforced?............................................... 82

How do climbers at Seneca Rocks integrate SKSR management into their social worlds? 87

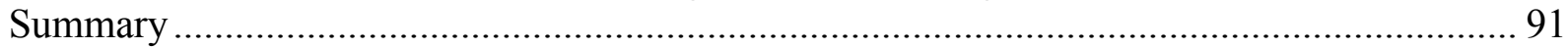

CHAPTER 5: DISCUSSION, CONCLUSIONS, AND RECOMMENDATIONS ……….......... 94

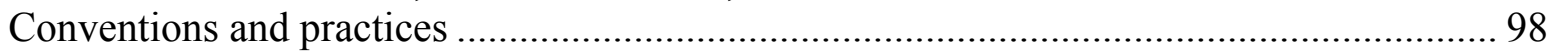

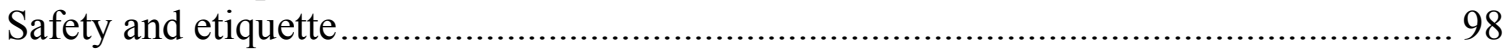

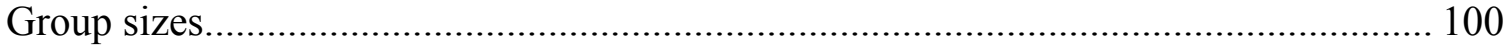

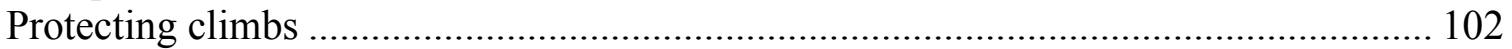

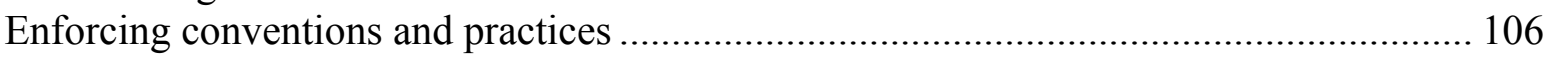

How climbers integrate SKSR management into their social worlds................................... 108

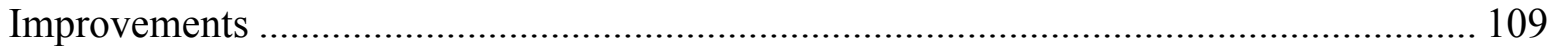

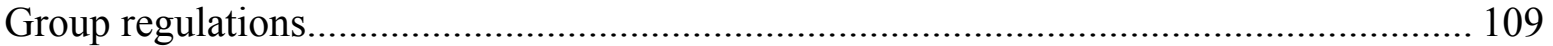

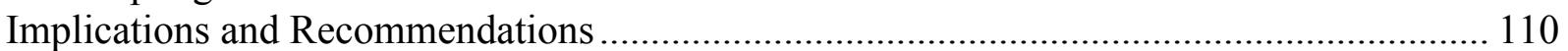

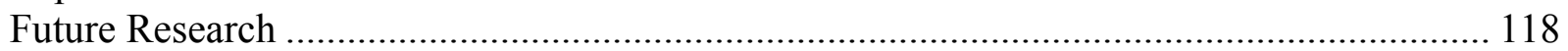

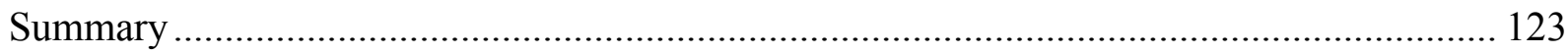

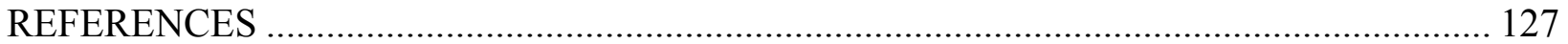

APPENDIX A: DEFINITIONS AND GLOSSARY OF CLIMBING TERMS ……….............. 140

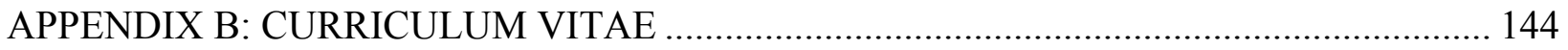




\section{LIST OF TABLES}

Table 1. Interview protocol.......................................................................................... 32

Table 2. Climbing fatalities in the United States and at Seneca Rocks, 1996-2009.................. 56

Table 3. Guide-to-client ratios in various climbing areas in the United States ......................... 70 


\section{LIST OF FIGURES}

Figure 1. Spatial aspects of climbing social worlds......................................................... 38

Figure 2. Places and discourses where climbers go ......................................................... 44

Figure 3. Tourists, regulars, and insiders at Seneca Rocks.................................................... 54

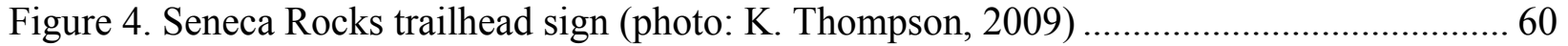

Figure 5. Positional map: Bolting at Seneca Rocks ................................................................. 81 


\section{CHAPTER 1: INTRODUCTION}

\section{Overview}

Since 1971 there have been 17 fatalities from falls at Seneca Rocks, part of the Monongahela National Forest's (MNF) Spruce Knob-Seneca Rocks National Recreation Area (SKSR). Most of these fatalities have been non-climbers falling from areas where technical climbing experience is strongly recommended. Between 2008 and 2009, however, there were two climbing-related fatalities (Beeston Today, 2009; Gurman \& Simonich, 2008). Both of the climbers who died were by all accounts skilled. In conversations with the SKSR Area Manager and long-time climbing guides at Seneca Rocks, none could recall the date of any previous climbing-related fatality. This is to say that climbing-related fatalities are relatively rare at Seneca Rocks. Regardless, the US Forest Service (USFS) is concerned about the safety practices of unguided climbers currently climbing at Seneca Rocks (J. Fosbender, SKSR Area Manager, personal conversation, July 24, 2009).

Seneca Rocks is, along with the Shawangunks in central New York and Looking Glass in western North Carolina, one of three areas in the eastern United States that offers multipitch traditional climbing. ${ }^{1}$ It is approximately a three-hour drive from both the Washington, DC, metropolitan area and Pittsburgh, Pennsylvania. Climbers from those two areas are a ten- to eleven-hour drive from both Looking Glass and the Gunks (as climbers call it), so Seneca Rocks is a comparatively convenient weekend destination for them. In addition to the convenience of the location, Seneca Rocks offers a large number of routes of moderate difficulty, making it an

\footnotetext{
${ }^{1}$ A pitch is approximately one or less than one rope length; multi-pitch climbing therefore involves climbing routes that are more than one rope length long. Traditional climbing involves lead climbing on removable protection from falls that climbers place and remove themselves, as opposed to climbing on permanent, fixed protection, as in sport climbing. See Appendix A for definitions of climbing terms.
} 
ideal destination for beginning and intermediate climbers who wish to hone their traditional climbing skills.

While climbing at Seneca Rocks has been documented since at least 1935 (Barnes, 2006), the USFS has little knowledge of the climbers who use the area in 2009. The last climbing management plan was published in 1996, and since that time there have been major changes in climbing as an American outdoor recreation activity as well as major social changes in the climbing community at Seneca Rocks itself. Since the mid-1990s, increased availability of indoor climbing gyms, both privately owned and at colleges and universities, has made climbing more accessible to the general public. This access has not only increased the number of people climbing - as of 2005, there were an estimated 9.2 million climbers in the United States (Outdoor Industry Foundation, 2006) - but has changed the way people learn to climb.

Whereas climbers used to learn to climb outdoors from a large, organized climbing club or a "mentor" - a more experienced climber who passed on the skills that climber had learned from another peer, more frequently contemporary climbers learn rudimentary skills in a built environment. If an individual who learned to climb in a gym decides to climb in the natural environment, they learn outdoor climbing skills from a variety of sources, ranging from certified guides who act in a "mentor" capacity to "transitioning to the outdoors" classes in climbing gyms to gleaning information from Web sites like rockclimbing.com. There is a large gap in the literature in this regard - to date only one study has been published that assessed how people's introduction to climbing affected their attitudes toward low-impact participation (Borrie \& Harding, 2002). Additionally, a recent thesis on paddlers who learned to raft in built versus 
natural whitewater environments suggested that the motivations and attitudes of participants differed considerably depending on how they learned (James, 2009).

The way people learned to climb was not the only thing that changed since the latest SKSR climbing plan. In 2005 long-time owner John Markwell sold The Gendarme, the area's climbing shop, and its associated climbing guide service, Seneca Rocks Climbing School (SRCS) to the owners of an outdoor shop in Virginia. Shortly after that, the head guide, who had been with SRCS for almost 30 years, retired from guiding and in 2008 opened a coffee shop and restaurant at the competing guide service, Seneca Rocks Mountain Guides (SRMG). The porch of the Gendarme had been the de facto after-climbing hangout for years, and held annual parties at the opening and close of the seasons, as well as on the Fourth of July, where climbers gathered to socialize and sometimes to raise funds for trail maintenance and new rescue cache installations. These parties continued after the change in ownership and sometimes coordinated with SRMG to hold simultaneous events on these dates. Last year, however, there were end-ofseason parties held on two different dates, one at each location.

SKSR management deals with Seneca Rocks as part of a larger management unit, and has taken a laissez-faire approach to climbing management there. They are aware of recent social changes, although they are unclear of the impact such changes may have on the nature of climbing at Seneca Rocks. The fatalities, of course, have raised additional concerns about the goings-on in the area. At this time, management does not know how many people climb at Seneca Rocks every year, the number of unguided versus guided climbers, or what the social worlds of climbing at Seneca Rocks mean for attitudes about safety, bolting, unguided group 
sizes, or self-policing, to name a few issues. This issue is not unique to SKSR: Schuster, Thompson, and Hammitt (2001) reported that in spite of climbing's increased popularity, resource managers frequently did not understand or know how to deal with climbers and climbing on public lands across the United States.

In addition to the social changes at Seneca Rocks, the USFS is dealing with changes in outfitter-guide regulations established in September of 2008 (USFS, 2008); these regulatory changes require all National Forest System (NFS) units to reassess the allocation of guided days among both priority (full-time commercial) permit holders and temporary (occasional use commercial) permit holders. It has already been determined that there is no ecological need to reevaluate the impact of guided climbing at Seneca Rocks; because of the long history of climbing there, any environmental impacts to the area have already taken place and are beyond mitigation. It has also been determined that climbing guide services are necessary at Seneca Rocks: their availability provides an opportunity for non-climbers and novice climbers to climb at Seneca Rocks in a safe, controlled environment (J. Fosbender, personal conversation, July 24, 2009).

The change in USFS outfitter-guide regulations that could affect how outfitter-guides are managed at Seneca Rocks has to do with how guiding days are allocated. A guide service is allocated a day for each client they take out each day, so a guide taking out five clients for a oneday trip uses five days and a guide taking one client out uses one. Under the new regulations the total number of allocated days for any area will come from a pool, based on the physical and social capacities of the area. These days are allocated between priority and temporary permit 
holders, and unused days from either type of permit can be reallocated to other permits. Group sizes for guide services at Seneca Rocks is limited to "six or eight" climbers at one time (J. Fosbender, personal conversation, July 24,2009$)^{2}$, although the guide-to-client ratio is usually lower than that for safety reasons. From my observation, most guided trips at Seneca Rocks involve one or two clients, with large groups occasionally going out when Boy Scout troops, church groups, university outdoor clubs, or other organizations either obtain a temporary outfitter-guide permit or retain the services of either SRCS or SRMG, the two priority licensees at Seneca Rocks.

Regardless of group size limits for guide services, however, group size is unlimited for unguided climbers. While a licensed guide can only take out a set number of clients at a time, unguided climbers could hypothetically go climbing in groups of twenty or more without needing a special use permit as long as there were fewer than 75 climbers in a group ( $\mathrm{J}$. Fosbender, personal conversation, July 24, 2009). It is unclear whether large unguided groups are a regular occurrence at Seneca Rocks or if these groups are accepted socially in the area if or when they do climb there.

Relationships between climbers and land management agencies have historically been fraught (Grijalva \& Berrens, 2003; Schuster, Thompson, \& Hammitt, 2001), and Seneca Rocks is no exception. At this area, there appears to be confusion about what agency manages the area. Many climbers at Seneca Rocks think the area is a National or State Park, and some of the more influential climbers at Seneca Rocks are firmly convinced the USFS is not competent to manage

\footnotetext{
${ }^{2}$ According to one guide I interviewed for this study the maximum number of permitted clients per guide is three, which indicates that there may be some lack of clarity as to the actual guidelines.
} 
the area. The climbers say "talk to us," SKSR management says "talk to us," but communication between the two is at best limited.

The confluence of all these unknowns leads to the question Julie Fosbender asked me during our July 24 conversation: "What is going on here?" SKSR management have a limited understanding of climbers, climbing, and the social worlds of climbers. They do not know how many people are climbing there, guided or unguided, or whether current group sizes are appropriate. They do not know what climbers want from the USFS - for example, whether climbers would like improved access to less frequently visited areas at Seneca Rocks proper. They do not know whether making changes to the current allocations in the outfitter-guide permit systems would have an effect on the social worlds that exist at Seneca Rocks. To a large degree, climbing activity at Seneca Rocks is going on under the USFS radar.

The current management climate in federal land management agencies makes the need to understand the diverse voices of the groups who use public recreation areas increasingly important. Having such an understanding makes agency outreach easier, which in turn facilitates partnership building (Hammit, Thompson, \& Schuster, 2001). Establishing a picture of the social worlds and subworlds that exist in the climbing community can help SKSR management make decisions that are appropriate for Seneca Rocks' user base with regard to the multiple climbingrelated issues that are currently in play.

\section{Purpose of study}

The purpose of this study was to provide SKSR management with an understanding of the social worlds of rock climbers at Seneca Rocks, to ascertain any management interventions 
that can improve access to climbing areas at Seneca Rocks, and to determine how permitted group sizes among guided and/or unguided climbers would affect the social worlds of climbers at Seneca Rocks.

\section{Research questions}

In order to determine "What is going on here?" at Seneca Rocks and based on some of the recent social changes in the area, the following questions guided my study:

$\mathrm{R}_{1}$ : What are the social worlds of climbers at Seneca Rocks? How can they be described? $\mathrm{R}_{1(\mathrm{a})}$ : Does how an individual learned to climb affect their membership in a particular social world at Seneca Rocks?

$\mathrm{R}_{1(\mathrm{~b})}$ : What practices exist in the social worlds of climbers at Seneca Rocks with specific regard to, but not limited to:

- Safety practices

- Climbing etiquette

- Group sizes

- Use of climbing equipment, including but not limited to removable protection and bolting

$\mathrm{R}_{1(\mathrm{c})}$ : How are acceptable practices communicated and enforced?

$\mathrm{R}_{2}$ : How do climbers at Seneca Rocks integrate SKSR management into their social worlds?

$\mathrm{R}_{2(\mathrm{a})}$ : What improvements or changes, if any, would climbers like to see in the management of SKSR?

$\mathrm{R}_{2(\mathrm{~b})}$ : What perceptions do climbers have of current SKSR group size regulations for both guided and unguided climbing? 


\section{Significance of the study}

Although there are currently an estimated 9 million participants in indoor and outdoor rock climbing (Nelson \& McKenzie, 2009) the academic literature addressing climbing and climbing-related issues is out of date and sparse (Nelb \& Schuster, 2008). Without recent information on the state of rock climbing and the conventions and practices of climbers today resource managers are left with incomplete and insufficient information to make sound decisions about climbing management. This study addressed the current practices of climbers at a popular east coast climbing destination as well as their attitudes toward management. Having up to date information will expand management understanding of this particular user group, which in turn can help them make better informed management decisions.

This study also expanded on social worlds theory (Unruh, 1980) in the recreation literature, in particular the nature of social subworlds participation. The findings of this study indicate that Scott and Godbey's (1994) study of recreation subworlds in the context of contract bridge can be extended to outdoor recreation, particularly their finding that subworld participation was the result of a conscious choice rather than a particular level or continuum of specialization, as posited by Bryan $(1977,1979)$. Further, this study provided insight into how climbers enforce area-specific conventions and practices, particularly those related to safety and route development. It illuminated the ways that climbers deal with conflict within the context of their social worlds, and how attitudes toward managing agencies can lead to communications gaps. Finally, this study provided a glimpse into the concept of metacognition (e.g, Kruger \& Dunning, 1999) in recreation decision-making, an area not previously explored in the recreation literature. 


\section{Limitations of the Study}

This study took place at Seneca Rocks between the fall of 2009 and the spring of 2010 and therefore reflects the nature of the climbing community at that time. The data in this study were collected with the aim of theoretical saturation; while this study did reach theoretical saturation per Clarke (2006), it does not necessarily reflect the views of the climbing community at Seneca Rocks as a whole. According to individuals who are at Seneca Rocks on a regular basis, visitation has decreased during the current economic downturn. The results of this study therefore may not reflect the nature of climbers and climbing at Seneca Rocks during times of less economic difficulty or when climbing-related visitation to the area is at higher levels.

Near the conclusion of this study five participants, all closely related socially, chose to withdraw from the study. These data were removed from the analysis and the data were reanalyzed to identify any effect the loss of these data had on the study's findings. While the overall findings remained internally consistent, some valuable insights about the history of climbing at Seneca Rocks were lost, and the findings regarding insiders at Seneca Rocks were not as fully developed as they had been initially.

Along with the aforementioned challenge, I was unable to obtain permission to conduct interviews with any climbers who had hired a guide service on their trip to Seneca Rocks. This was not for lack of trying; the individuals from whom I requested interviews were not interested in participating, stating either that they were tired from their day climbing or that they had social engagements that interfered with the proposed interview times. I was able to observe the social participation of some unguided climbers, but overall they were not interested in participating in the study as informants. Their voices are therefore lacking from interviews. 
Because this study is a close examination of traditional rock climbing at Seneca Rocks the study's results may not be generalizable to other climbing areas, particularly to areas where sport climbing or bouldering predominate.

\section{Definitions}

Due to the large amount of climbing terminology used throughout the interviews, definitions are presented in Appendix A. 


\section{CHAPTER 2: REVIEW OF LITERATURE}

\section{A sensitizing framework}

In a situation such as the one at Seneca Rocks where research questions can be lumped under the very general, "What is going on here?" a qualitative approach was the appropriate choice. Existing climbing literature is for the most part out of date with respect to social and technological changes in the activity (Gerdes, Hafner, \& Aldag, 2006; Nelb \& Schuster, 2008). Puchan (2004) concluded that contemporary adventure recreation like rock climbing contained so many unknowns that the area was ripe for extensive study; the results of this study bore out that assertion. As the focus of this study is on the social worlds at Seneca Rocks, an interactionist approach was theoretically appropriate (Hall, 1987; Scott \& Shafer, 2001; Unruh, 1980). Other social worlds studies in the recreation literature have, for the most part, taken a similar theoretical path (e.g., Fuller, 2003; Kyle \& Chick, 2002; Scott \& Godbey, 1994; Scott \& Shafer, 2001). Keeping with the traditions of qualitative research, this literature review addresses sensitizing concepts that will help provide a general conceptual focus in what could otherwise be an overly broad study (Patton, 2002).

\section{Why sensitizing concepts?}

"Whereas definitive concepts provide descriptions of what to see, sensitizing concepts merely suggest directions along which to look" (Blumer, 1969, p. 147148).

According to Clarke (2005) establishing a conceptual framework that involves either/or propositions or narrows the research to a point where the researcher misses how the individuals being studied "frame their experiences," leading to "premature theoretic/analytical closure" 
(p.77). In other words, analyzing data based solely on conclusions from the existing literature can lead the researcher's analysis to find matches for prior findings and miss important discoveries in her own data. In qualitative research it is therefore preferable to work with concepts that provide more general boundaries, such as the social worlds/arenas framework I applied in this study (Clarke, 2005; Patton, 2002). Charmaz (2005) stressed the importance of approaching a study by using sensitizing concepts from a disciplinary perspective, but emphasizes that this perspective was a starting point, not an ending point (p. 17). The concepts discussed here are presented as guidelines for analysis rather than a rigid analytical frame.

\section{Social worlds and symbolic interactionism}

According to Kyle and Chick (2002), "Social worlds research has provided leisure researchers with an understanding of how social networks support and reaffirm leisure behaviors" (p 429). A social world is made up of the people who participate in it, the social organizations that revolve around it, the things that happen, and the shared practices participants undertake that distinguish them as particular members of that social world. The underlying premise of social worlds research is "the notion that actors, events, practices, and formal organizations can coalesce into a meaningful and interactionally important unit of social organization for participants" (Unruh, 1980, p. 272). Social worlds can be established across space and time, ranging from a local focus to a more global perspective; many social worlds (e.g., "the climbing world," "the hiking world") are not centrally located, although they may extend across space (Buchanan, 1985; Goffman, 1959; Unruh, 1980). This is to say that a social world could consist of "people who climb at Seneca Rocks," or "climbers in the United States," depending on how the unit of analysis - the social world - was bounded. 
Involvement in social worlds is voluntary and partial (Unruh, 1980). People may come and go as they please, and are unable to know everything about the social world in which they are involved. Therefore, participants take part in one of the many subworlds that make up a more generalized social world. Likewise, people can be involved in more than one social world - for example, someone involved in an angling social world might also be involved in hiking or knitting social worlds, depending on where their interests lie. Finally, because social worlds are structured informally, communication tends to be mediated by print and television media -- and in more recent years, the internet - more so than face-to-face interaction. The more geographically diffuse a social world, the more likely its participants are to engage in one of these communication forms to interact with each other (Ditton, Loomis, \& Choi, 1992; Fuller, 2003; Gahwiler \& Havitz, 1998; Manzenreiter, 2007; Unruh, 1980).

Social worlds may fragment into subworlds, depending on available resources, particular objects of interest, developments in technology, ideology, intersections with other social worlds, or recruitment of new members to a group (Ditton et al., 1992). In their study of bridge players Scott and Godbey (1994) found that this process was the result of a conscious choice to participate in a particular subworld, and that each subworld represented a unique type of recreation involvement rather than a continuum of specialization behaviors, as Bryan (1977, 1979) had posited. The level of commitment to the practices of each subworld was found to be equivalent among participants thereof, even though externally perceived levels of expertise were different. An individual's choice of recreation subworld may not be related to specialization or commitment as much as personal perspective and recreation choice (Buchanan, 1985; Ditton et al, 1992; Green \& Chalip, 1998; Kyle \& Chick, 2002). 
According to Unruh (1980) there are four types of membership in a given social world: strangers, tourists, regulars, and insiders. Strangers are not directly involved in a social world but rather provide "points of references and comparison for other worlds" (p. 281). In the case of this study SKSR staff and management who are directly involved with managing the resource where climbing takes place could be considered strangers, as they do not directly participate in the social world of climbing at Seneca Rocks and have little awareness of its internal workings but still have an external influence on it. Tourists have little long-term commitment to the social world itself but take part because they are curious or find it entertaining. Regulars are involved long term in the ongoing activities of the social world, and insiders "focus on creating and sustaining activities for other participants, recruiting new actors, and intimate knowledge of social world activities” (p. 282; see also Gahwiler \& Havitz, 1998). Goffman (1959) suggested that the insiders had the most to gain or lose in a face-saving situation and therefore most likely to act as group representatives or act as an internal behavioral police force. This study focused on the latter three groups: tourists, regulars, and insiders.

The social worlds literature has by and large been informed by a symbolic interactionist framework. As described in the previous section, symbolic interaction operates under three general premises:

1. people react toward people and things according to the meanings they attribute toward them;

2. meanings of individual things arise from meanings generated from the social worlds of which people are members; and 
3. meanings of those things are recreated and modified by an individual through personal interpretations based on (1) and (2) that help them make sense of the social worlds to which they belong (Blumer, 1969; Charmaz, 2005; Denzin, 1974; Kyle \& Chick, 2002; Snow, 2001).

The majority of social worlds studies in the recreation literature approach social worlds from this particular interpretive tack (e.g., Colton \& Morrione, 1973; Ditton et al., 1992; Kyle \& Chick, 2002; Scott \& Godbey, 1994). In interactionist studies " [t]he terms, conventions, and practices are used intentionally in lieu of values, norms, and rules. Assumed values, norms, or even rules often are not taken at face value. Actors may use them as resources or interpret them pragmatically in relation to the immediate situation. Practices and conventions may develop which, in essence, add to the official manual. In addition, many practices represent covert alterations of official values, norms, and rules" (Hall, 1987, p. 13). The collective actions that make up these conventions and practices of a social world are constantly being constructed and reconstructed as participants interact with their surroundings. (Blumer, 1969; Clarke, 2005; Hall, 1987; Shalin, 1986; Snow, 2001). Weber (2001) argued that current adventure recreation studies are based on a priori assumptions from academics and practitioners, and have not examined participants' perceptions of their activities. An interactionist approach assumes that social worlds are always in a state of flux, making it an appropriate choice both to examine the way the climbing worlds at Seneca Rocks are currently being constructed among its participants and to fill the gap in the literature that Weber identified. 


\section{Rock climbing: safety, etiquette, and group sizes}

Depending on the type of climbing a climber chooses to engage in and the location in which she climbs, practices in climbing are locational, style-specific, contested, and subject to change over time (Fuller, 2003; Schuster, Thompson, \& Hammitt, 2001; also, Barnes, 2006; Piana, 1983, Watts, 1992). Style (how a particular route or area is climbed) and ethics (appropriate behavior toward the resources at a particular climbing area) are, to a large degree, based on locally established, loosely held, and mostly unwritten "rules," although some guidelines may be set forth in a local guidebook, as it is at Seneca Rocks (Barnes, 2006). These rules may be contested even within a local climbing community (Fuller, 2003). In many cases these debates depend on what practices are acceptable at a particular climbing area and what practices a climber from another area brings with them to a different crag.

In an activity with no governing authority and no apparent desire for one, maintaining overall climbing "norms" is impossible; hence the regional/local practices that exist from crag to crag. National debates over a unified climbing style or ethic have resulted in increasing fragmentation among climber self-identities, with people in some cases referring to themselves as a particular type of climber (sport climber, trad climber, boulderer) rather than a climber in general. This divide started early in the history of modern free climbing, with debates among Yosemite Valley climbers divided between the stylistic purists and those who thought a route should be attempted by any means necessary (Roper, 1994; Wells, 2002). When sport climbing and the development of routes on rappel and from points of aid became more prevalent Higgins (1986) originated the term "traditional" climbing in his essay "Tricksters and Traditionalists, a polemic over style that in essence divided climbers into "purist" and "cheater" camps in terms of climbing styles. In one of the only extant studies involving a case of contested practices in rock 
climbing, Fuller (2003) examined these "bolt wars," the debate about when and if bolting is appropriate and whether traditional or sport climbing is a more "pure" form of climbing. She concluded that the traditionalists had lost the debate due to the nature of climbing culture itself:

The orthodox [in Fuller's study traditional climbers, like the climbers who use Seneca Rocks] were also hampered by aspects of climbing culture itself. Not only did they lack authority structures capable of banishing heresy [in this case sport climbing], they were unable to create such structures because of aspects of the symbolic system they were seeking to defend. ... A related problem dogged climbing traditionalists. Their references to the sacred character of climbing ethics were ultimately undermined not only by the historical plasticity of these ethics, but also by the symbolic association of climbing with individualism and freedom. Indeed, in many ways deviance and heresy had a positive resonance in the context of climbing culture. Attempts to enforce a rigid boundary excluding the new practices incited a backlash that sport climbers were able to exploit with appeals to freedom and by casting themselves as iconoclasts. (p. 25-6).

In 2006 Higgins revisited the stylistic divide he described in "Tricksters and Traditionalists." He argued, unlike Fuller, that debates over style were not settled, as evidenced by lengthy Internet discussion board arguments over the styles of new and/or highly publicized ascents as well as by increases in climbing regulations. He suggested that climbing areas disseminate stylistic and historical information through guidebooks, websites, and other media and that in some cases they regulate climbing styles via elected committee. Climbing guidebooks generally have a section explaining stylistic practices and first ascent histories in the foreword sections (e.g., Barnes, 2006; Piana, 1983; Watts, 1992), so it is assumed that Higgins was suggesting this information be shared in guidebooks for newly developed climbing areas in keeping with current general practice.

The following section of the literature review is largely a discussion of unknowns. As Nelb and Schuster observed (2008), most studies on rock climbing were undertaken prior to the 
advent of easily accessible climbing gyms; technical innovation in climbing equipment that increased ease of use, decreased weight, and improved safety; climbing as a popular marketing narrative; and other developments which have changed the face of the activity. Because of these changes, the number of unknowns in climbing from an academic standpoint profoundly outweighs the knowns. Among those unknowns are practices related to climbing safety, etiquette, and group sizes, three issues about which SKSR management would like information.

Overall, there is a relative paucity of academic literature on rock climbing safety practices. A 2002 study by Attarian established that a majority of climbers who participated in an Internet survey thought first aid, rescue, and climbing safety skills were important for managing risk in the activity. Gerdes, Hafner, and Aldag (2006) found that traditional climbers were more likely to sustain injuries than sport climbers, although most of these injuries were attributed to overuse, not to climbing accidents or poor safety practices. Nelson and McKenzie (2009) found that emergency room visits related to rock climbing injuries increased by $63 \%$ between 1990 and 2007; they posited that the increase in injuries may be related to climbers making the transition between climbing in an indoor gym to outdoor climbing. Three quarters of the climbing injuries reported in this study were related to falls. Rock climbing injuries were also found to be more likely than other activities to require hospitalization (Nelson \& McKenzie, 2009). If managers on public lands are to address any safety issues that appear to be occurring at the climbing areas they manage, it is important both to take the temperature of what the safety practices are stated to be in a given climbing social world and how those practices are actually put to use. 
Likewise, there have been no studies that I have been able to find regarding rock climbing etiquette. In climbing, "etiquette" consists of behaviors like checking to make sure nobody is below you when you drop a rope either to toprope or rappel, shouting "rock!" if there is rockfall or another object falling toward where other people are or may be climbing, and other practices based both on consideration of others climbing nearby and their safety. Another aim of this study is to illuminate these practices in the climbing social world at Seneca Rocks.

The recreation research concept of crowding does not translate well to rock climbing. With the exception of some studies on hunting, crowding studies have largely taken place either in federally designated wilderness areas, where some degree of solitude is generally a recreation management priority, in the context of whitewater rafting, or related to other activities which involve linear recreation (Donnelly, Vaske, Whittaker, \& Shelby, 2000; Manning, Freimund, Lime, \& Pitt, 1996; Manning, 1999). While these activities and studies occur on an X-Y axis, climbing takes place along a $\mathrm{Z}$ axis - the vertical - and is dispersed among multiple routes. Some routes may see more traffic due to relative difficulty or general popularity, but the very nature of the activity limits the number of people who can be on one route at one time, generally to parties of two or three.

From my experience, where group size comes into consideration is at the bases of routes, generally in a situation where someone in a group has put up a toprope. Toproping itself is the contested practice here in my experience - at Seneca Rocks lead climbers are supposed to be given priority over topropers (Barnes, 2006). Group size, therefore, is a function of whether people are toproping, which permits a larger number of climbers to use a route for a longer 
period of time, or leading, which generally involves two or three people on a route for a shorter period of time. The issue in this case is not one of crowding, but one of what are perceived as appropriate social practices. Because there have been no studies, empirical or otherwise, of this issue, more exploration is needed, especially because my personal observations could be -- to put it simply -- wrong. Therefore another aim of this study is to determine how the climbing subworlds at Seneca Rocks engage in practices involving varying numbers of people and how those practices affect other subworlds.

There is yet another relative unknown in the recreation literature, which is how learning a recreational activity in a built environment affects a participant's perception of that activity in the outdoors. To date, two studies have made note of this phenomenon. As part of a larger study Borrie and Harding (2002) found that attitudes toward low-impact sport climbing behaviors at Kootenai Creek, Montana, were affected by the way people were introduced to climbing. Climbers who learned to climb indoors were more likely to be uncomfortable climbing near Native American artifacts and with establishing bolted routes themselves than climbers who learned to climb outdoors on sport routes. Those who learned to sport climb outdoors were more comfortable with establishing sport routes themselves. This particular study addressed attitudes in a sport climbing area; whether similar beliefs are in play in traditional climbing areas like Seneca Rocks is unknown.

The second study that addressed the built environment as a mediator in people's constructions of a recreational activity was James's 2009 thesis on whitewater paddling in built environments. James found that whitewater rafters and kayakers who learned their respective 
activities on a built course were more likely to see rafting as a social activity than those who learned to kayak or raft in the natural environment. While the model he chose ended up being a poor predictor of recreation behavior among the participants he surveyed, he did make one salient observation that deserves further exploration: "Natural settings require the user to adapt to match their environment, whereas built environments can be adapted to match the user" (abstract). How recreationists negotiate the transition from the built environment to the natural environment and what practices they carry from the built environment to a natural one are areas that are still relatively unexamined in the recreation literature.

\section{Summary}

In this chapter the sensitizing framework of the study was discussed. This qualitative study is based in the social worlds and symbolic interaction literature, which have been used to study a wide array of topics in outdoor recreation. Further, the paucity of up-to-date recreation literature related to rock climbing was discussed, and gaps in that literature were identified. The following chapter addresses the analytical method used in this study. 


\section{CHAPTER 3: METHOD}

Although the majority of research in parks and recreation is conducted under a positivistic paradigm (Henderson, Presley, \& Bialicheski, 1994; Sean \& Chick, 2002), qualitative research has been used to illuminate complex recreation questions for years. Various "flavors" of grounded theory have been used to study a diverse array of topics, including leisure constraints (e.g. Culp, 1998; Little, 2002), leisure involvement (e.g., Sean \& Chick, 2002), recreation choice behavior (e.g. Downing \& Clark, 1985), recreation conflict (e.g. Hunt, Lemelin, \& Saunders, 2009; Marx \& Chavez, 2002), place attachment (e.g. Mitchell, Force, Carroll, \& McLaughlin, 1993), social carrying capacity (e.g. Porter \& Tarrant, 2005), recreation specialization (e.g. Scott \& Godbey, 1994), environmental education (e.g. Smith-Sebasto \& Walker, 2005), and public participation processes (e.g. Tuler \& Webler, 1999).

In this study I used Adele Clarke's (2005) situational analysis/constructivist grounded theory approach. Aside from its analytical rigor, this method's advantages included the inclusion of nonhuman actants in the analysis, its interpretivist approach in analyzing social worlds and arenas, its ontological view that knowledges are reproduced and contested, its insistence on giving voice to divergent viewpoints, and its use of mapping heuristics to elaborate upon Julie Fosbender's question that sparked this project: "What is going on here?" All of these analytical components were essential to providing the USFS with a clear view of the social worlds of Seneca Rocks climbers without privileging any one of the multiple points of view from which that area's climbers approach the activity (Donnelly, 2006). 


\section{Dealing with complex social situations - constructivist grounded theory}

Grounded theory is a rigorous qualitative analytic method that is frequently used to describe social processes and/or subprocesses. First developed by Glaser and Strauss in the 1960s, the approach has fractured into multiple approaches with epistemological and ontological differences. Traditional grounded theory takes a positivistic, teleological approach to qualitative data, assuming that such research will lead to generalizations and normative statements. Applying Glaser's or Strauss's methods is intended to describe a single social process and related subprocesses. It assumes that the researcher holds expert authority on the subject she is studying, that she is completely objective toward the data, and that the research will have an end result of some sort of formal theory (Charmaz, 2005; Clarke, 2005; Glaser, 1978; Glaser \& Strauss, 1967; Strauss \& Corbin, 1998).

Glaser's (1978) approach to grounded theory operates under the assumption that a researcher should enter a project as a tabula rasa. In this approach, "all is data" (Glaser, 1978, p. 42), even literature, which should not be reviewed prior to the start of a research project.

Regardless of how the project is begun, however, the end result is intended to make teleological statements about social processes, generally in a structuralist vein. In Glaser's grounded theory, social processes occur within and are generated by particular social structures without the involvement of human agency, the idea that individuals can act of their own free will outside of the constraints of existing social structures (Glaser, 1978).

Although Glaser and Strauss worked together to develop the "original" grounded theory method of which Glaser is still a proponent, Strauss's ontological split with Glaser integrated 
human agency into the analysis, suggesting that social worlds are mutually constructed by their participants. Although all is still data in Straussian grounded theory, consulting literature beforehand is acceptable in order to sensitize oneself to theoretical constructs that can help narrow the focus of a study and guide the analysis. The end result of a Straussian grounded theory study, however, is still to produce teleological theory; other than some analytical differences the final result is essentially a poststructural version of Glaser where human agency is taken into account (Giddens, 1979; Strauss \& Corbin, 1998).

A student of both Glaser and Strauss during different periods of her graduate career, Charmaz (2005) took a more explicitly constructivist approach following Strauss and Corbin (1998). Charmaz embraced Blumer's (1969) symbolic interactionism as an analytical framework, based on the following principles:

1. people react toward people and things according to the meanings they attribute toward them;

2. meanings of individual things arise from meanings generated from the social worlds of which people are members; and

3. meanings of those things are recreated and modified by an individual through personal interpretations based on (1) and (2) that help them make sense of the social worlds to which they belong (Blumer, 1969; Charmaz, 2005; Denzin, 1974; Sean \& Chick, 2002; Snow, 2001).

While the analytical process in Charmaz's constructivist grounded theory is similar to both Glaser's (1978) and Strauss and Corbin's (1998), her approach took the ontological position that meanings are contested and that knowledges are both multiple and situated (Clarke, 2005; 
Charmaz, 2005; Mills, Bonner, \& Francis, 2006). Because there is no possibility of a central "reality" in this analytic approach, it is not possible to develop teleological theories. What Charmaz suggested instead was that substantive theory was the most likely result of a constructivist grounded theory study:

Most grounded theories are substantive theories because they address delimited problems in specific substantive areas ... The logic of grounded theory can reach across substantive areas and into the realm of formal theory, which means generating abstract concepts and specifying relationships between them to understand problems in multiple substantive areas (see Kearney, 1998). ... Each exploration within a new substantive area can help us to refine the formal theory (Charmaz, 2005, p.8).

As well as being useful for developing substantive theories, constructivist grounded theory has an ontological advantage when examining social worlds, as is the intent of this study. As stated above, constructivist grounded theory takes a relativist approach, assuming that knowledges are situated and that "differences and complexities are analytically central" (Clarke, 2005, p. 294; also Mills, Bonner, \& Francis, 2006). The goal of constructivist grounded theory is to theorize rather than to make a universal statement about a particular world. "The form of grounded theory followed depends on a clarification of the nature of the relationship between researcher and participant, and on an explication of the field of what can be known.

Constructivist grounded theory is positioned at the latter end of this methodological spiral, actively repositioning the researcher as the author of a reconstruction of experience and meaning" (Mills et al., 2006).

Clarke's (2005) approach, an offshoot of Charmaz's (2005), also involves the original analytical rigor of Glaser's and Strauss's constant comparative method. While her method involves the same open, axial, and selective coding as so-called traditional grounded theory, 
Clarke rejects Glaser's positivism. Rather, she embraces Clarke's symbolic interactionist approach and replaces Strauss and Corbin's problematic conditional matrix, which can force analysis into "a pre-established direction" (Charmaz, 2005, p. 119), with a series of situational, project, and positional maps as additional analytic tools. She also incorporates nonhuman actors/actants into the analysis after Foucault (1973; 1980) and Latour (1999).

Reflexivity is of utmost importance when using an interactionist/constructivist approach, as it is critical for the researcher to attempt to view the worlds of the participant from the participants' points of view rather from her own (Blumer, 1969; Denzin, 1974; Dupuis, 1999; Patton, 2002). This does not mean that the researcher is removed or excluded from the analysis, as it is in positivistic studies, but rather that she is aware of and able to separate her own positions from those of the people she is studying (Blumer, 1969). Dupuis (1999) argued that in leisure research, a "a deeper and more comprehensive understanding of what leisure means to different people and how leisure is experienced in different contexts can only be enriched by a fuller use of the self in leisure research, not by the omission of the self" (Dupuis, 1999, p. 48).

Because the climbers who use Seneca Rocks are, like most contemporary climbers, philosophically diverse (Schuster, Thompson, \& Hammitt, 2001) and the meanings they make there are therefore varied, it is important not to privilege a particular point of view; using a constructivist approach helps avoid this trap in analysis (Charmaz, 2005; Clarke, 2005). In order to present an accurate depiction of the social worlds/arenas extant among Seneca Rocks climbers to USFS management, giving equal voice to divergent perspectives is crucial. Differences are as important as similarities when attempting to reach a more complete understanding of multiple 
social worlds (Clarke, 2005; Dupuis, 1999). A picture of the worlds these climbers construct will help bring a richer perspective to future climbing management decisions and make it easier for SKSR management to engage with the climbers who use Seneca Rocks.

\section{Situational, project, and positional mapping}

Clarke's (2005) method uses three heuristic tools as exercises to ensure that the researcher is interrogating the data in as many directions as possible during the coding phases. These maps are designed to encourage analysis of three aspects of a social world.

- Situational maps help to establish the elements of a social world and the relationships among its members (both human and nonhuman). Situational maps “include all the analytically pertinent human and nonhuman, material, and symbolic/discursive elements of a particular situation as framed by those in it and the analyst” (Clarke, 2005, p. 87; emphasis in original). In other words, situational maps are a "big picture" look at the people, ideas, and things that make up the social worlds in question, from the perspective of the informants as well as the analyst.

- Social worlds/arenas maps help develop an understanding of "collective commitments, relations, and sites of action" by examining how social worlds and subworlds come to be and why (Clarke, 2005, p. 86, 110). These maps examine the structures of and interactions between different actors/actants in social subworlds.

- Positional maps help to simplify what positions are and are not being articulated in the data, providing the researcher with further guidance toward theoretical 
saturation as well as opportunities to further explore the unsaid in a social world (Clarke, 2005, p. 86).

Essentially, Clarke has formalized and focused the "sorting of data into buckets" that is commonly applied in other approaches to grounded theory (Charmaz, 2005; Strauss \& Corbin, 1998). While these maps may not be used in a final project, they help the researcher in both an organizational and an analytical sense.

\section{The Importance of Nonhuman Actors/Actants}

Qualitative research generally involves three types of data: observations, interviews, and artifacts (Patton, 2002). While artifacts have long been woven into qualitative discourses, Foucault, Latour, and others argued that they should be given more prominence with regard to their influence over human (inter)action. In The Order of Things, Foucault (1973) examined the contested meaning-making involved in the social construction of material objects and how those material objects affect human discourse, human interpretation of the world around them, and the power-knowledge structures humans recreate (Foucault, 1973; 1980). In the recreation literature, researchers have used Foucauldian analysis to examine topics as diverse as certification frameworks (Dieser, 2005), race and racism in recreation (Philipp, 1999), representations of adventure tourism (Cloke \& Perkins, 1998), and the effects of globalization on leisure (Rowe, 2006).

The idea of nonhuman actors/actants was developed more fully in Actor-Network Theory (ANT) (Latour, 1999). As discussed by Latour (1999), inanimate objects have semiotic influences over day-to-day interactions; in other words, the absence or presence of "stuff" has an influence on the actions of humans and must be given an equal voice in the analysis. This 
includes both natural and manmade objects; Latour (1999) argued that it was not possible or appropriate to separate nature-culture or culture-technology from each other, as they all were part of the human experience. By giving inanimate objects an agentic position, the displacement of what Foucault (1973) calls "the knowing subject" allows agency "to be conditionally analyzed rather than assumed" (Clarke, 2005, p. 298). Displacement of the subject means that "there is no subject position whose links to others is definitively assured, and, therefore, no social identity that is fully and permanently acquired" (Lee, 1999). This is not to say that individuals cannot establish a social identity or that human agency is not possible, but that identity and agency are negotiated, continually being constructed and reconstructed through individual experience.

While Clarke (2005) engages the theories underpinning Foucault's archaeological/genealogical studies and Latour's ANT, her approach does not engage the actual analytical methods Foucault and Latour developed. As discussed above, Clarke took Charmaz's (2005) interpretivist grounded theory approach, using the analytic techniques developed by Glaser and Strauss (1967) but taking an interactionist view of the data. What is important here is that Clarke explicitly acknowledges a greater role of technology in people's day-to-day interactions and the need to take material influences into strong consideration when seeking to understand a particular situation or social world.

In the case of this study, there are two nonhuman actants which have a major influence on the (inter)actions of climbers at Seneca Rocks. The first is the nature of the rock formation itself, whose cracks have historically lent themselves to traditional climbing, but since the 1980s has seen a bolts more frequently installed on both the east and west faces (Barnes, 2006). The 
second influential nonhuman actant is the protective gear that climbers use while ascending routes. Over the past ten years, climbing gear has evolved to absorb greater loads and is both easier to place and lighter to carry. Ropes have likewise increased in strength and decreased in weight and thickness. Climbing harnesses have become both lighter and more comfortable than older webbing seat-harnesses. Granting these nonhuman actants a greater level of influence on how climbers "do" climbing is crucial for this analysis with respect to interviewees" attitudes toward both the resource itself and climbing safety (Rossiter, 2007). Both of these issues are critical to the USFS; giving the influence of nonhuman actants greater weight in the analysis will increase management's understanding of climbers at Seneca Rocks and their interactions with the material world around them.

\section{Study area}

SKSR is located in eastern West Virginia, near the West Virginia-Virginia state line. It is approximately a three and one-half hour drive from both Pittsburgh, Pennsylvania, and the D.C.Baltimore metropolitan areas. Over one half of the United States' population lives within a day's drive or less of the state of West Virginia (West Virginia Department of Commerce, 2010), meaning Seneca Rocks is relatively close to a large number of potential visitors. Seneca Rocks is one of three major traditional climbing areas in the eastern United States, along with the Shawangunks in central New York and Looking Glass in western North Carolina.

\section{Data collection}

Between September of 2009 and May of 2010, 22 semistructured qualitative interviews were conducted at various locations near Seneca Rocks. Fourteen of these interviews were taped; of those fourteen, two took place in a single interview between two climbing partners and myself 
and one took place in a single interview between five individuals and myself. This interview was discarded from the data sent after the participants revoked their consent to participate. The other eight were recorded in field notes due to informants' refusals to be tape recorded. Additionally, five followup interviews were conducted after codes emerged from later interviews that had not been addressed in early ones. In order to represent the variation and differences in perspectives among climbers in the area, theoretical sampling was conducted to engage as wide a variety of climbers as possible. Interviewees included:

- owners of area outfitting, guiding, and retail services targeted at climbers

- climbing guides

- $\quad$ outdoor educators

- $\quad$ unguided climbers who socialized at climbing related businesses

- unguided climbers who socialized in local campgrounds

- climbers new to Seneca Rocks

- climbers who had climbed at Seneca Rocks for over 10 years

- climbers who learned to climb outdoors

- climbers who learned to climb in a climbing gym

Additional data included in the analysis were available accident reports from 1996 (the date of the last climbing management plan for Seneca Rocks) through 2009, participant-observations from places where climbers socialized at Seneca Rocks, and academic and popular ("grey") literature (Charmaz, 2005; Strauss \& Corbin, 1998). I was unable to engage in participantobservation while climbing with other individuals at Seneca Rocks, although I was able to engage in some observation on approach trails and at the bases of climbs. 
In keeping with Clarke's (2005) method, sampling continued until theoretical saturation was reached (see also Becker, 1957; Strauss \& Corbin, 1998). As the analysis proceeded and gaps emerged, additional sampling took place; sampling stopped when the analysis was theoretically saturated and no new codes were being generated or elaborated.

\section{Interview protocol}

Constructivist grounded theory, like other flavors of grounded theory, use a semi- to unstructured interview format to gather data from informants (Charmaz, 2005; Clarke, 2005; Strauss \& Corbin, 1998). My semistructured interview protocol is described in Table 1, along with the research questions each question addressed.

Table 1. Interview protocol.

\begin{tabular}{|c|c|}
\hline Question & Research Question(s) \\
\hline How did you become a climber? & $\mathrm{R}_{1}, \mathrm{R}_{1(\mathrm{a})}$ \\
\hline $\begin{array}{l}\text { Why do you choose to climb at Seneca Rocks? How long have you climbed } \\
\text { here? How frequently do you climb here? }\end{array}$ & $\mathrm{R}_{1,} \mathrm{R}_{1(\mathrm{a})}$ \\
\hline $\begin{array}{l}\text { If I were climbing at Seneca Rocks for the first time and you didn't know } \\
\text { anything about me, what would you tell me I should know before I went } \\
\text { climbing? How much practice should I have in doing those things? }\end{array}$ & $\mathrm{R}_{1(\mathrm{a})}, \mathrm{R}_{1(\mathrm{~b})}$ \\
\hline $\begin{array}{l}\text { What kinds of things do you like to see when you're climbing here? How } \\
\text { should those things be encouraged? }\end{array}$ & $\mathrm{R}_{1}, \mathrm{R}_{1(\mathrm{a})}, \mathrm{R}_{1(\mathrm{~b})}$ \\
\hline $\begin{array}{l}\text { What kinds of things do you not like seeing when you're climbing here? How } \\
\text { do you think those things could be changed? }\end{array}$ & $\begin{array}{l}\mathrm{R}_{1}, \mathrm{R}_{1(\mathrm{a})}, \mathrm{R}_{1(\mathrm{~b})}\left(\mathrm{R}_{2(\mathrm{~b})}\right. \\
\text { when group size is } \\
\text { mentioned) }\end{array}$ \\
\hline $\begin{array}{l}\text { If you see a climber doing something you think is unsafe, how do you deal with } \\
\text { it? What about something that you think is inappropriate? Who do you think } \\
\text { should be responsible for dealing with those sorts of things? }\end{array}$ & $\begin{aligned} \mathrm{R}_{1}, & \mathrm{R}_{1(\mathrm{a})}, \mathrm{R}_{1(\mathrm{c})}, \mathrm{R}_{2}, \mathrm{R}_{2(\mathrm{a})}, \\
& \mathrm{R}_{2(\mathrm{~b})}\end{aligned}$ \\
\hline $\begin{array}{l}\text { What kind of interaction have you had with the guide services when you climb } \\
\text { at Seneca Rocks? How would you describe those encounters? }\end{array}$ & $\mathrm{R}_{1}, \mathrm{R}_{1(\mathrm{a})}$ \\
\hline $\begin{array}{l}\text { Tell me about a typical climbing trip to Seneca Rocks. Do you always climb } \\
\text { with the same partners? How many people do you usually go climbing with? Do } \\
\text { you ever come down without a partner? }\end{array}$ & $\mathrm{R}_{1}, \mathrm{R}_{2(\mathrm{~b})}$ \\
\hline What do you like to do after you've finished climbing for the day? & $\mathrm{R}_{1}, \mathrm{R}_{1(\mathrm{a})}, \mathrm{R}_{1(\mathrm{~b})}, \mathrm{R}_{1(\mathrm{c})}$ \\
\hline $\begin{array}{l}\text { Now I'd like to ask you about management at Seneca Rocks. How much } \\
\text { interaction have you had with the Forest Service when you climb here? How } \\
\text { would you describe those encounters? }\end{array}$ & $\mathrm{R}_{2}$ \\
\hline $\begin{array}{l}\text { If you could ask the Forest Service to change anything about Seneca, what } \\
\text { would you have them change? }\end{array}$ & $\mathrm{R}_{2}, \mathrm{R}_{2(\mathrm{a})}, \mathrm{R}_{2(\mathrm{~b})}$ \\
\hline $\begin{array}{l}\text { Is there anything else you would like to tell me about climbing at Seneca } \\
\text { Rocks? }\end{array}$ & All, potentially \\
\hline
\end{tabular}




\section{Analysis}

\section{Constructivist grounded theory}

In keeping with the analytic process of grounded theory data were analyzed continuously throughout the project. That is to say, analysis began at the completion of the first interview and continued through the completion of the final interview. Additional interviews were conducted as gaps in the analysis emerged (Charmaz, 2005; Strauss \& Corbin, 1998). All recorded interviews were transcribed and analyzed in TAMS Analyzer (Weinstein, 2008) for coding. Data were coded using Clarke's (2005) constructivist grounded theory/situational analysis method, a variation on Glaser and Strauss's (1967) and Strauss and Corbin's (1998) constant comparative method. "The researcher analyzes data by constant comparison, initially of data with data, progressing to comparisons between their interpretations translated into codes and categories and more data. This constant comparison of analysis to the field grounds the researcher's final theorizing in the participants' experiences" (Mills et al., 2006). During the interviews, I took detailed field notes to be included as additional data, and also wrote detailed memos discussing observations from that day and any analytic issues I needed to work out. These memos were also included in the data (Charmaz, 2005; Clarke, 2005; Strauss \& Corbin, 1998).

\section{Memos and reflexivity}

While memoing as an analytical process is useful in expanding on concepts and immersing the researcher in the data (Strauss \& Corbin, 1998) it has a second advantage: it provides an opportunity for the researcher to assess her personal views of the data and establish distance between personal constructions of a particular situation and interviewees' constructions of the same. In the case of this study Anderson (2006) would call me a "complete member researcher" (p. 378), meaning that I belong to the social world I studied in this project. While I 
engaged in this research fully aware that it was acceptable in constructivist studies to selfreference when appropriate, I was also aware it was not acceptable to impose my own social constructions on someone else's. Memoing provided me an analytic space to reflect on my role as a researcher and my involvement with the data, and helped me maintain reflexivity during the course of this study.

\section{Triangulation and member-checking}

Triangulation occurred between the various interviews conducted and the other data collected, as is dictated in this analytic method. After the analysis was complete, memberchecking took place between three selected participants in the study and the researcher to further confirm the results (Charmaz, 2005; Clarke, 2005; Patton, 2002). Initial member-checking supported the findings of this study. It also, however, led to the discovery that several informants were identifiable through direct quotes. This discovery led to further alteration of identifying features of several individuals, paraphrasing quotes in some places, and asking permission from three informants to use quotes necessary to illuminate findings but that may potentially lead to their identification in spite of the foregoing precautions.

Five participants revoked their consent to participate in the study during memberchecking. Those data were therefore not admissible to the study and were removed from the analysis. Therefore, shortly before completing this study I determined that five of my informants had provided data that were not admissible to the study, leaving me with a total of seventeen admissible interviews, necessitating a re-analysis of the data to ensure that my findings were consistent with the remaining interviews. Although I lost a great deal of knowledge regarding the oral climbing history of Seneca Rocks due to this setback the overall findings remained 
consistent and I therefore proceeded with the reporting of results. The discussions of the evolution of climbing ethics at Seneca Rocks in this study are therefore taken primarily from Barnes's (2006) history of route development and my own personal knowledge, gained over the seven years I have interacted with other climbers and discussed the climbing history of Seneca Rocks with long-time climbers there.

As a result of discussions with informants several quotes were also removed, descriptions of some group characteristics were altered, and some supporting data were omitted because there was no way to protect anonymity. In one case a quote was removed because there was potential for reopening a conflict that had been resolved, and the individual in question thought it better to avoid that possibility.

\section{Summary}

In this chapter the research method used in this study was elaborated. This study used Clarke's (2005) situational analysis, which is a constructivist approach to grounded theory based in symbolic interactionism (Blumer, 1969; Charmaz, 2005). The interview protocol and the research questions each question in the protocol addresses were outlined and general descriptions of the 22 informants who participated in the study were provided. Issues related to triangulation, reflexivity, and member checking were addressed, including issues related to potential identification of some informants through their statements. The following section of this dissertation addressed the results of the analysis, followed by a discussion of those findings, recommendations for SKSR management, implications of the study, and recommendations for future research. 


\section{CHAPTER 4: RESULTS}

\section{Overview}

Between September of 2009 and May of 2010 I conducted 22 interviews with climbers who climbed at Seneca Rocks, including beginning climbers, frequent climbers at Seneca Rocks, guides, and guide service owners. Fourteen of these interviews were taped; eight interviewees did not permit tape recording and were therefore recorded in written field notes. Five informants revoked their consent to participate in the study; these data were discarded from the final data set. Interviews ranged from 30 minutes to one and one-half hours in length. Because these interviews took place over a specific time period they should be considered reflective of the social world at that time; interviews with long-time climbers at Seneca Rocks indicated that the social composition of climbers has varied depending on the relative popularity of traditional climbing and the economic ability of participants to travel to Seneca Rocks.

Most of the climbers I interviewed and observed were in their late 20s or older and held some sort of professional job, like engineering, medicine, teaching, or law. One was retired. The younger climbers I interviewed and observed worked as guides, cooks, or construction workers; I also interviewed two undergraduates and two graduate students from two different universities. From my and others' observations at Seneca Rocks most of the climbers who go there are in the older age group, although without an actual count of climbers at Seneca Rocks it is not possible to determine whether this is an accurate reflection of the overall climbing population.

While in the process of member-checking I discovered that some climbers were readily identifiable by their speech patterns; in the interest of protecting the identities of these 
individuals identifying details in the following section are altered and some quotes are

paraphrased. In the cases of guides who are identified as such gender has sometimes been altered as well as there are only a small number of female guides at Seneca Rocks, which made them easily identifiable. Additionally, time guiding and climbing at Seneca Rocks has been omitted in some cases as this was an identifying detail to review readers.

\section{Research Questions}

\section{What are the social worlds of climbers at Seneca Rocks? How can they be described?}

\section{Where people go and why people go there}

The social worlds of climbers at Seneca Rocks are, to a degree, situated spatially (Figure

1). In the mornings climbers stop at one of the guide services for coffee and, in the case of one guide service, breakfast. Both guide services offer coffee and muffins for sale in the morning, but one offers espresso drinks, juices, and various pastries; in the fall they were offering full service breakfasts including waffles, eggs and bacon, and oatmeal. At both sites dogs wander around on the porches, hoping for a scrap; the owners of the guide services wander among the climbers discussing routes, the weather, climbing gear, and climbing trips away from Seneca that either the guides or the nonguided climbers have taken. It is not unusual to see a climber at one of these sites one morning and at the other the next; it is not a matter of social loyalty as much as the amount of time a climber has decided to take in the morning before he or she starts climbing for the day. Climbers who have chosen to eat at a more leisurely pace eat a full breakfast at the latter guide service; climbers who are grabbing a quick cup of coffee or muffin before they head out to the rock stop at the former. The guide service that serves only coffee and muffins is also the local gear shop, so climbers sometimes choose to stop there if they have forgotten something or need to rent shoes or a helmet for the day. 
Figure 1. Spatial aspects of climbing social worlds

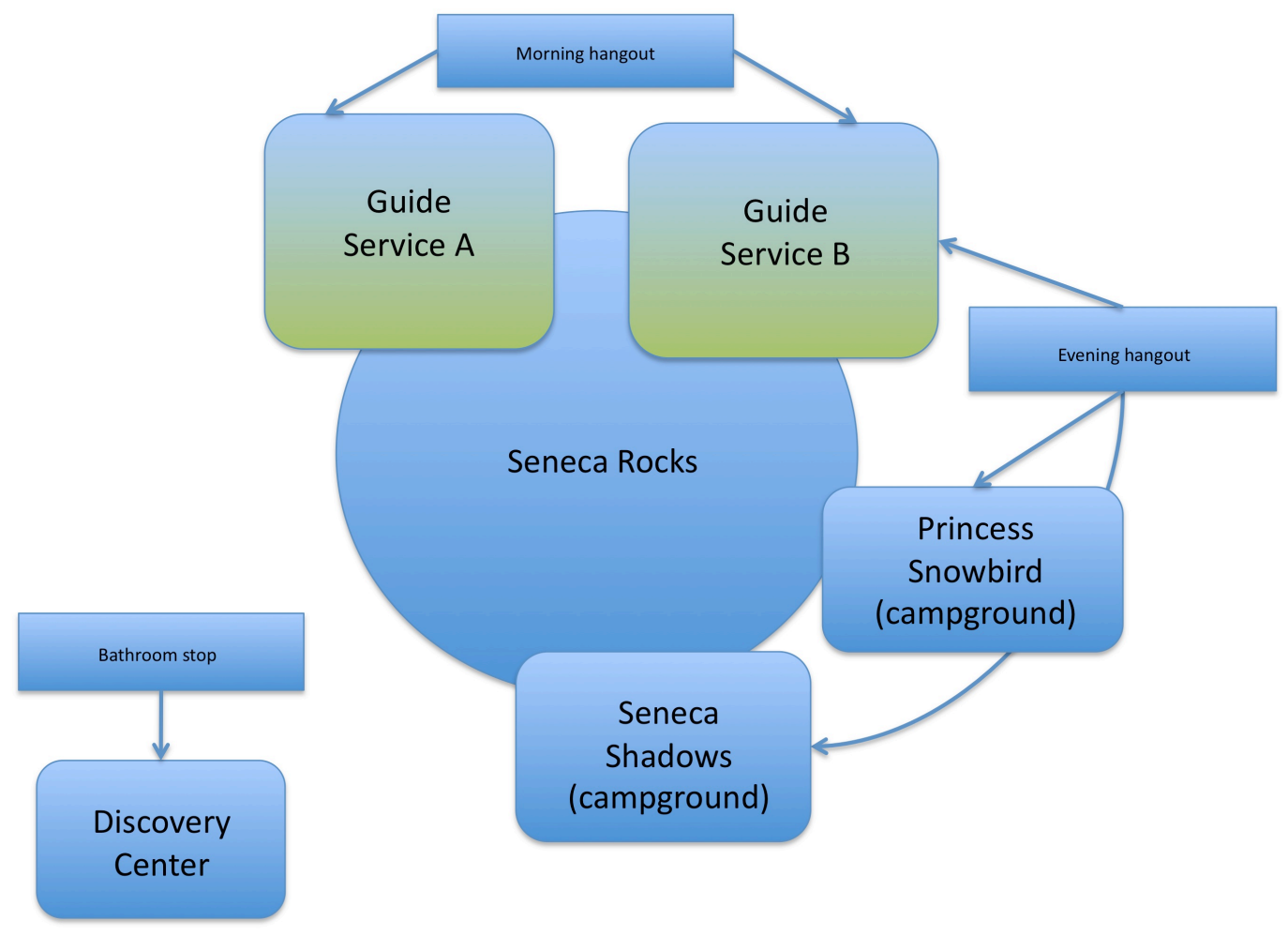

On the days I observed climbers at these locations between ten and twenty people were at each guide service in the mornings; the remainder went directly to Seneca Rocks from their campsites. In the south parking lot, which is sited below the Seneca Rocks Discovery Center, climbers organized gear, about a third of them putting on their harnesses and clipping gear to harnesses or slings in the parking lot and the other two-thirds sorting climbing equipment into backpacks to carry up the trail to the bases of climbs. Most of the climbers were male, most of them Caucasian (there were a small number of Asians but no African-Americans or Hispanics), and most of them in their late 20s or older. In my time observing below the Seneca Rocks Discovery Center I saw only one team of female climbers walking to the trailhead; the other women there had male climbing partners. In my experience this is not unusual at any crag, as 
few women climb relative to the number of male climbers at both outdoor and indoor climbing areas.

The Seneca Rocks Discovery Center does not figure into climbers' social worlds, especially since vault toilets were installed in the Seneca Rocks parking lots several years ago. The Discovery Center might be a stop on a rainy day, but, from my observations, is mostly a place where people refill their water bottles or use the restrooms if they go in at all. "There's that wall in there - I guess whenever I went through it it wasn't something that terribly interested me" (Sean, 23, first time climbing at Seneca Rocks). People who go to Seneca Rocks to climb are there to climb, not to participate in activities outside of climbing, and the Discovery Center does not currently appear to be attractive to climbers.

Across the interviews I conducted, climbers all had similar perceptions of what was attractive to them at Seneca Rocks. The soaring white Tuscarora quartzite fins attracted climbers for the types of traditional climbing opportunities it offered. A typical description of the climbing area was: "it has exposure. It has world-class routes at every level, you know, it has situations where ... you can take them anywhere and everywhere. Seneca has, in my opinion, has it all” (James, 25, three years climbing at Seneca). Climbers find ample challenges at the difficulty levels they are seeking, and the routes require that a climber develop a strong technical skill set, meaning that learning is a major ongoing component in the act of climbing at Seneca Rocks. Guides at Seneca Rocks are considered to be the most knowledgeable technicians in the climbing community there: "The guides here are experts. If you have a question they can answer it," said George, 42, who had been climbing at Seneca Rock for six years. The guides, in spite of other 
climbers' perceptions of their expertise, believe they still have new things to learn: "And so any time you can learn a better system or here's a neat trick that makes this much more efficient, you know, time, a lot of times is safety in the mountains. So I really try to do some continuing education" (Roy).

The style of climbing at Seneca Rocks and its relative closeness to major metropolitan areas was another attractant: “There's a few big cities close by, close enough to make it worth the trip. You got DC, and you got Pittsburgh, and you got even Columbus. I mean you've got colleges and climbing communities in all those areas that come to Seneca Rocks because it's the only place you can go really go trad climbing, you know?" (Peter, 40, 12 years climbing at Seneca). A student who has climbed at Seneca Rocks only one time summed up the attraction to traditional climbing in a way that also encapsulated the responses of many of the more experienced climbers I interviewed:

I love the feeling that you get whenever you're climbing and you know that everything that you're using to get up the hill you're using to come down with. At the end of the day, there will be no sign of your presence there. You know, but, perhaps a few scratches on the wall and a little bit of blood. Um, that was, that was the most positive thing I took away from that trip ... was, you know, sport climbing, you can push your grade, that's sure, but, but there was just a whole nother aspect with climbing, with pro that I hadn't been exposed to (Sean).

On Sean's trip to Seneca Rocks his partner, an experienced climber, took him up an easy route to the summit. Seneca Rocks is one of the only rock climbing areas on the east coast with a true summit, and offers a fairly large number of routes of moderate difficulty relative to other climbing areas (Barnes, 2006). "You have an actual summit, you have easy to moderate routes that are really rock climbing instead of dirty, grungy gullies, and it's a trad area ..." (William, 
63,22 years climbing at Seneca). The routes' relative difficulty is made more attractive by the large concentration of routes in the area (Barnes, 2006).

While the climbing area itself is attractive for the activity, Seneca Rocks' natural and rural settings are also major attractants to climbers from both urban and rural areas. Above the tree line, Seneca Rocks affords views of farmland and forest, with only a small number of structures visible outside of the businesses situated at the intersections of US Highways 28 and 33. Climbers enjoyed the view of the valley from high on the rock as part of the actual physical activity of climbing. Nicholas, 45, a climber from the Washington, D.C. metropolitan area, described the setting as the main reason he and his partner chose to climb at Seneca Rocks: 'It's the rural setting. Going up and looking out at all the farms. We come here to get out of the city. If it wasn't like this here, we wouldn't come."

In spite of being located in a relatively remote area Seneca Rocks has local amenities that climbers frequent both in the morning and at the end of the day. Along with Ground Up, a small restaurant that offers espresso drinks and pastries, and The Gendarme, which sells coffee and homemade muffins, climbers frequent the $4 \mathrm{U}$ and Valley View restaurants on US 28 for breakfast and the Front Porch Restaurant for dinner when they are not cooking their own meals. The Gendarme has been in business since the 1970s and remains a popular evening climber hangout for those climbers who wish to socialize outside of their immediate social group. On weekend evenings I witnessed up to 20 climbers socializing on The Gendarme's porch at any given time. The Gendarme is the mainstay of climbing social life because of its longevity at Seneca Rocks and because of the new owners' choice to maintain it as it was prior to its purchase in 2004. Historically, The Gendarme has been more than a gear shop. It is a place to find 
climbing partners, to leave notes for other climbers on the white board outside the shop, to get information about particular routes, and to discuss the day's activities after climbing.

Seneca Rocks Mountain Guides (SRMG), across the street from the Gendarme, does not have a regular evening social scene, a change in recent years. Occasionally clients from that day will socialize briefly before leaving, but unless SRMG is hosting a concert or party, which it does occasionally, most socializing appears to occur at the Gendarme. According to one longtime climber at Seneca Rocks the change in ownership at The Gendarme affected where people chose to socialize, because ownership reverted from an individual who used to climb at Seneca Rocks to individuals who currently climb there. Older climbers continue to socialize at The Gendarme because it is where climbers have always socialized, but younger climbers and guides used to socialize at SRMG more frequently prior to The Gendarme's sale.

Along with socializing at the Gendarme evenings at Seneca Rocks revolve around food, beer (and occasionally marijuana), and socializing at the campgrounds where people are staying or at the Gendarme, the local climbing shop. Food and beer are central foci of before- and afterclimbing activity, whether it consists of admiring the salmon filets that another climber is cooking on a picnic table at The Gendarme, eating pizza at the Front Porch Restaurant next door, or discussing types of beer people like to drink. "[mimes lighting a pipe and toking, laughs] [I] usually like enjoy the hike down, you know, if it's dusk, or grab a beer, eat some food, usually. Um, relax. Yeah. Get, like, a fire going, you know? I guess the ideal day would be going back and prepping a bunch of food and just cooking up a good meal, you know? That would be ideal. With a great, like, hike out, you know? Sunset or something like that" (James). Climbers tend to 
camp either at Seneca Shadows, the USFS campground, or at Princess Snowbird, owned by the Yokum family. At the time of this writing the Yokums charged $\$ 6.50$ per person per night to stay at Snowbird and the USFS charged $\$ 13.00$ per walk-in tent site per night to stay at Shadows, so for every two individuals sharing a campsite the price is not an issue. Both campgrounds have available showers and partial views of Seneca Rocks. Seneca Shadows has clearly denoted campsites with tent pads, picnic tables, and trailer hookups, whereas Princess Snowbird has fire rings, a few picnic tables that people move from area to area, no clearly delineated campsites, and a few trailer hookups. The choice of campground is one of social, rather than physical setting.

Shadows, as most climbers call it, is the quieter of the two campgrounds, with designated camp sites, tent platforms, and a fee per site, making it more affordable for large groups than Snowbird. Snowbird, on the other hand, has fire rings scattered about a large, grassy field people can camp wherever they please, and can spread their campsites over a larger area than at Shadows. There is little management presence at Snowbird, and evenings can be alcohol fueled and rowdy among the mix of motorcyclists, large extended families, and climbers who stay there on weekends. In the campgrounds climbers socialize among the people they are camping with but generally do not visit others' sites unless somebody they know is staying there. Choices of campsites appear to be a matter of personal preference - quiet or rowdy evenings? - rather than a reflection of climbing philosophy, which more strongly defines social worlds at Seneca Rocks. 
Figure 2. Places and discourses where climbers go

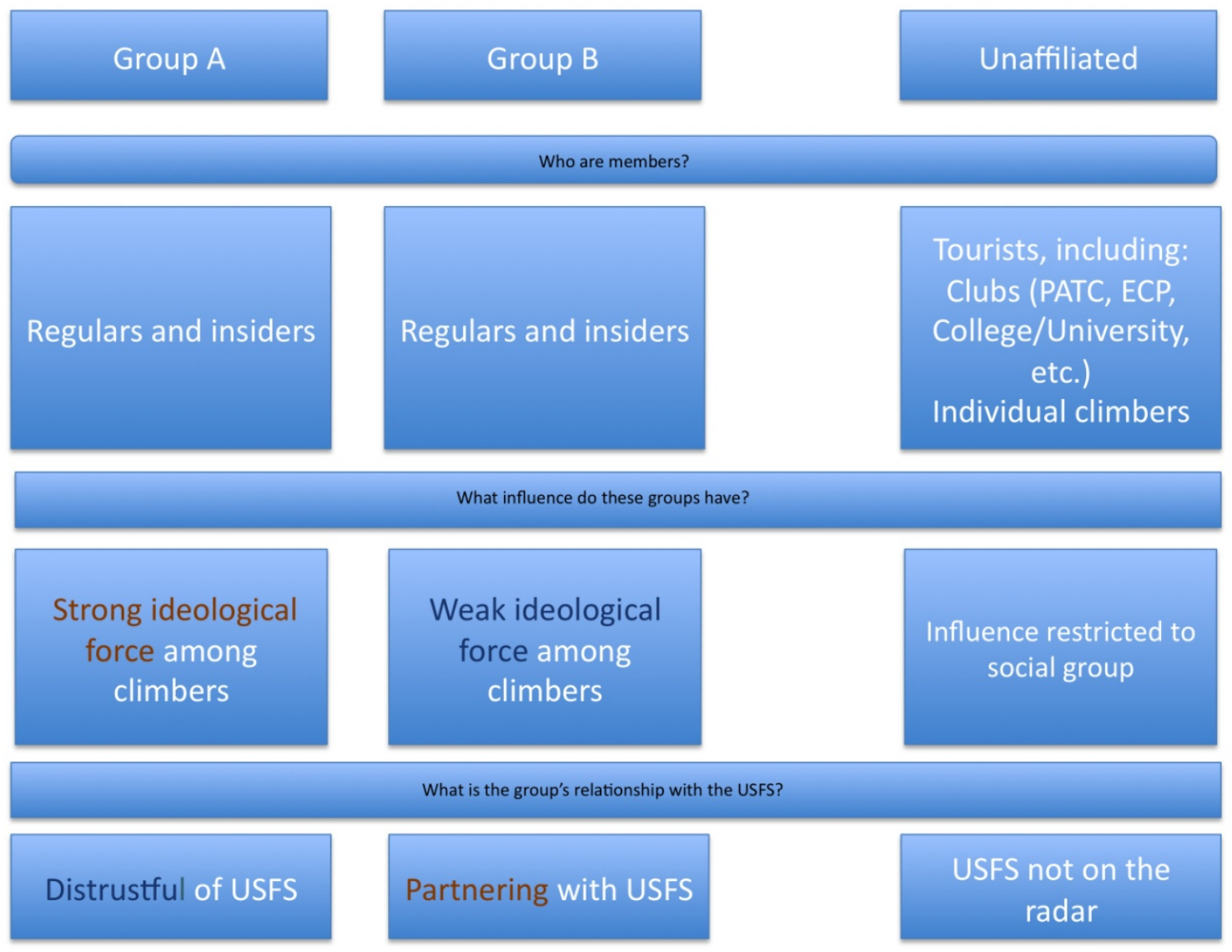

In Figure 2 the social worlds of Seneca Rocks are broken into three groups: two groups closely affiliated with one of the two main insider groups, and a third group that associates with neither one. The insider groups consist of long-time climbers, many with decades of experience climbing at Seneca Rocks, and some with fiduciary interests in climbing there. On the whole, climbers are friendly with each other and socialize indiscriminately between the two insider groups. The climbers perceived as "leaders" of the two groups, on the other hand, have some philosophical differences that have led to expressions of frustration and disappointment as well as mistrust between these groups. 
Climbers who are not members of climbing clubs tend to socialize at either establishment, although philosophically they tend to rely on the ideas about route development the main source of conflict between the two insider groups and discussed in more depth in the section on bolting -- expressed by Group A. This appears to be a matter of self-selection rather than a case of direct influence - no climber that I interviewed expressed a change in attitude toward climbing practices based on the influence of one insider group over the other. The major influence most insiders, who tended to have the greatest overall climbing experience and expertise, had on other climbers was during social discussions of safety practices in nonclimbing situations, and the safety information obtained from either insider group was identical in content during my observation sessions.

Although the guide services at Seneca Rocks have some social influence on unguided climbers it is important to note that many climbers socialize mostly within their own groups, whether that be school groups, clubs, or groups of friends. The climbing guides, due to their training (most have at least one American Mountain Guides’ Association guide certification), were perceived as experts among nonguide climbers at Seneca Rocks, and were universally liked and respected among the climbers I interviewed. Their influence, however, extends only to the people who socialize at those guide services. Climbers who were members of clubs were more likely to socialize within those clubs, whose spheres of influence are limited by membership.

During my observations among Group A I heard individuals express a sense of futility in dealing with the USFS due to the turnover there making it difficult to see changes through, as well as hostility toward the USFS for failing to open Champe Rocks to general climbing access. 
Group B, on the other hand, worked directly with the USFS and found them to be very helpful in accomplishing some of their goals, although this group did not express interest in access to Champe. This means that the USFS is more likely to hear from only one of the two groups with the most knowledge about the area, leaving them with less complete information about the social complexities of climbing at Seneca Rocks.

\section{Defining Seneca Rocks by what it is not}

The climbers I interviewed described the natural and social settings at Seneca Rocks as reasons they chose to climb at Seneca. They also compared the climbing opportunities at Seneca Rocks to those at other areas in the United States. These other locations were used to illuminate the uniqueness of the experiences climbers had at Seneca Rocks as well as what made Seneca Rocks attractive to them.

Regionally, one of the attractors to Seneca Rocks was the nature of the climbing there. "Seneca is the best place on the East Coast to have a mountaineering style rock climbing experience. Most other places are crags that finish in the woods, you don't finish on a true summit, you know, unless you get to the Adirondacks or the White Mountains or something, so it's a very unique experience here" (William). Other nearby climbing areas do not have true summits, making Seneca Rocks attractive. The summit was referenced by beginners, long-time unguided climbers, and guides, and it contributed to experiences described as "alpine," "mountaineering," and "backcountry." As William mentioned, Seneca Rocks is one of the few climbing areas on the east coast with a true summit; in relatively close large areas like the New or Red River Gorges as well as in smaller areas like Coopers Rock outside of Morgantown, West Virginia, climbing takes place on a cliff side where it is possible to reach the top of a climb and 
walk off. At Seneca Rocks, on the other hand, if climbers choose to take a route to the summit (not all routes finish there) they must rappel several times to reach the ground again.

Another comparison climbers made was related to the level of gear placement skill that is required to climb safely at Seneca Rocks. Climbers described placing protection at Seneca Rocks as "crazy," "inventive," "more technical on some routes," "tricky," and "more advanced" than gear placements at other areas. One climber described Seneca Rocks as the opposite of Indian Creek in Utah, "where you're just plugging a cam in." Indian Creek is known for its "splitter" cracks, that is, cracks that are the same width from top to bottom. In areas such as Indian Creek the climbs are strenuous, but the difficulty with gear placements is more likely to be whether a climber can find a large enough quantity of the same size piece of gear to attempt a route rather than the nature of the placements themselves. At Seneca, by contrast, "you need to know how to equalize a nut," a gear placement in which two nuts are placed against each other in opposite directions, then tied together to make the force on each piece equal in case of upward or outward pull on the pieces or of the downward force of a fall. The intent of this gear placement is to make two pieces of gear function as a single piece when one piece of gear will not fit in a crack. Gear placements at Seneca Rocks are not as simple as in locations with splitter cracks, where one determines how many of a particular piece of gear is needed and the placement works every time; it takes practice, creativity, and analytical skills to be able to place gear well there.

The physical attributes of Seneca Rocks are one comparison climbers made to other climbing areas; another comparison was the social attributes of the area. For long-time Seneca climbers Seneca Rocks is considered to be a friendly place populated with other climbers whose 
behavior is both more welcoming and more mature than at other climbing areas. "That's one thing I always appreciate about Seneca. It attracts good people. People who are, I feel, are in the sport for the right reasons and really appreciate the beauty of this place" (Brian, 30, 10 years climbing at Seneca Rocks). Climbers like the availability and predictability of hangouts at Seneca Rocks and the friendships they promote, describing them as "like an old shoe," and "a good place to meet people."

When I was seeking younger and inexperienced climbers to interview for this project I spoke with the director of West Virginia University's Outdoor Recreation Center, who expressed skepticism that I was going to find many users of the Student Recreation Center's climbing wall who also climbed at Seneca Rocks. His skepticism was well-founded: only one of the interviews I conducted was obtained through West Virginia University, and only three tabs were torn off of the 20 flyers I distributed around campus. According to him and several of the guides that I interviewed, many climbers who learn to climb in the gym are opting to engage in sport climbing outdoors - it is less equipment-intensive, has a shorter learning curve, and is less intimidating to many beginners. The transition from gym climbing to traditional climbing will be addressed in more depth in the sections on learning and safety; I bring it up here because although it is not unusual to see college-aged climbers at Seneca Rocks, particularly if they are part of a university outing club, in my experience it is more likely to encounter climbers in their late 20 s and older among the frequent climbers at Seneca.

Another comparison climbers at Seneca Rocks make to other places is the level of crowding. Regular climbers at Seneca found ways to avoid the heavily trafficked areas on busy 
weekends. For some, their solution was to climb during the week; others climbed routes that were less well known or required more complicated or strenuous access. Another group avoided Seneca Rocks altogether on long weekends, knowing from experience that the crag was going to be busy. Climbers who were less familiar with the area were more likely to complain about crowding. "I expected a more wilderness experience. Unless you climb in the middle of the week you can't get away from people. We could have just gone to [crag near hometown]" (Marshall, 27, second time climbing at Seneca).

Climbers who climbed regularly at Seneca Rocks were also more likely to state that they would climb with an unfamiliar climbing partner there than they would at other places, largely due to their familiarity with the area. The nature of these partnerships is described in more depth in the following "aside."

\section{An aside about climbing partnerships}

Climbing partnerships are not as cut and dried as they appear on the surface. Across the climbing literature there are references to Gaston Rebuffat's description of "the brotherhood of the rope" (Harrer, 1959/1998, p.181), which in some ways has been misinterpreted to a universal truism. Rebuffat developed this term when describing two teams of climbers from two different countries on the North Face of the Eiger who were running into bad weather and other trouble and teamed up to complete the climb to ensure that everyone made it safely to the summit. This was a temporary partnership. These climbers did not start climbing together on a regular basis (or at all) after this incident - it was a situation born of convenience that worked to mutual advantage (Harrer, 1959/1998). 
Mutual advantage can describe many climbing partnerships. Climbers seem to have two particular types of climbing partnerships - those born of mutual convenience, like Rebuffat's brotherhood of the rope, and those cultivated over time. The term "climbing partner" is in and of itself evocative - partners - spouses, closeness, emotional connections, and so on - but the term also can be used to refer to business partners. Some partnerships are more like the former, others like the latter. Many climbing partnerships appear to be born of convenience. These partnerships consist of people who, after some vetting, appear to be compatible for the day's goals and are involved for maybe a day or two in going climbing together. "And then you have to go through the process of vetting the partner and, you know, finding out what they did, you know, that whole process of kind of making sure ...” (Peter). This aligns with Donnelly’s (1982) observations that most climbing partnerships are transitory and do not involve any type of emotional closeness or connection. There may be some beers drunk afterwards, but the link between people is still relatively superficial. This is an interesting dichotomy: people are willing to put their lives in the hands of someone else (literally) but are willing to jettison any emotional investment, climbing with an unfamiliar partner for the sole purpose of maximizing personal utility for the day.

James: Man, but, you know, when I was starting off it was [regular] partners all the time. You know. Now just being down here there's more climbers, pretty much who's free. You know, do you have off tomorrow morning.

Q: So you come down without a partner sometimes?

James: To here? Oh, yeah. Yeah.

Trust in climbing partners is gained, however, not assumed. Several climbers talked about how they assumed they were free soloing (climbing without protection) until they were sure that the other person was a competent belayer. "I will generally if I do go out with 
somebody and I'm not real sure the situation I'll climb something easier then, a lot easier, something I, you know, pretty much play the guide game, but don't, you know, I'm not going to fall on it, so... It's like pretty much climbing routes I can free solo. For a couple routes, and if I feel really comfortable after that point I, you know, go ahead and climb harder things" (Peter).

Sean spoke specifically about climbing an easy route to make sure that the person they were climbing with was competent. The three climbers I interviewed who were new enough to the activity that they had not considered lead climbing were more likely to limit their partnerships to the people who were teaching them to climb due to their own inability to assess others' skills: 'I know those guys. They know what they're doing. I don't know enough to just go out with some random person" (Mitchell, 26, three months climbing at Seneca). A climber with over 20 years' experience described how he thought beginners should choose partners: 'I think it depends totally on who you come down with. If you come with a really knowledgeable person, you don't really need to know a whole lot, 'cause they'll babysit you the whole way up and the whole way down and you'll learn on the job" (William).

For more advanced climbers the casual climbing partner is not someone with whom to push boundaries, unless perhaps they come recommended from a trustworthy source (generally guides and trusted other climbers). Times where climbers are looking for challenges at their "limit" generally require a different type of partnership.

This other kind of partnership involves the partners people do have mutual emotional investments in. These are generally people with whom a climber has climbed for a considerable 
amount of time (usually years) and socialize outside of climbing. These are the people with whom climbers are more likely to push their limits - there is a deeper sense of trust, perhaps because of the outside emotional relationships involved in this kind of partnership. "On certain occasions, on certain - every big thing I've ever done I have the same guy" (James). Local and nonlocal climbers who were not beginners talked about having a regular, trusted, partner for hard routes - in potentially risky situations climbers are not willing to hand the rope to a casual partner.

\section{Does how an individual learned to climb affect their membership in a particular social world at Seneca Rocks?}

Half of the climbers I interviewed started climbing in a climbing gym; the other half started climbing outdoors. This was not a result of my sampling frame but was purely coincidental. All but one of the climbers under 30 who I interviewed learned to climb in an indoor climbing gym; as indoor gyms are more readily available on college campuses and in major cities than they were even ten years ago it follows that younger climbers would have more opportunities to take advantage of indoor climbing. Where climbers began to climb, however, had little effect on their social world memberships. Their level of commitment to Seneca Rocks had a much greater influence. From my observations unguided climbers who are new or relatively new to Seneca Rocks tended to separate themselves socially from climbers who climbed regularly at Seneca Rocks. This is not to say that these climbers have no social group identity; rather that they tend to socialize within the group with which they are climbing, particularly if they are camping in large groups. Guided climbers who are new to Seneca Rocks tended to socialize at the guide services after a day on the rock and ultimately interact with the 
climbers who climb regularly at Seneca Rocks since the latter group also socializes in these areas.

Some unguided climbers are content to socialize only within the social circle within which they have defined their trip. They come to Seneca Rocks "to hang out with my friends" (Todd, 22, first time climbing at Seneca Rocks). If there is a slide show, cookout, concert, or other organized event at one of the guide services they may attend that event along with the other members of their social group, but exploring other social worlds generally does not interest them. Others avoid the public social scene because it seems "fragmented and cliquish" to them. Still others have been visiting Seneca Rocks for a long time, but for them it is a once-in-a-while trip with a group of friends, and the attention is focused there due to the "special" nature of the trip. In Unruh's (1980) classification of the levels of commitment to a social world, these individuals would qualify as tourists: they have little long-term commitment to the social world, participate when they find it interesting to them, and do so in a limited fashion (Figure 3). 
Figure 3. Tourists, regulars, and insiders at Seneca Rocks

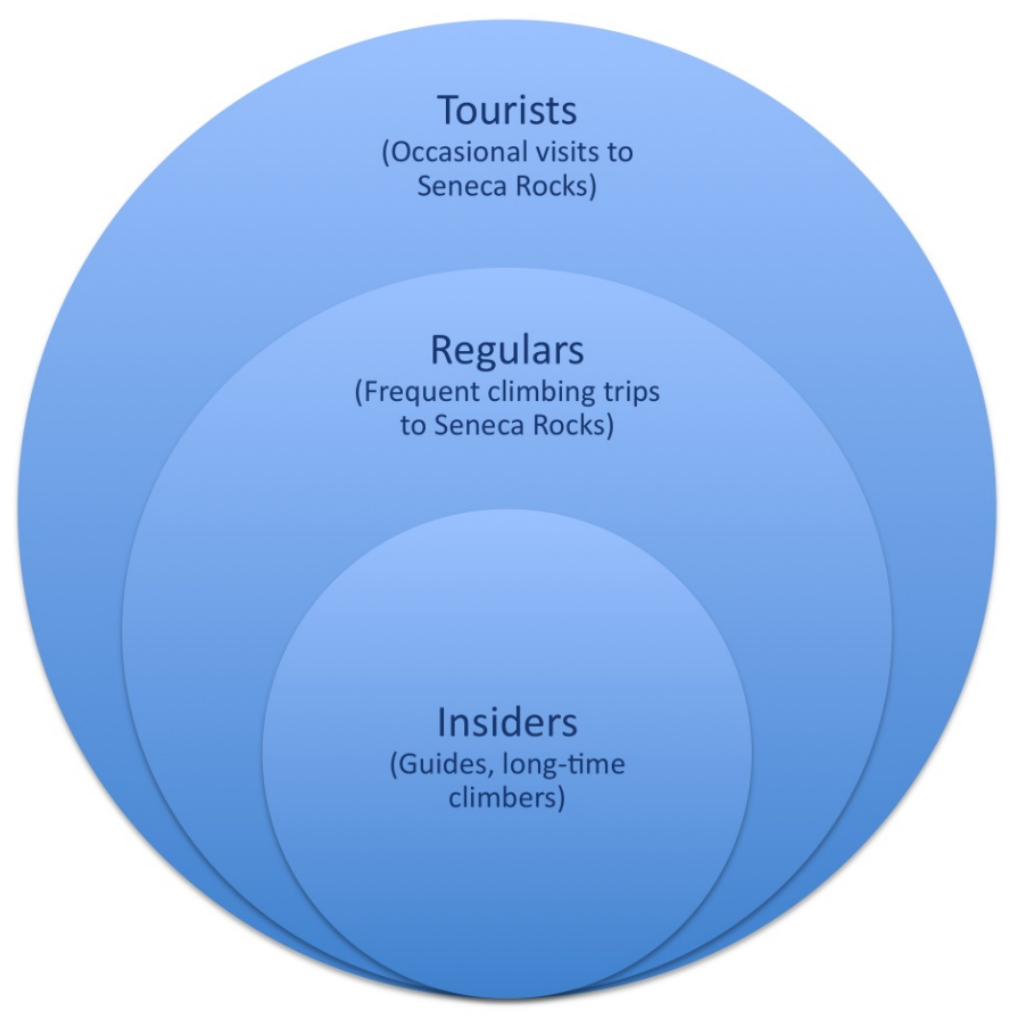

Examples of why the tourists at Seneca Rocks climbed there included: "it's where the [university outdoor] club decided to go this weekend" (Marty, 19, second time climbing at Seneca), "this is our big once-a-year trip" (Xavier, 51, eight years climbing at Seneca), and "we were tired of all the crowds at the local crags, so we came up here" (Marshall). They tended to climb with the same people at the gym, at crags near their hometowns, and occasionally to one or more major climbing areas as a social unit; that is to say, they traveled in large groups and socialized within them, with little commitment to a particular climbing area. Regulars, on the other hand, liked the "challenge" of the rock, encountering people they had met before, and the availability of social venues. Like tourists, they climbed at the gym and at nearby crags, but tried 
to travel to Seneca Rocks as frequently as possible. Insiders described Seneca Rocks as "[having] it all," providing a "myriad" of climbing opportunities, and "like a family." This group traveled to Seneca Rocks on a regular basis, lived nearby, and/or found jobs near Seneca Rocks that allowed them to climb there on a weekly to daily basis.

Because all but a few of the insiders at Seneca Rocks are guides or former guides, they do tend to have an extremely high level of climbing expertise, not only relative to Seneca Rocks but to the specialized training they have received as part of their jobs. If one were to follow this line through to the tourist groups, it could be assumed that the groups with the least commitment also possessed the least skill. Rather, the tourists tended to possess the widest range of skills - some tourists were beginning climbers following more experienced climbers in their group; others were climbers with over 20 years' experience up to and including high-altitude mountaineering. The broad range of skill sets among the tourist climbers as well as the reasons they choose to climb where and when, however, may be more reflective of how they choose to allocate their climbing time rather than any indicator of specialization or commitment as a subworld delimiter. (Bryan, 1977; Ditton et al, 1992; Green \& Chalip, 1998; Sean \& Chick, 2004).

\section{What practices exist in the social worlds of climbers at Seneca Rocks with regard to safety practices? To climbing etiquette?}

According to the American Alpine Club (AAC; 2009), 112 climbing accidents (including mountaineering and ice climbing) occurred in the United States in 2008, the most recent year data have been compiled. Immediate causes of non-mountaineering accidents included falling or slipping (59.8\%), gear failure (14.3\%), and poor decision-making or technique from either the belayer or leader $(22.3 \%)$. The most frequently reported contributors to those accidents were 
climbers exceeding their abilities (8.9\%), placing poor or no protection $(23.2 \%)$, belayer error $(8.0 \%)$, and bad weather (7.1\%). Over the 14-year period since the SKSR climbing management plan was developed, there have been 345 reported climbing-related fatalities in the United States (including ice climbing and mountaineering fatalities) including three reported at Seneca Rocks. National data for 2009 climbing related fatalities were not available at the time of this writing, meaning that the number of fatalities nationwide between 1996 and 2009 is underreported in Table 2.

Table 2. Climbing fatalities in the United States and at Seneca Rocks, 1996-2009

\begin{tabular}{ccc}
\hline Year & U.S. $* *$ & Seneca Rocks \\
\hline 1996 & 31 & 1 \\
1997 & 31 & 0 \\
1998 & 20 & 0 \\
1999 & 17 & 0 \\
2000 & 24 & 0 \\
2001 & 16 & 0 \\
2002 & 34 & 0 \\
2003 & 18 & 0 \\
2004 & 35 & 0 \\
2005 & 34 & 0 \\
2006 & 21 & 0 \\
2007 & 15 & 0 \\
2008 & 19 & 1 \\
2009 & Not & 1 \\
& available & 3 \\
\hline Total & 345 & \\
\hline
\end{tabular}

* Adapted from AAC (2009), 89-90

** Includes mountaineering and ice climbing fatalities

Because accidents reported to Accidents in North American Mountaineering (AAC, 2009) are submitted on a voluntary basis it is an incomplete record of the climbing accidents that have occurred in a given year, although it is the most exhaustive resource available. In recent years the AAC has relied not only on written reports submitted by volunteers from the AAC Safety Advisory Council, but on online reports and discussions of accidents (AAC, 2009). The 
discussions of accidents that follow are a combination of eyewitness and rescuer accounts and online discussions of the accidents in question. It is important to note that only accidents leading to serious injury or death are discussed in this section, as minor injuries are generally not reported to the AAC or other sources.

Because there is no record of the number of people who climb at Seneca Rocks, it is not possible to determine the frequency of major accidents relative to the number of climbers participating in the activity. According to one insider, there is generally one accident serious enough to warrant a rescue every year that person has climbed at Seneca Rocks. Of the five accidents discussed at length in print and online sources between 1996 and 2009, two involved broken ankles (AAC, 1997; Accident at Seneca 4/15, 2006), one a cracked vertebra (Accident on East Face Seneca 10/25, 2009), one a concussion (Seneca Accident on Front C, 2007), and one a crush injury (Rockfall at Seneca Rocks WV, 2005). The first two accidents were the result of equipment failure - one possibly from a defective piece of equipment, the third inadequate protection, the fourth belayer error, and the last from rockfall.

Falling rock is considered an objective hazard by climbers, meaning that it is a naturally occurring hazard that is outside of the climber's control and that is factored into the risk equation of a climb (Graydon \& Hanson, eds., 1997; Long \& Luebben, 1997). In the case of this particular accident the size of the rock that fell was considerable: eyewitnesses described it as "televisionsized." Most of the time falling rocks are relatively small, although even a small object falling can cause injuries. Rockfall is a relatively frequent occurrence at Seneca Rocks, and climbers there tend to both wear helmets and encourage others to wear them for protection. The climbers I 
interviewed who had extensive experience climbing at Seneca Rocks recommended that climbers wear helmets. Further, accepted climbing practice in any climbing area is that if a climber knocks down any object they should yell "Rock!" to warn people below of a potential hazard (see, e.g., Graydon \& Hanson, eds., 1997). Yelling "Rock!” was another recommendation that guides and experienced climbers made to keep the climbing experience there safe for those nearby: "You know, don’t drop crap on 'em. You know, it's not a good idea. [laughs] They're not going to appreciate it and somebody could get hurt" (Peter).

Along with safety practices related to objective hazards like rockfall, experienced climbers recommended having good rappelling skills to climb safely at Seneca Rocks. "Lots of people figure out the way to get up, but they forget to figure out how to get down. Drop a belay plate, get up there in the dark and don't know where to find the right tree to reach the ground. Yeah. Biggest thing I see at Seneca is gym climbers who know how to climb pretty well but they don't know any of the safety features, what happens if you drop your [belay] plate, you know. They don't know what to do" (William). William went on to tell me about a climber whose hair had become stuck in her rappel device, requiring him to set a second rappel to extricate her so she could continue her descent. Along with needing the skills to rappel both with and without a rappel device, knowing the location of the rappel stations to avoid becoming benighted was mentioned by all of the long-time Seneca climbers I interviewed, as the two-sided formation can be confusing to navigate for climbers unfamiliar with the area.

The USFS trailhead signs at Seneca Rocks warn, among other things, that being stuck on a route in the dark is not grounds for a rescue. Experienced climbers recommended carrying a headlamp due to the amount of time it can take to climb and descend long routes. Several 
climbers related versions of this cautionary story that has been in circulation at Seneca Rocks for years regarding becoming benighted at Seneca: A climber came to the porch of The Gendarme after dark, seeking a rescue for some friends of his that had not returned. The head guide from Seneca Rocks Climbing School hiked to the bottom of the crag and shouted up to the climbers to find out if everything was okay. After determining that nobody was injured, he asked them if they had a light, to which they replied, "no." He then asked if the climbers were tied into an anchor. Again, they replied, "no.” The guide's response, "Well, you should be. I'll see you in the morning," at which point he left. (Cautionary discourses are a part of how climbers negotiate and enforce safety issues; they are discussed in more depth in the section addressing $\mathrm{R}_{1(\mathrm{c})}$.) It is expected at Seneca Rocks that climbers take responsibility for subjective hazards - that is, situations they can control (Graydon \& Hanson, eds., 1997; Long \& Luebben, 1997) - like carrying a headlamp or knowing how to rappel. 
Figure 4. Seneca Rocks trailhead sign (photo: K. Thompson, 2009)

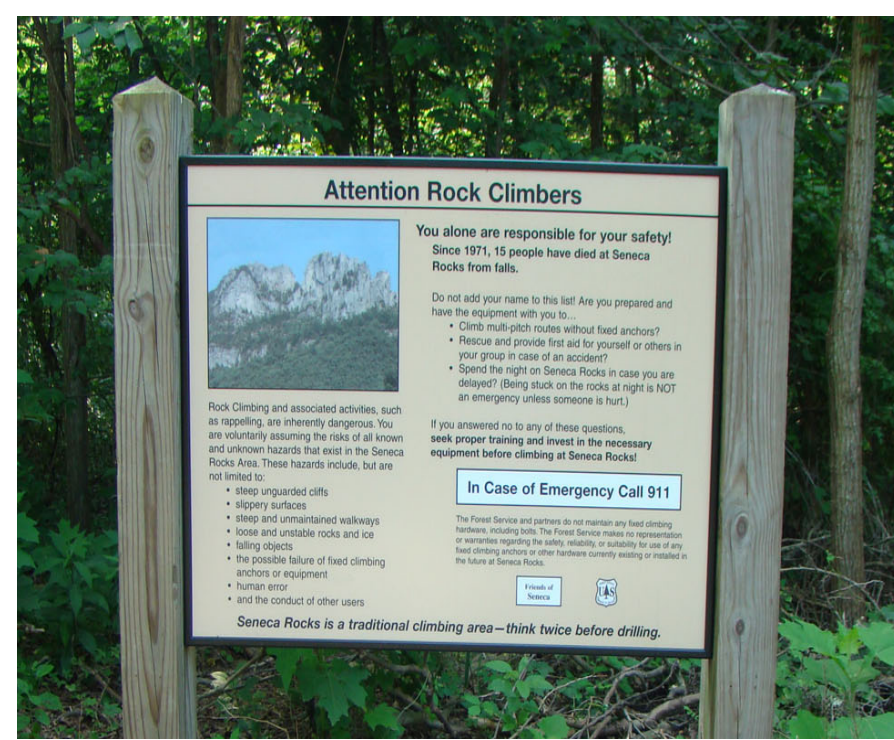

Along with carrying proper equipment, having strong critical thinking skills and self-knowledge are part of the skills that climbers at Seneca expect each other to have. "You have to be honest with yourself if you have the skills, if you're capable of doing a climb" (Sheldon, 45, eight years climbing at Seneca Rocks). One frequent discussion held among climbers I

observed was that there is no one-size-fits-all best way to climb safely, a misconception they perceived as held by beginning climbers: good decision-making depends on the climbers' surroundings, including available protection, condition of the rock, weather, security of a stance from which to place gear, and a
Because the text in Figure 4 is small in the photograph I have reproduced it here: Attention Rock Climbers: Rock climbing and associated activities, such as rappelling, are inherently dangerous. You are voluntarily assuming the risks of all known and unknown hazards that exist in the Seneca Rocks Area [sic]. These hazards include, but are not limited to:

- $\quad$ steep unguarded cliffs

- $\quad$ slippery surfaces

- $\quad$ steep and unmaintained walkways

- loose and unstable rocks and ice

- falling objects

- the possible failure of fixed climbing anchors or equipment

- human error

- $\quad$ and the conduct of other users

You alone are responsible for your safety! Since 1971, 15 people have died at Seneca Rocks from falls. Do not add your name to this list! Are you prepared and have the equipment with you [sic] to (cont'd next page) 
myriad of other factors. These are skills that develop over time. The beginning climbers I interviewed lacked confidence in their own abilities to make situationally appropriate decisions. A college student who was making the transition from sport to traditional climbing mentioned that he was not as sure of himself when he was placing gear: "I'm on trad, I don't have the confidence in myself that I have climbing sport" (Sean).

Although the climbers I interviewed stressed the importance of both self-awareness and selfconfidence in climbing, they also expressed concern about people lacking those skills. Eight of the climbers I interviewed discussed situations they got into as beginners in which their overconfidence could have led to injury and, fortunately, did not. Their stories ranged from getting lost while climbing at high altitude to making decisions on single-pitch climbs that "were technically not, uh ... best practices, if you know what I mean" (Brian). As discussed above, making nonfatal mistakes is considered part of the learning process in traditional (cont'd from previous)

- Climb multi-pitch routes without fixed anchors?

- Rescue and provide first aid for yourself or others in your group in case of an accident?

- Spend the night on Seneca Rocks in case you are delayed? (Being stuck on the rocks at night is NOT an emergency unless someone is hurt.)

If you answered no to any of these questions seek proper training and invest in the necessary equipment before climbing at Seneca Rocks. In Case of Emergency Call 911 (emphasis in original).

The Forest Service and partners do not maintain any fixed climbing hardware, including bolts. The Forest Service makes no representation or warranties regarding the safety, reliability, or suitability for use of any fixed climbing anchors or other hardware currently existing or installed in the future of Seneca Rocks. Seneca Rocks is a traditional climbing area - think twice before drilling (emphasis in original). 
climbing. Regardless, several climbers expressed concerns that learning to climb in the gym was giving climbers new to climbing outdoors a false sense of their abilities in an outdoor setting.

Climbing gyms provide a contained environment in which people can learn the basics of belaying and climbing movement; some climbing gyms also offer the option to lead sport climbs, in which lead climbers clip bolts for protection. When an individual climbs in a gym they climb set routes denoted either by colored holds or tape to indicate where a climber should place his or her hands and feet. What climbing gyms do not provide are objective hazards, like rockfall, poisonous snakes, nesting pigeons, or thunderstorms. They also do not teach routefinding skills (to state the obvious, natural rock does not provide colored indicators of where to step next) or safety assessment skills, things that Seneca climbers find necessary to climb at Seneca Rocks safely. When a climber climbs in a gym, they can learn the movement and develop the strength to climb routes of considerable physical difficulty. Because of the nature of climbing gyms, however, these climbers cannot learn the critical thinking skills necessary for traditional climbing in that setting. The combination of physical skill without basic outdoor skills, critical thinking skills, and technical skills can lead to poor decision-making when climbing outdoors.

Most of the poor decisions made due to inexperience or overconfidence were along the lines of the climber whose hair got caught in her rappel device: not something that would cause serious injury or death, but something that required a more experienced climber to extricate them because the climber in the bad situation did not know what to do. Making the transition from gym to crag, however, sometimes meant that a climber's lack of technical skills contributed to a chain of events that resulted in serious injury. Here an insider described the chain of events 
leading to the 2009 accident involving inadequate protection (see also: Accident on East Face

Seneca 10/25, 2009):

We had what could have easily turned into a fatality last fall. Have you done Conn's East? [Q: Yes.] So off the Soler ledge, the crux section where you have to climb out to the little bulge area past the pin and on to the Orange Aid/Alcoa ledge, the leader had climbed up and clipped the pin and gotten through the hard moves and then ran it out to the anchors. Subsequently his second, who was carrying the pack with all the gear and all the water, you know, greatly weighed down, um, probably climbing at her limit anyway got up into that move and came off. And the pendulum that resulted actually had her swinging into the left-facing corner of Conn's East Direct. Just above Castor and Pollux. So she swung, and at the, the apex of the arc, which is actually upside-down apex she impacted that corner at maximum speed and velocity. She had, in that process flipped upsidedown and came into it backwards, which is probably what saved her life. The pack exploded. She had rented a helmet. And she cracked C5. So once again, here's somebody who could physically do the moves. You know, the leader could physically climb and do the moves. But did not have any inkling of the, the greater overall arching picture of climbing and climbing safety. And to that person climbing was, it never even considered protecting for the second. Never entered their mind because they'd never seen the accident. But also had never taken a course where someone said if you're going to lead, one of the things you always need to be ... wary of in a traverse is protecting behind the crux. But you in a straight up and down climb, there's no need to. So, then, someone who, once again, has the physical climbing ability but doesn't have enough climbing experience to be really be safely out there climbing.

Protecting for the second refers to the act of placing enough gear on a traverse to prevent the climber who is following the leader (the second) from taking a long fall if they should fall on that traverse. In this particular situation the leader of the climb did not know about this safety practice. Not placing enough protection on the traverse in question led to the second falling, swinging into the rock, and cracking a vertebra. Lack of knowledge and skill when undertaking a potentially dangerous activity like climbing usually leads to minor incidents at Seneca Rocks but can also cause major accidents. 
Half of the climbers I interviewed for this study had initially learned to climb in a climbing gym. Learning to climb in a gym is not an instant recipe for accidents when climbing in traditional style, but making the transition to climbing in the outdoors without some sort of mentor or guide to teach basic skills can contribute to poor skills self-assessment. According to their promotional materials, both guide services at Seneca Rocks assess their clients' abilities before they go climbing. One service chooses to directly target gym climbers by offering a gymto-crag transition course; the other approaches the issue more subtly by advertising a customized experience for every client.

In a nutshell, basic traditional climbing know-how is something that climbers expect of their peers at Seneca Rocks. Knowing how to rappel, how to belay, routefinding skills, anchorbuilding, and rappelling skills were skills that all experienced climbers thought a climber should have to climb at Seneca. If a climber were to come to Seneca Rocks without such skills, finding an experienced climber or hiring a guide to teach them what they needed to know to climb safely was considered important by all climbers I interviewed, including the inexperienced climbers. A guide service owner told me that half of his business was from people wanting to learn new things and the other half from people who had "scared themselves" and realized they needed to learn more skills than they thought they did. Self-rescue classes were one of this service's more popular offerings.

Self-rescue is a technical climbing skill in which climbers use the equipment they use to protect a climb to rescue themselves or their partner, reducing the need for outside rescues if there are minor accidents. Even though the guide services offer these classes and climbers are 
taking them, there was a tendency for the climbers I interviewed to assume that the guide services would be handling rescues at Seneca Rocks. Examples of this assumption are reflected in statements like, "I think the guide services work a lot together to, work on their own to keep this place safe. They're the ones doing the rescues and, you know, I think it's just fine,' (James) and 'I don't worry about something happening. The guides are here and they know what they're doing" (Rudy, 42, 10 years climbing at Seneca Rocks). Rescuing injured climbers is not a given responsibility of the guide services, but they willingly undertake rescues all the same, as they have the skills to do so and are frequently nearby due to the nature of their work:

It's [a responsibility] that we accept. By and large, regardless of what side of the street you're talking about, we are in fact the most qualified people to be doing it. So, if we're there, and it does not compromise a client's safety, we'll respond. Generally speaking what happens is if the guides are out climbing and somebody hits the ground anybody in town goes. And we are more athletically inclined, we know the crag better, so we can get there faster just because we're more physically fit. We know how to get there faster, so we do, and because we teach self-rescue we understand the rope systems that you need to employ to effect the rescue.

Very few individuals I interviewed were aware that the local volunteer fire department is trained in high-angle rescue and respond to accidents at Seneca Rocks. Of the few who were aware, none thought that the volunteer firefighters had the knowledge of the area, the fitness, nor the appropriate technical skills to rescue an injured climber quickly and safely - several individuals I interviewed discussed situations where the volunteer fire department either assessed the situation poorly, possibly leading to greater danger, or where the volunteer fire department rescue setup was so unwieldy that it would have added valuable time to an evacuation.

In spite of the shared sense that the guides had the best and most appropriate training to undertake rescues at Seneca Rocks, guides and experienced climbers who had participated in 
rescues said that helping injured climbers eventually took an emotional toll on them. One individual described the feeling as "PTSD." Individuals who had participated in rescues of seriously injured climbers discussed how seeing other climbers undertaking unsafe practices made them "upset," "angry," and "pissed off" because they were concerned that they would have to rescue those people later.

Guo, Chen, Lu, Tan, Lee, and Wang (2004) found that nonprofessional rescuers who participated in rescue and recovery after a 1999 earthquake in Taiwan were more likely to show signs of posttraumatic stress (PTSD) than professional rescuers; results from studies from around the world indicate that spontaneous and nonprofessional rescuers experience a higher rate of PTSD than professional rescuers and nonparticipants (e.g., Johnsen, Eid, Løstad, \& Michelsen, 2006; Mitchell, Griffin, Stewart, \& Loba, 2004). These studies, however, tend to focus on major natural or man-made disasters where nonprofessional rescuers were exposed to the aftermath of the event for comparatively long periods of time.

One study exists examining PTSD in mountain guides that contradicts the findings of these prior studies: Sommer, Ehlert, Paul, and Soraya (2004) found that Swiss mountain guides showed a low prevalence of PTSD relative to the frequency of their trauma exposure. It is difficult to extrapolate the results of the Swiss study to guiding at Seneca Rocks, however, considering the vast difference in numbers of available guides (1347 versus 10$)$, the comparative level of geographical dispersement in the area (the Swiss Alps versus Seneca Rocks), the differences in guides' responsibilities between Switzerland and the United States, and the fact 
that the Swiss study did not include the amount of time respondents had worked as guides as a variable.

\section{What practices exist in the social worlds of climbers at Seneca Rocks with regard to group sizes? What perceptions do climbers have of current SKSR group size regulations for both guided and unguided climbing?}

The unguided climbers I interviewed for this study generally climbed in pairs, with the occasional group of three on a route. With the exception of the two beginners I spoke to and with guides taking out clients who were beginning climbers, nobody admitted to toproping during an interview. There were many complaints about other people toproping, generally for one of three reasons:

1. Toproping on popular routes made access to those routes difficult.

2. Toproping crowded the bases of climbs.

3. Toproping was considered inappropriate for a traditional climbing area like Seneca Rocks.

This attitude toward toproping could be seen as a collision between the values of climbers who learned to climb outdoors and those who learned to climb indoors - except that half of the climbers I interviewed started climbing indoors. The Seneca Rocks guidebook discourages toproping and reminds climbers that leaders have priorities over climbers who are toproping a route. This means that if someone is climbing a route on toprope and another climber wishes to lead the route, the party on toprope must concede priority and let the lead climber climb ahead of the toproping party (Barnes, 2006). Toproping, therefore, is not taboo, but is considered to be of lower priority than lead climbing at Seneca Rocks. 
Among the climbers I interviewed there was a tendency, however, to place blame on poor toproping behavior on "gym climbers" and "beginners" not knowing any better:

"So people who have not been climbing for a long time don't understand. To them the person who comes up to them and says 'you need to pull your toprope; I want to lead this' - they feel like, we were here first, go find something else to do. The person who's been climbing for a long time, the ethos ... was ... in the lead climbing area you need to not be sucking up multipitch trad climbs by setting up topropes on the first pitch and blocking everybody out. So you get people who truly don't know any better and think that they're in the right to drop topropes" (Roy).

Interestingly, none of the climbers I interviewed mentioned toproping as a practice in which they participated at Seneca Rocks. From participant-observation, however, I found that when climbers were discussing climbing with each other they would talk about routes they had toproped at Seneca Rocks as well as good places to take beginners toproping. In these cases lead climbers were given priority if they intended to climb the route being toproped, in keeping with Barnes's (2006) recommendation. The practice of toproping in and of itself was not what it perceived as inappropriate; not yielding to lead climbers was what was considered poor practice.

At present the only group size regulation for unguided climbers at Seneca Rocks falls under the aegis of the USFS special use system, which requires a permit for groups of 75 or more people. There are only a few areas at Seneca that have enough space at the bases of climbs to support large groups and access to some of those sites requires strenuous hiking, which is a deterrent to the casual participant. Neither in my interviews nor during participant-observation sessions did I find any evidence that guided or unguided groups that large were congregating anywhere. Although some unguided climbers travel and camp in large groups they generally split up into pairs or threes to go climbing. 
Unguided climbers did not have complaints about the sizes of guided groups. Without fail the people I interviewed had positive things to say about the guides' professionalism, knowledge, and friendly demeanor both on and off the rock. There were no concerns expressed about the numbers of guided clients at Seneca Rocks. One guide suggested that splitting the guide-to-client ratio to allow for a larger number of clients on toprope might be worth considering. "I could literally take four people from the Head, on Luncheon Ledge, and manage them safely. But the rule says ... three. So we follow the rules and we do three." The manager of a college outdoor program, on the other hand, thought that the current regulations were appropriate: "When they changed the guide to client ratio this last time around? I thought that was a good decision" (Kelly, 37, six years climbing at Seneca Rocks).

At some climbing areas the guide-to-client ratio varies depending on whether they are offering toproping or lead or multipitch climbing; at others the guide-to-client ratio is static across types of guide services being offered. Table 3 provides examples of both types of guiding scenarios from traditional climbing areas in the United States. This list is by no means exhaustive - it is mean to illustrate differences in guide service policies. 
Table 3. Guide-to-client ratios in various climbing areas in the United States

\begin{tabular}{|c|c|c|c|}
\hline Guide service & Location & $\begin{array}{l}\text { Toprope maximum } \\
\text { guide-to-client ratio }\end{array}$ & $\begin{array}{l}\text { Lead/multipitch maximum } \\
\text { guide-to-client ratio }\end{array}$ \\
\hline $\begin{array}{l}\text { Uprising Adventure } \\
\text { Guides }{ }^{1}\end{array}$ & $\begin{array}{l}\text { Joshua Tree National } \\
\text { Park }\end{array}$ & $1: 6$ & $1: 4$ \\
\hline Mountain Madness $^{2}$ & $\begin{array}{l}\text { Red Rocks National } \\
\text { Monument }\end{array}$ & $1: 4$ & $1: 4$ \\
\hline $\begin{array}{l}\text { Northwest Mountain } \\
\text { School }^{3}\end{array}$ & $\begin{array}{l}\text { Wenatchee National } \\
\text { Forest (Leavenworth) }\end{array}$ & $1: 6$ & $1: 2$ \\
\hline $\begin{array}{l}\text { High Xposure } \\
\text { Adventures }\end{array}$ & $\begin{array}{l}\text { Shawangunks/Mohonk } \\
\text { Preserve }\end{array}$ & $1: 4$ & $1: 4$ \\
\hline $\begin{array}{l}\text { Atlantic Climbing } \\
\text { School }^{5}\end{array}$ & Acadia National Park & $1: 4$ & $1: 3$ \\
\hline $\begin{array}{l}\text { Adventure Schools } \\
\text { Rock Climbing }\end{array}$ & $\begin{array}{l}\text { C\&O Canal National } \\
\text { Historical Park } \\
\text { (Carderock) }\end{array}$ & $1: 5$ & $1: 4$ \\
\hline $\begin{array}{l}\text { High Plains Outdoor } \\
\text { Institute }^{7}\end{array}$ & $\begin{array}{l}\text { Medicine Bow-Routt } \\
\text { National Forests } \\
\text { (Vedauwoo) }\end{array}$ & $1: 3$ & $1: 3$ \\
\hline $\begin{array}{l}\text { Outdoor Wilderness } \\
\text { Leadership School }^{8}\end{array}$ & $\begin{array}{l}\text { Shenandoah National } \\
\text { Park, C\&O Canals } \\
\text { National Park, SKSR }\end{array}$ & $1: 6$ & $1: 2$ \\
\hline
\end{tabular}

\footnotetext{
${ }^{1}$ Uprising Adventure Guides, 2010

${ }^{2}$ Mountain Madness, 2010

${ }^{3}$ Northwest Mountain School, 2010

${ }^{4}$ High Xposure Adventures, 2010

${ }^{5}$ Atlantic Climbing School, 2010

${ }^{6}$ Adventure Schools Rock Climbing, 2010

${ }^{7}$ High Plains Outdoor Institute, 2010

${ }^{8}$ Outdoor Wilderness Leadership School, 2010
}

Not all outfitter-guides operate at the maximum permitted guide-to-client ratio, nor do all guide services in a particular location offer the same ratio. Without further research into the permitting process across agencies and locations it is not possible to determine overall trends; the above table is provided solely as an example of how guide-to-client ratios can vary. Additionally, because outfitter-guide permit guide-to-client ratios are determined on a site by site basis there is no consistency across climbing areas. 


\section{What practices exist in the social worlds of climbers at Seneca Rocks with regard to the use of climbing equipment, including but not limited to removable protection and bolting?}

\section{Removable protection}

Early on in this study I was under the impression that choices of gear reflected the social worlds that climbers occupied. Further analysis, however, indicated that the types of gear that people used tended to be reflective of where they climbed the most (different types of rock take different gear more easily due to their differing crack structures and relative friability) and how recently they purchased the gear in question. People who climbed at Seneca Rocks and the Shawangunks on a regular basis tended to recommend tricams, a piece of gear that can be used either actively or passively, for the crack systems there, but even tricams were a subject for debate between regular climbers at Seneca Rocks, as they can be difficult to place without practice. Beginners frequently borrowed a more experienced partner's gear or had a small rack because they were buying components piece by piece. Only one climber I interviewed preferred to use only passive gear (gear with no moving parts); the others used a mix of passive and active (gear with moving parts) protection. Data from participant-observation indicated that climbers used the gear they found practical and comfortable, although some of these decisions are informed by discourses about why other climbers find particular types of gear to be superior for particular situations.

Where the divide in views on removable protection is more apparent is between experienced and inexperienced climbers. Not all tourists are inexperienced climbers, but the inexperienced climbers are, generally speaking, tourists in Seneca Rocks' social worlds. Experienced climbers regularly referenced "bad anchors" and "bad gear placements" - that is, anchors and gear placements that would not hold a fall -- that they had seen inexperienced 
climbers make. The less experienced climbers were more likely to believe that camming devices (active protection) were foolproof. They found cams "faster to place" than passive protection and thought that "you can stick them anywhere." When there were experienced climbers in the social groups where inexperienced climbers made such claims they were quick to correct them, but inexperienced climbers who associated only with other inexperienced climbers (e.g., in university climbing clubs) had no immediate access to such a correction.

\section{Bolting}

One of the problems with defining traditional climbing is that there are a variety of differences in how climbers construct the term. The two constants are that (a) there is some sort of "ethic," or accepted series of practices involved, and (b) placing removable protection happens at some point in a while engaging in traditional climbing. Until Yosemite pioneers Yvon Chouinard, Tom Frost, and Royal Robbins began importing, developing, and advocating "clean" removable protection in the 1970 s pitons were used as protection on climbs. They were hammered into and out of cracks, leaving scars on the rock (Chouinard \& Frost 1972).

At that point in time, however, climbing using removable protection was not called “traditional climbing;" it was just called "climbing." As Jeff Achey (2005) observed in a Climbing magazine editorial: "This troublesome term ["traditional climbing"] was introduced into the climbing lexicon in 1984 at the height of the "Bolt Wars" by the master California climber Tom Higgins. ... Higgins penned a Mountain $\left[\right.$ sic ${ }^{3}$ magazine article titled "Tricksters and Traditionalists," which slapped the wrists of hangdoggers and rap-bolters, calling them cheaters - tricksters - and invented the contrasting term traditionalists for those who played by

\footnotetext{
${ }^{3}$ This piece originally appeared in the Sierra Club's Alpine magazine.
} 
the traditional rules. From the get-go, however, there was something wrong with the "traditional" in traditional climbing. First, the trick/trad border was disputed - mother's little helpers like pins [pitons] and bolts were traditional in some parts of the country in 1984, but 'tricks' in others. ... Yet despite its flawed nature, the term stuck, quickly morphing into 'trad' and eventually becoming a concept that you could dispute around a campfire" (p. 12). In this sense "traditional," or "trad" climbing became an early political statement in opposition to the new wave of sport climbing, in which climbs were developed after preinspection of the route and removal of lichen and loose rock on rappel, as well as bolts being placed on rappel rather than on lead. Fuller (2003) argued that the traditionalists lost the "bolt wars" that erupted from this debate due to their desire to enforce rules on other climbers, an act not possible in an individualistic and sometimes anarchic activity:

The orthodox [in Fuller's study traditional climbers, like the climbers who use Seneca Rocks] were also hampered by aspects of climbing culture itself. Not only did they lack authority structures capable of banishing heresy [in this case sport climbing], they were unable to create such structures because of aspects of the symbolic system they were seeking to defend. ... A related problem dogged climbing traditionalists. Their references to the sacred character of climbing ethics were ultimately undermined not only by the historical plasticity of these ethics, but also by the symbolic association of climbing with individualism and freedom. Indeed, in many ways deviance and heresy had a positive resonance in the context of climbing culture. Attempts to enforce a rigid boundary excluding the new practices incited a backlash that sport climbers were able to exploit with appeals to freedom and by casting themselves as iconoclasts. (p. 25-6).

In the sense that sport routes became acceptable at some climbing areas, and indeed some climbing areas' entire existences are predicated on the existence of sport routes, Fuller's argument holds for American climbing in general. At climbing areas like Seneca Rocks, however, the debate is still active among small groups of climbers. Ultimately this debate is about how to define traditional climbing, and in some cases how to enforce a personal 
conception of what traditional climbing is or should be. Roy, an insider whose discussions of bolting and its history at Seneca follows, brought up the issue of bolting without my prompting and had the most to say about it; the other climbers who are quoted here talked about bolting after I asked about their perceptions of it in follow-up interviews.

Long and Luebben (1997) avoided the term "traditional climbing" entirely in Advanced Rock Climbing, a popular instruction book, opting to use "sport climbing" and "adventure climbing" instead throughout the book to delineate the two most common types of climbs. Eric Horst (2001) described the prevailing ethic at Seneca: “As a bastion of ground-up ethics and natural protection, Seneca requires competent gear-placing and routefinding skills. Few climbs at Seneca are defined by a line of bolts - instead crack and corner systems, and long, wandering face climbs are the norm. And despite the 1990s upgrading of many popular lines, younger climbers may still find that many routes feel undergraded" (p. 219). Barnes (2006) noted that climbing style and ethics at Seneca have changed over time, although bolts have been placed on aid or from stances since at least the 1980s - and that from the 1990s on bolting on rappel has occurred only on lines where it would not be possible to do so otherwise. Further, Barnes speculated that Bring on the Nubiles "may be the last significant Seneca route to go all clean no bolts or pins" (p. 89), meaning that every route developed since the mid-1980s has included at least one bolt or piton and that he foresaw no major routes being developed in the future without including some sort of fixed protection at some point on the route. Currently at Seneca Rocks there are over 450 routes. According to the most recent guidebook (Barnes, 2006) 82 routes have at least one bolt or a combination of bolts and pitons. 17 are listed as having fixed pitons and no 
bolts (although there are more routes with fixed pitons than this - fixed pitons are generally listed as a routefinding tool or a description of poor protection).

More recently the idea of headpointing (rehearsing a difficult route on toprope until a climber can do all of the moves on a route in sequence, then climbing it free), a style imported from Britain, has become popular in some climbing areas, including the New River Gorge, another climbing area in West Virginia. In the 1990s there were questions about the validity of redpoint ascents (sending a route after more than one try, usually by rehearsing the moves on lead) and pinkpoint ascents (doing the same but with preplaced gear), although that debate has waned in recent years - difficulty has replaced style, particularly in commercial climbing publications like Climbing and Rock and Ice. In short, how traditional climbing is defined is contested among climbers in general as well as at Seneca Rocks.

For some climbers traditional climbing means a route was developed by way of a groundup first ascent with no falls, no hangs, and no fixed protection. A first ascent at Seneca rocks is not "official" unless the climb was done from the ground up, without preinspection on rappel, and with no hangs or falls on the ascent (Barnes, 2006). While this is noted in the guidebook for the area, first ascent practices at Seneca Rocks have been established based on the practices of early climbers in the area. Even so, these rules have been negotiated over time, especially when to place bolts. A 1970 s route containing a single bolt, Sunshine, had that bolt removed and replaced several times before a consensus was reached that the first ascentionist should have final say over whether a climb needed bolts for protection. In the early 2000s, there was a similar debate over whether there should be anchors placed at the top of The Burn, next to Sunshine, 
which made it easier for climbers to toprope the route. In both cases the bolts were eventually left in place.

Most climbers I interviewed were not interested in discussing bolting, although one climber on a new route that mixed removable protection and bolts informed me that "The bolts are where you need 'em," and another said, "I don't want to see sport routes here, but sometimes you've got to have a bolt for safety. I just don't want to see them sprouting up all over the place" (Peter). When and where bolts should be installed is currently more of an issue among the insiders who consider themselves locals: they are small in number but strong in influence regarding bolting. Some of them are also the people who place bolts, either by someone else's request or when they are developing a new route.

At Seneca Rocks fixed protection has historically been placed on lead, in keeping with socalled "traditional" ethics - as opposed to bolts placed on rappel, a trend started in France and Oregon in the early 1980s (Ament, 2002; Samet, 2004). Barnes (2006), however, indicated that bolts have indeed been placed on rappel at Seneca Rocks when it was not possible to place bolts on lead. It is unclear how many bolts have been placed on rappel or where those bolts were placed. Regardless, retrobolting (the act of adding bolts to a previously climbed route) is not permissible at Seneca without the approval of the first ascentionist. Sometimes the first ascentionist places the bolts; sometimes someone else does after gaining permission, for example, "I talked with [guide] and we decided to add another bolt on [route] so more people will climb it" (First ascentionist). 
By the same logic, if a climber puts up a new route that climber has the personal discretion to do so with the understanding that this is a traditional climbing area and bolts are to be few and far between and generally placed where removable protection would not otherwise be available. Since the mid 1980s, however, every new route developed has included at least one bolt or piton (Barnes, 2006). There are a several reasons for this change: one, Seneca Rocks is no longer "home" to people like Cal Swoager, a prolific route developer in the 1970s and 1980s who climbers from that era described as tripping on acid and talking to a hand puppet while climbing new routes that were both incredibly difficult and incredibly dangerous, nor do there appear to be people who are interested in being a Cal Swoager. Two, most of the continuous crack systems have already been "climbed out" at Seneca Rocks - there are no more traditional routes that can go up with out a couple of bolts to protect in "blank" spaces unless the first ascentionist is willing to commit to enormous distances between gear placements or the possibility of gear pulling out during a fall, potentially leading to groundfall. A third is that contemporary climbers, especially people who have started trad climbing recently, are simultaneously risk-averse and putting themselves into dangerous positions due to lack of knowledge. They rely on the gear to take care of them but do not necessarily understand how to place it correctly, as discussed in the prior section on safety practices.

Bolts placed for protection on or after first ascents are not the only bolts placed at Seneca Rocks. They may also be placed as fixed anchors at the top of a pitch or on a rappel route. The only route where there appears to have been disagreement was at the lip of the first pitch of The Burn, which is a route with a short approach that is popular for toproping. Prior to these anchors being installed climbers used a tree on the ledge at the top of the first pitch to anchor, 
leading to damage to that tree. In 2004 the bolts at the lip of first pitch The Burn were chopped and chained to a tree at the base of the route. I lived in Oregon at the time of this incident but received an angry phone call from a friend of mine who threatened to round up a posse to find out and beat up the chopper. The posse never materialized, but the controversy was great enough that it made its way through the Seneca Rocks gossip channels all the way to the west coast. They also generated an angry letter to Alpinist magazine claiming that such bolts were not placed for preservation but were "lip service designed to placate our conscience in the face of everincreasing exploitation" (Heinbach, 2004, para 1).

Some of the objection to the bolts at the top of The Burn was related to the frequency with which it is toproped instead of lead climbed. Opposition to toproping, however, also led to opposition to that particular set of anchor bolts. Although opposition has been expressed, the replacement bolts have stayed in place for the past six years, and there have been no further efforts to remove them. Such an exchange through actions, though, reflects the contested nature of placing bolts on routes at Seneca Rocks among the small number of climbers concerned about the issue, as well as how such exchanges may be resolved.

\section{Bolt chopping}

The action of placing bolts is one side of the debate over bolting's place in traditional climbing. The other is the removal of bolts without permission, called "bolt chopping" among climbers. Chopping embodied the apex of the bolt wars, and still occasionally takes place at crags around the country (Achey, 2005; Ament, 2002; Fuller, 2003). Sometimes bolt chopping is an ethical statement ("we don't bolt here"), sometimes a territorial statement ("you are not a local"); sometimes a critique of a first ascentionist's climbing style on the ascent ('I don't like 
the way you bolted that route") and sometimes a personal statement ("I don't think bolts should be placed on climbing routes"; see, e.g., Ament, 2002). In the previous section I described the controversy over the bolt placed on Sunshine, one of the earliest bolts placed on lead at Seneca Rocks, as well the controversy over the anchors at the lip of the first pitch of The Burn. The bolt on Sunshine was chopped several times, replaced several times, and finally left in a consensus decision that if the first ascentionist had drilled the bolt on lead and had the nerve to climb the route in the first place, the first ascentionist should have the right to decide whether the route should include a bolt. Rather than being the end of the discussion about bolting at Seneca Rocks, however, Sunshine was the beginning.

The anti-bolting contingent at Seneca Rocks believes that there is an imbalance of power with respect to how bolting decisions are made there. "You know, I could go up there and spend a lot of time taking bolts out. That makes some people extremely angry. ... it's a rather interesting imbalance in that they feel like they have the god-given right to put a bolt in, but I don't have the god-given right to go take it out. It's a rather interesting imbalance there. Like, okay, what makes you so special that you can drill a hole, that I can't go undrill a hole?” (Roy) The group that places bolts appears to abide by the accepted practices set forth in the guidebook (Barnes, 2006). The debate about bolting, however confined to a small group of actors, is between preservationist attitudes and the strategic use of bolts.

Bolting at Seneca Rocks is a complex issue among a small number of people, as there are only a small number of people at Seneca Rocks willing and able to place, replace, and remove bolts. On one side of the debate are a small number of insiders who would like Seneca Rocks to 
remain the Seneca Rocks of thirty years ago, with bold and risky first ascents and no fixed anchors (other than for rappels) at the tops of climbs. On the other are insiders - also a small number, but a somewhat larger group of people -- who want to place bolts strategically on new routes to reduce groundfall and ledge potential, increasing what they perceive as both the safety and the climbability of the routes; to place anchor bolts where doing so reduces pressure on trees and soils; and to retrobolt routes if requested to do so by first ascentionists. All of these bolting behaviors are based on the evolution of practices in the area over time. For regulars and tourists bolting does not seem to be an issue one way or the other as long as bolting is not excessive and is done in keeping with practices of the last 25 years or so; for the most part positions on bolting among these climbers, when articulated, are not part of a coherent overall position on bolting (Figure 5). If there is a well-placed bolt on a route where gear could not otherwise be placed and it keeps them from getting hurt, there is no issue involved. If there is not a bolt on a route that takes removable protection and the potential is there for getting hurt, they stay off the route. In this context adding bolts sometimes increases traffic on particular routes, reduces pressure on popular routes, and improves the overall climbing experience for unaffiliated climbers, but has a negative impact on the experiences of climbers who believe that once ascended, routes should be maintained in their original condition in perpetuity. 
Figure 5. Positional map: Bolting at Seneca Rocks

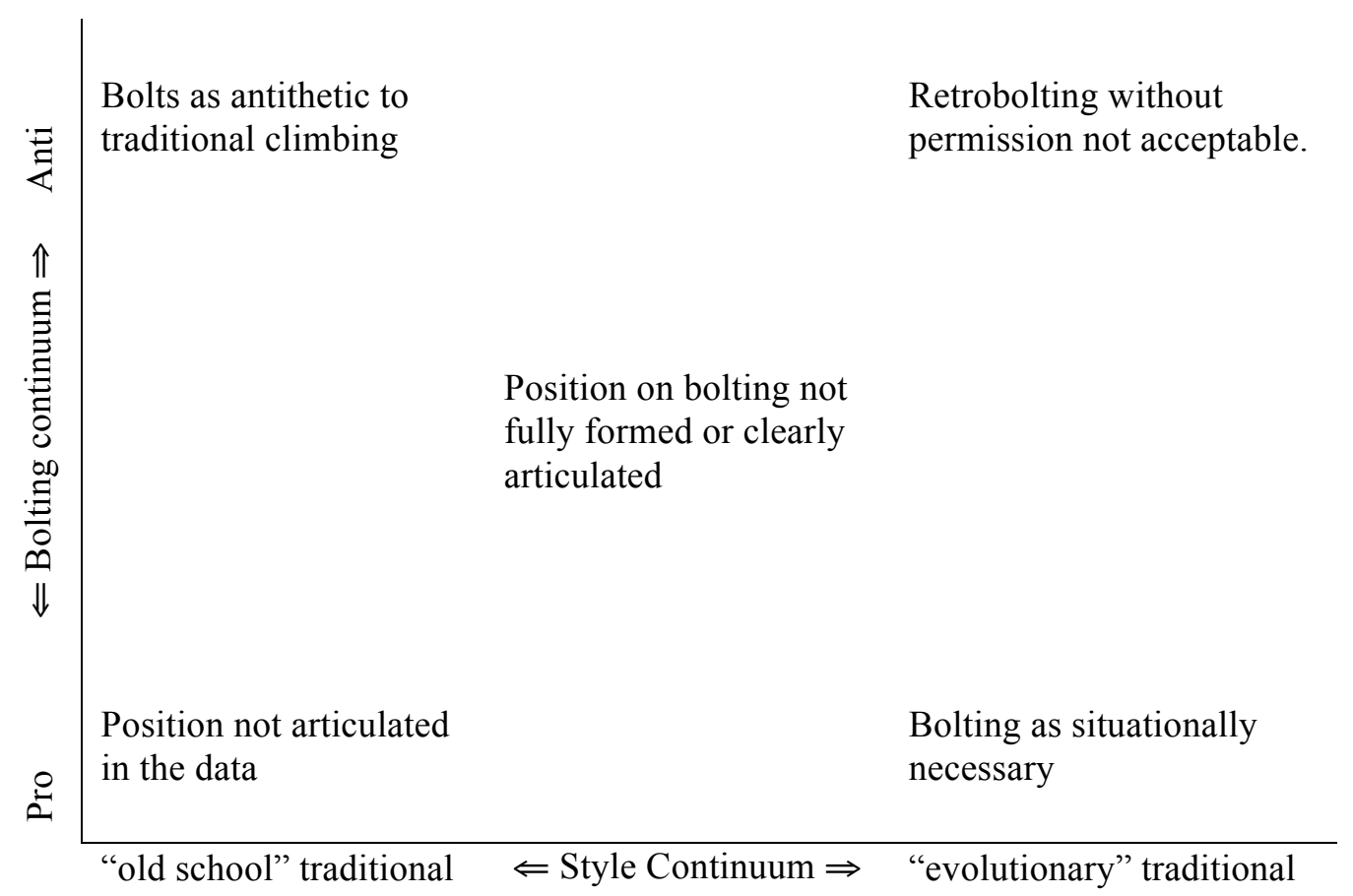

The greater issue with bolting at Seneca Rocks is how it may be portrayed to the USFS. The pro-strategic-bolting insiders are affiliated with Group A, the insider group that is skeptical of the USFS. The anti-bolting-on-principle insiders are affiliated with the Group B, the insider group that partners with the USFS. If the anti-bolting-on-principle insiders are the ones with the strongest USFS relationship, the portrayal of bolting at Seneca Rocks reflects their personal perceptions of bolting and where bolting fits in a contested definition of traditional climbing. The USFS does not, however, have the opportunity to hear other positions on bolting as a part of traditional climbing: to place bolting in the negotiated context of the multiple meanings of traditional climbing or the historically developed practices of traditional climbing at Seneca Rocks. All of the parties involved want Seneca Rocks to stay a traditional climbing area. While 
they all want the same thing that thing has meanings that are subtly - and some times not so subtly -- different.

\section{How are acceptable practices communicated and enforced?}

Acceptable practices in climbing at Seneca Rocks are largely communicated through narrative discourses. In the case of bolting storytelling is used to establish an individual's position on the practice as well as their "rightness" in their arguments. Such narratives are also used, however, to express approval or disapproval of safety practices in general, and are frequently employed during post-climbing socializing to disseminate information. "When you're in those areas I think that, you know, those conversations do come up. Something does happen, you know, where somebody hasn't been as safe or somebody sees something unsafe it's a sure bet that it's going to get brought up on the porch, people are going to talk about it, it's going to be encouraged. You know? I mean, and it's not so much gossip, you know it sounds like gossip in a lot of ways, but, you know, it's - you know, people want this resource to be what it is. And they want it to stay what it is. And so therefore they're gonna talk about those things. And they're going to encourage other climbers to do so" (Peter).

If an accident occurs, climbers analyze what errors were made to try to avoid those mistakes themselves. In more recent years these discussions take place not only in the social areas around a crag like Seneca Rocks but in the wider arena of the internet. The most recent fatality at Seneca generated a four-page discussion thread on rockclimbing.com involving 75 posts and 19,894 views. ${ }^{4}$ This incident involved a brand-new, narrow-diameter climbing rope being cut on a sharp edge, so there was considerable discussion of the relative safety of climbing

\footnotetext{
${ }^{4}$ http://www.rockclimbing.com/cgi-

bin/forum/gforum.cgi?post $=2171991 ; \mathrm{sb}=$ post_latest_reply;so=ASC;forum_view=forum_view_collapsed;
} 
on "fat-" versus "skinny-" diameter ropes, with no consensus ultimately reached. The fatality prior to that generated a two-page thread containing 40 posts and receiving 13,232 unique views. ${ }^{5}$ Based on a combination of eyewitness reports and feedback from sources the posters considered reliable, participants concluded the accident was a combination of insufficient gear placement and gear failure during a fall. After a discussion of the events that led to the accident participants advised each other to place protection frequently when climbing something they considered to be difficult.

Because fatalities are relatively rare occurrences at Seneca Rocks, however, most social narratives that communicate and enforce safety practices involved people discussing how they personally could have done something better (e.g., placing protection on a particular part of a route, catching a leader fall), practices they witnessed that they thought were inappropriate or unsafe (e.g., throwing litter on the ground, having a conversation with someone else while belaying a leader, leaving dogs unsupervised at the bases of multipitch climbs), or things that went wrong during their own climbing that day. Most of the latter stories are told with a large dollop of humor, but are followed either by the storyteller explaining what he or she should have done or a discussion of how to avoid similar incidents in the future. In some cases the stories involved objective hazards like pigeons and snakes startling climbers; in others they involved human error that could have led or did lead to injury. Advice given during my observations ranged from choosing a different time of day to climb a route that resulted in dehydration and sunburn to suggesting techniques that speeded up anchor-building when climbers were trying to retreat from a climb more quickly.

\footnotetext{
${ }^{5}$ http://www.rockclimbing.com/cgi-

bin/forum/gforum.cgi?post=1989666;sb=post_latest_reply;so=ASC;forum_view=forum_view_collapsed;
} 
Stories that were told in a self-deprecating manner were met with appreciation, particularly if the moral involved the self and how the storyteller could have done better that day. Stories that deprecated someone else were accepted if climbers were discussing behavior that fell outside of accepted conventions and practices (e.g., not burying human waste, putting an inexperienced climber in a dangerous situation), and friendly critiques were accepted, particularly if they were presented humorously. Narratives that involved a more experienced climber putting down their less experienced partner in public, however, were not accepted and led to the other climbers involved in the storytelling session placing direct blame on the more experienced climber for not taking responsibility for their partner. In other cases making mistakes was not criticized unless there was no learning from it or the action could have led to a serious injury or fatality.

Direct interventions at the crag are treated with the same situational ethics as social storytelling. Actions that could lead to serious injury or death merit an intervention at the crag, whereas mistakes that are not perceived to have the potential for serious harm do not warrant intervention. "It's a thin red line. Because you want people to go out and - it's adventurous, like, expedition out there. I'm sure when we all started climbing up in here we had our days where like stuff might come at us, we're climbing up there, or like something goes wrong and we survived a day and we learned from it, and that's really what's gonna learn a lot more than somebody stepping out of the bushes and being, like, hey, that's not how you do this. Or you need to put this here, put that there" (Matthew, 22, three years climbing at Seneca). In Lyng's (1990) paradigm, such attitudes fall under the aegis of edgework, or voluntary risktaking in order to experience "self-determination and self-actualization" (p. 878). To intervene, therefore, in a 
nonfatal climbing error was to interfere with this process. Similar attitudes have been found in studies of BASE jumpers (Allman, Mittelstaedt, Martin, \& Goldberg, 2009), adventure racers (Schneider, Butryn, Furst, \& Massucci, 2007), and skydivers (Laurendeau, 2006).

Climbers I interviewed advised that intervention depended on the situation, that whether to say something was a judgment call, and that the ultimate outcome depended on whether the climber in question was willing to learn. "It depends on what the situation is. Uh, offer friendly advice and if they want to go kill theirself let 'em. I mean, it's a free world. You know, some of 'em listen great, some of 'em really wanna learn. ... As [John] Bachar used to say, 'the dumb ones die"" (William).

Inexperienced climbers I interviewed relied on their more experienced partners to tell them if they were doing something that was dangerous. In some cases their reliance on their partners led them to shut out potentially valuable advice from other climbers: "I know [partner] knows what he's doing. Some guy I've never met? I'm not going to trust them” (Mitchell). In these cases the overall inexperience of the climber led them to rely on a single authority due to their own inability to assess the accuracy of the advice being given them by outsiders. In one interview I conducted with a beginning climber their lack of knowledge led them to two erroneous conclusions about unsafe climbing behavior: (1) that practicing placing gear on toprope was not "real" trad climbing, when in fact guides and experienced climbers suggested “mock leading" as a way to hone one's skills as a beginner; and (2) that Spectra webbing was safe to rappel on even after being exposed to sun and weather, and that it was unnecessary to check its condition before using it. 
Sean: Double check, make sure that you got your head straight, and take care of yourself. Generally if webbing's white you probably shouldn't be using it, because it's really faded. Unless it's Spectra.

Q: Even then I don't want to be on Spectra that's been out in the elements for a while, either, because it deteriorates.

Sean: But it starts white.

Q: Yeah, but it deteriorates with UV radiation. Trust but verify.

The former idea is a reflection of inexperience but not likely to lead to an accident; the latter is the only case during my interviews when I intervened to clarify a misunderstanding - because my informant's retaining that misunderstanding could lead to serious injury or death.

Another way that experienced climbers communicated acceptable practices was to try to set a good example through their own behavior. Several guides stated that they were more likely to wear a helmet and to place gear more frequently when they were climbing recreationally at Seneca Rocks than they would at other climbing areas, in order to set an example of the behavior they preferred to see among unguided climbers. Likewise, climbers who climb regularly at Seneca try to model the behaviors they would like to see in others. "When you're out at the crag. Encourage. Double-check" (James). 


\section{How do climbers at Seneca Rocks integrate SKSR management into their social worlds?}

How a climber integrates SKSR management into their social worlds depends on their membership in the social worlds of Seneca Rocks. As might be expected, tourists had less overall awareness of who managed Seneca Rocks and about the existence of a climbing management plan. Only two of them reported direct encounters with USFS personnel, and both of them had had these encounters in the Seneca Rocks Discovery Center. Three of the tourists I interviewed knew that the USFS was the managing agency; two had no idea who managed Seneca Rocks, and two referred to multiple agencies in their interviews. The latter individuals referred to West Virginia State Parks, the National Park Service, and the USFS as agencies who managed Seneca Rocks, sometimes using them interchangeably over the course of a single thought: "It can't be the Forest Service. If it was the Forest Service you'd have to pay. You can climb here free because it's a state park. That's one of the things I like about the Park Service running Seneca" (Marty). The individuals who climbed infrequently at Seneca Rocks and who were aware that the USFS was the managing agency thought that having a climbing ranger someone familiar with climbing who could put a "face" on the USFS - would "make there be more of a relationship" between the climbing community and the USFS.

Q: How much interaction have you had with the Forest Service when you climb here?

William: Almost none. Other than the visitors' center, you - you know, they don't have rangers that, you know, go up around the rocks or at least I haven't seen any. The ones that I've talked to have all been really nice, but they don't seem to ... well, they don't seem to interact that much with the climbers. I mean, you don't see one when you come down on, you don't see anybody hanging out on the road just to talk or ask any questions or do anything. 
Q: If you could have the Forest Service change anything about Seneca, what would you have them change?

William: There's not a whole lot that I see that - unless they plan to become climbing rangers, which I don't think they do, I don't see where there's a real need to do anything that isn't being done already.

Regulars, the unguided climbers who climbed frequently at Seneca Rocks, were aware that the USFS managed the area. All but one of the six regulars I interviewed were unaware of the existence of a climbing management plan, and the one who was aware of its existence knew nothing about its content. Like the tourists, regulars reported no encounters with USFS personnel in the climbing areas at Seneca Rocks; unlike the tourists, regulars had little interest in USFS involvement with climbers in the actual climbing area. "They don't come up there. And that's okay, because they don't know anything about climbing anyway" (Nicholas). Although regulars felt that the USFS lacked knowledge about climbing, they still desired more USFS interaction with the climbing community: "Just [to] have a presence -- more of a presence, more of an involvement, you know, make themselves known a little bit better, be upfront at the - when they do have the chili cookoff and when they have the Cinco de Mayo and - or if there's trail building efforts. Because they always tend to be in the background. I mean, they're there, you know they're there, but you don't really have any upfront contact with them, you know?” (Peter).

Like regulars, insiders were aware that the USFS managed Seneca Rocks, although their views of the USFS were more complex. (During one observation session an insider claimed that the USFS should not manage recreation at all - nor should they manage forests, because the government took the revenues from timbering and used it to support "the military-industrial complex.") Insiders had had both social and business interactions with USFS personnel off the rock, although they also had not had interaction in the climbing areas. They described this 
situation as "fine," "okay," and "I don't think it's a problem." Several insiders thought that the USFS should provide access to Champe Rocks, on USFS property north of Seneca Rocks. These insiders understood that there were fiscal constraints to USFS action: "Yeah, I mean, I think Steve [Kickert]'s doing a great job and I don't know how much more - I mean, I don't know what more they could do that would be cost-effective" (James).

The insiders I interviewed held a few strong opinions on the USFS but mostly expressed a general desire for minimal regulation of climbing. There was no interest expressed in having the USFS regulate climbing further that it was currently regulated because it was "kind of a pain" and would take away from the individual freedom of climbing: "What draws me to rock climbing in general is the wildness of it. That it's like, you go up there and you can basically go do whatever you want and just get to climb in this big thing and it makes kind of no sense in the evolution in the world because it's not really doing anything to contribute other than to make us happy. So by putting in like rules and regulations it kind of just, it takes all the fun out of it" (Matthew). The perceived leaders of the two insider groups, however, had divergent views of the USFS and its role in the climbing community.

As discussed above, one group of insiders at Seneca Rocks held a distrustful view of the USFS. Some of this mistrust was based on national level policy decisions, such as the banning of fixed anchors in Wilderness areas in the late 1990s, a policy developed from the erroneous assumption that bolts had to be placed with power drills. Local USFS interactions, however, have also played a part in this distrust. Some of this reaction involved an earlier SKSR practice of having a USFS employee checking outfitter-guide permits at trailheads, which led to one 
individual making threats to discontinue assisting in rescues and throwing a rescue cache on a USFS office lawn (this policy has since been discontinued and the rescue cache was returned to its original location). Another cause for this distrust of the USFS was perceptions of the handling of requests to open Champe Rocks and other "satellite" crags to climbing, something the USFS is not interested in doing (J. Fosbender, personal conversation, July 24, 2009). There is a sense among this group of resistance to the requests of user groups, of bureaucratic gatekeeping on access-related issues, and of a general mistrust of federal employees.

The perceived leader of Group B, the group that partnered with the USFS on climbingrelated issues, has a different view of the USFS and its role in climbing at Seneca Rocks. This individual has taken a proactive stance toward the USFS and credits that with Group B's positive relationship with SKSR management and the results of interacting with the intention of forming a partnership: "I think a lot of times people in house are so used to having the animosity relationship they've probably found somebody who's pleasant and cooperative, it's a little bit easier for them to be pleasant and cooperative. And when they really know that we want to be a good - we want to partner. We want to be a positive partnership, versus, you know, some kind of rivalry, and a push me pull you, um, you know. It's a little bit easier to get things done. Well, it might not be easier to get things done but ultimately it's better." This individual did not mention a desire for access to satellite crags or any long-term issues with the USFS, except to mention the "love-hate relationship" between the USFS and the original owner of The Gendarme. 


\section{Summary}

Although the social construction of traditional climbing is contested among climbers at Seneca Rocks, there are more similarities than differences. Where climbers choose to camp is related to personal preference rather than social world affiliation. Tourists tend to associate within the group with which they came to Seneca; regulars tend to socialize at The Gendarme and Ground Up; and insiders socialize at The Gendarme, Ground Up, and Seneca Rocks Mountain Guides. The Seneca Rocks Discovery Center is not a focus of climber interaction.

Climbers at Seneca Rocks are concerned about each other's safety but only intervene directly when there is the possibility of serious injury or death. Learning from one's mistakes is considered part of the learning experience. Climbers are willing to help an injured climber but would like to see greater self-reliance among beginning trad climbers. Unguided climbers rely on the guide services to effect rescues, a role the guide services are willing to accept. Long-term participation in climber rescues, however, takes an emotional toll on the rescuers and makes them even more risk-averse with regard to other climbers' actions.

The type of gear climbers use is not as relevant to social world membership as their abilities to use it properly. There is some concern about gatekeeping among tourists, who are either not interested in socializing outside their own social groups or who do not feel welcome among the regulars and insiders. Regulars and insiders, on the other hand, tend to attribute lack of skill among less experienced climbers to lack of training and to learning to climb in the gym, even though many of the regulars and insiders I interviewed also learned to climb in the gym. 
The guide services are making an effort to ease the gym-to-crag transition with customized course offerings; there is concern that gym climbing is leading to poor decision-making on the part of climbers making the transition from the built to the natural environment.

There is greater disparity of opinion among insiders than among other groups; the main point of contention appears to be over bolting. Unguided climbers tend to hold views closer to insider Group A, the group that believes in bolting strategically (for environmental and safety purposes) than insider Group B, the group that does not believe in any bolting at all - if they hold a strongly developed position about bolting at all. In 2004 a minor "bolt war" sprung up over when to place and remove bolts, but it was resolved quickly through a combination of action and inaction; that issue appears to be at an impasse at the moment.

Tourists at Seneca Rocks are less likely to be aware of what land management agency is responsible for Seneca Rocks; regulars and insiders are aware that the USFS is the managing agency. Although one tourist would like to see a climbing ranger at Seneca Rocks -- along the lines of Rocky Mountain and Yosemite National Parks - the majority of climbers in any social world were happy with management conditions and interactions as they were at the time this study was conducted. Insiders tended to have the greatest direct exposure to the USFS and formed their views of the agency based on past interactions as well as national level climbing management policies. Insider Group A, whose social views are in greater alignment with the majority of climbers I interviewed, distrusted the USFS as a whole whereas insider Group B, whose views differ about appropriate route development and alteration, is partnering with the USFS. 
In the following chapter I discuss the relationship of these findings to the literature and discuss the implications of those findings. I also offer recommendations to the USFS about climbing management at SKSR and the USFS in general. Finally, I address future research needs related to the social worlds literature and to rock climbing in general. 


\section{CHAPTER 5: DISCUSSION, CONCLUSIONS, AND RECOMMENDATIONS}

The purpose of this study was to provide SKSR management with an understanding of the social worlds of rock climbers at Seneca Rocks, to ascertain any management interventions that can improve access to climbing areas at Seneca Rocks, and to determine how permitted group sizes among guided and/or unguided climbers would affect the social worlds of climbers at Seneca Rocks. In this section I address the structure of the social worlds at Seneca Rocks in relationship to extant social worlds literature, including conventions and practices related to safety and self-policing, climbing etiquette, group sizes, and climbing protection. Also discussed are the implications of the study and recommendations for potential management interventions related to access and permitted group sizes. Finally, I address future research needs related to both social worlds literature in recreation and rock climbing in general.

\section{The social worlds of rock climbers at Seneca Rocks}

Social worlds are informal social organizational structures that individuals can enter and leave freely (Ditton, Loomis, \& Choi, 1992; Fuller, 2003; Gahwiler \& Havitz, 1998; Manzenrieter, 2007; Unruh, 1980). The interaction of people, places, actions, organizations, and practices "can coalesce into a meaningful and interactionally important unit of social organization for participants" (Unruh, 1980, p. 272). These social worlds may fragment into subworlds based on choices individuals make to participate in a particular subworld; each subworld represents personal perspective and recreation choice rather than a continuum of 
specialization behaviors or a level of commitment (Bryan, 1979; Buchanan, 1985; Green \& Chalip, 1998; Kyle \& Chick, 2004; Scott \& Godbey, 1994).

At Seneca Rocks social worlds are indeed fragmented into subworlds, the most fragmented of which exist at the level of casual participants, or tourists; and among members with the greatest personal investment in the social world, or insiders (Gahwiler \& Havitz, 1998; Goffman, 1959; Unruh, 1980). Climbing tourists at Seneca Rocks enjoyed climbing at Seneca Rocks but considered it to be a destination on a group outing, a once-in-a-while opportunity to climb with friends, or one climbing destination among a series of options to visit on occasion. This group was made up of beginning climbers and experienced climbers who made occasional trips to Seneca Rocks. These tourists were affiliated with large, organized groups either from climbing clubs or from groups of people who planned occasional trips to Seneca Rocks as a selfcontained social unit. Tourists to the Seneca Rocks climbing social world tended to socialize only within their own group, accept only the conventions and practices they learned from respected members of that group, and to hold little interest in other climbers around them. Some beginners, however, asserted that gatekeeping among regulars prevented them from gaining a foothold in that group (Goffman, 1959). As the literature suggested, these climbers do not hold a long-term commitment to Seneca Rocks (Unruh, 1980); rather, they climb there as an expression of social solidarity with an established group with no strong ties to a participation in a specific style of climbing or in a particular place.

The other group whose membership was fragmented into subworlds was that of the insiders. Climbing insiders at Seneca Rocks tended to live and work nearby. They had the greatest historical knowledge of contested and accepted conventions and practices in the area and 
made an effort to reconstruct them to their benefit (Unruh, 1980). Some acted as representatives of the climbing community to the USFS; Goffman (1959) suggested that such action reflected how insiders could act to protect their status as such, as they had the most to gain or lose in a face-saving situation.

There were two insider subworlds at Seneca Rocks, divided along the lines of their views of the USFS and their views of what they believe Seneca Rocks should be. One group was skeptical of USFS management and believed that new route development and bolting for environmental and safety purposes was appropriate. The second made an effort to partner with the USFS and wished to preserve Seneca Rocks' conventions on bolting as they were in the 1970s. Members of each of these subworlds negotiated their positions through the individuals with whom they chose to assert their positions (Blumer, 1969; Clarke, 2005; Hall, 1987). The first subworld negotiated presumed boundaries through direct action (i.e., bolting and making first ascents) and communication of their positions with climbers in other subworlds, generally the regulars. Over time this led to a reconstruction of practices that were rarely contested by regulars and sometimes met with no reaction at all, much as Fuller (2003) described in her analysis of the "bolt wars" among climbers in the 1980s. At Seneca Rocks this reconstruction took place through gradually challenging the boundaries of what an "acceptable" first ascent was over time - from an ascent using all removable protection to one where placing bolts became an accepted practice. The second insider subworld contested the existing conventions and practices - largely reconstructed by the first group - by communicating their positions to outsiders (in this case the USFS) as well as to regulars who associated with them, and by taking direct action 
against practices they did not accept. They also negotiated presumed boundaries through direct action (i.e., working with the USFS to make improvements at Seneca Rocks).

Animosity arose between those two groups when conflicting constructions of "best practice" came into play but eventually reached an impasse. By their inaction the anti-bolting group tacitly conceded their strongly held position, leaving the pro-bolting group's reconstruction of practices over time in place. These practices are unique to Seneca Rocks, as climbers in different climbing areas tend to negotiate locational style and ethics over time through a series of unwritten rules and sometimes written guidelines (Barnes, 2006; Fuller, 2003; Schuster, Thompson, \& Hammitt, 2001). The former group's reconstruction is in keeping with the written guidelines based on unwritten rules negotiated over time and set forth in the most recent Seneca Rocks guidebook (Barnes, 2006). The latter group's corresponds with a personal desire to preserve opportunities for climbing experiences, perceived as slipping away, as the activity of climbing as a whole fragments into subactivities and changes over time (Fuller, 2003; Scott \& Godbey, 1994).

Unlike tourists and insiders, the regulars at Seneca Rocks were a relatively cohesive group. Their positions on conventions and practices reflected the areas of consensus among insiders: the desire for participants to climb safely, the need for practice and instruction to gain skills, and the importance of freedom to make personal choices while participating in climbing. They associated with both insider factions to varying degrees. Unlike the tourist-climbers at Seneca Rocks, regulars chose to interact with individuals outside of the group with which they traveled. 


\section{Conventions and practices}

\section{Safety and etiquette}

Regardless of what social world they belonged to there, climbers at Seneca Rocks were concerned about their own and each other's safety. When to intervene in a potentially dangerous incident was based on what Fuller (2003) called "appeals to freedom" (p. 26) - it was important to climbers that they help each other avoid serious injury or death, but also that they preserve the perceived independent nature of the climbing experience by allowing climbers to make nonfatal mistakes as part of the learning process. It was expected among climbers at Seneca Rocks that individuals engage in self-aware self-assessment, that they be capable of managing subjective hazards, and that they be capable of integrating objective hazards into their traditional climbing skillsets. The climbers I interviewed were concerned that overregulation of safety practices, whether from an outside source or from other climbers, would take away the freedom and individualism they perceived as intrinsic to the activity, in keeping with Lyng's (1990) edgework paradigm.

There was some concern among insiders and regulars that inexperienced traditional climbers who were making the transition from a built climbing environment might be accident prone due to lack of safety skills and knowledge paired with the physical ability to climb routes that were difficult. There were also concerns that these climbers were taking behaviors from the built environment to the natural one, like toproping in large groups and not yielding toproped climbs to lead climbers. At the same time, beginning climbers, usually tourists, were hesitant to accept advice from climbers they did not know and tended to associate with their close social groups. The issue with not accepting advice from unknown climbers, although it too can be incorrect, is that climbers who trust only one individual and who do not have the skills to assess 
that individual's knowledge or ability may be receiving incorrect information with no way to reassess or correct it. This conundrum reflected the Dunning-Kruger effect (Kruger \& Dunning, 1999): unskilled people who do not realize they are unskilled tend to overestimate their abilities, although increasing their skills leads them to a better understanding of the skills they lack. Further to this finding, Kruger and Dunning asserted that incompetent individuals are less likely to be able to recognize competence in both themselves and other people. This trend could be seen in the inexperienced climbers' tendency to adhere to information only from trusted members of their own groups as well as their unwillingness to accept advice from climbers with whom they were not familiar.

There is nothing wrong on its face with keeping to one's own social group; with respect to the issue of safety, however, unwillingness to associate with other, more experienced climbers may be depriving beginners of critical safety information. The other side of this coin is the sense from tourists that regulars and insiders are insular and unwelcoming, although the regulars and insiders do not perceive themselves this way. This perception, however, may also be preventing less experienced climbers from seeking the information they need, assuming they are aware that they need it.

The individuals who generally had the most experience and training - guides - had accepted a position of responsibility to the other climbers at Seneca Rocks by accepting a role as primary actors in rescues. Nonguide insiders as well as regulars and tourists assumed that guides would take that position based on previous actions by both full-time guide services. Although willing to take on the responsibility, long-time guides reported traumatic effects of participation. 
Guo, Chen, Lu, Tan, Lee, and Wang (2004) found that nonprofessional rescuers who participated in rescue and recovery after a 1999 earthquake in Taiwan were more likely to show signs of posttraumatic stress (PTSD) than professional rescuers; results from studies from around the world indicate that spontaneous and nonprofessional rescuers experience a higher rate of PTSD than professional rescuers and nonparticipants (e.g., Johnsen, Eid, Løstad, \& Michelsen, 2006; Mitchell, Griffin, Stewart, \& Loba, 2004), although these studies tend to focus on major natural or man-made disasters where nonprofessional rescuers were exposed to the aftermath of the event for comparatively long periods of time.

One study exists examining PTSD in mountain guides; however, that contradicts the findings of these prior studies. Sommer, Ehlert, Paul, and Soraya (2004) found that Swiss mountain guides showed a low prevalence of PTSD relative to the frequency of their trauma exposure. It is difficult to extrapolate the results of the Swiss study to guiding at Seneca Rocks, however, considering the vast difference in numbers of available guides (1347 versus 10), the comparative level of geographical dispersement in the area (the Swiss Alps versus Seneca Rocks), the differences in guides' responsibilities between Switzerland and the United States, and the fact that the Swiss study did not include the amount of time respondents had worked as guides as a variable. These self-reports from long-time guides at Seneca Rocks merit further investigation.

\section{Group sizes}

Few climbers I interviewed expressed any concern about either unguided or guided group sizes at Seneca Rocks. With the exception of three climbers, all of my informants were at Seneca Rocks to lead climb. One of the individuals who did not lead was learning to climb on toprope 
with friends who were insiders at Seneca Rocks; the other two had followed experienced leaders on one or more routes. One tourist was disappointed that there was not more of a "wilderness experience" at Seneca Rocks, although this perception had not deterred him from returning to Seneca for a second climbing trip. The remainder did not mention group sizes at all. Likewise, few regulars mentioned group sizes, either guided or unguided. The one regular who had participated in climbing at Seneca Rocks both as an unguided climber and as an outdoor trip leader, thought that the current guide-to-client ratio was acceptable compared to prior established ratios.

Overall the current guide-to-client ratio did not appear to be a concern at Seneca Rocks. Even among insiders there was little concern about group sizes. One guide service owner suggested without my prompting that the number of clients permitted at a time might be divided between clients on toprope and clients on multipitch climbs. Other guides that I interviewed did not broach the subject. Both guide services were having difficulty attracting clients due to the current economic climate. According to guides and former guides that I interviewed, climbingrelated visitation to Seneca Rocks has decreased over the past several years, which may contribute to the perceptions of crowding levels at the current time.

Quantitative investigation into the number of unguided topropers denying lead climbers priority on the rock, in keeping with accepted practices at Seneca, may be warranted if conflict between the two groups increases. Without knowing how many climbers visit Seneca Rocks, what proportion of those climbers toprope at Seneca, or how frequently lead climbers are being 
denied priority, it is difficult to determine exactly how much of an issue this sort of toproping behavior is.

\section{Protecting climbs}

Climbers use the equipment that they find most suitable to them and to the areas in which they climb. What protection climbers use is not at issue in terms of how social worlds are bounded; it is their ability to use gear effectively that reflects their memberships. The majority of tourists I interviewed were inexperienced climbers who relied upon members of their particular subworld (clubs, friends) for information on the safe uses of removable climbing gear. In one case there was a central group "leader" who had the knowledge and experience to enforce climbing safety in the tourist group; the other groups, however, often lacked some sort of focal individual who could provide the information they needed to use their gear safely, quickly, and effectively. Tourists did not own more active gear than nontourists, but they did tend to treat it as quick to use and universally reliable, which is not the case with any piece of climbing equipment. As discussed above, tourists' status as beginners made them unlikely to rely on safety information from unknown climbers because they lacked the ability to assess those outsiders' knowledges (Kruger \& Dunning, 1999).

Regulars and insiders tended to have greater overall experience and expertise placing removable protection. These two subworlds' members also tended to have been climbing for longer periods of time and to possess greater overall experience climbing at Seneca Rocks. As Scott and Godbey (1994) found in their studies on social subworlds, tourists at Seneca Rocks showed little inclination to enter into the subworlds of the regulars or insiders but remained entrenched within the small social subgroups with whom they visited Seneca. Most tourists 
showed no interest in social worlds outside their own, although one tourist did describe members of the other subworlds as insular. Although there were a small number highly skilled climbers involved in this subworld, the majority of them appeared to be relative novices to climbing in general as well as to traditional climbing. Unruh (1980) suggested that membership in social subworlds was related to the level of commitment participants had to a particular social world. Should tourists develop a greater commitment to traditional climbing as an activity choice, it therefore follows that they would be more likely to become regulars.

Where tourists appeared to have the least overall competence with placing removable climbing protection, insiders had the greatest competence with placing fixed climbing protection. A small subset of insiders was the only group in this study who currently did so. It appears that bolts were being placed for safety and ecological reasons. The conflict between individuals about bolting's appropriateness appears to have reached an impasse at this time. That such a conflict occurred, however, is emblematic of the negotiated meanings of traditional climbing which have been debated both verbally and through actions in multiple locations over the past 40 years, described in depth by Fuller (2003) as well as in Tom Higgins' (1984) seminal work dividing climbers into "Tricksters and Traditionalists."

Generally speaking, the accepted and sanctioned bolting behaviors at a particular crag are malleable and unwritten. Guidebooks tend to be instructive in this case. Prior to the list of climbing routes and their locations, the authors usually provide a history of climbing and route development in the area, including the evolution of conventions and practices used to develop particular routes (see, e.g., Barnes, 2006; Piana, 1983; Watts, 1992). The Seneca Rocks 
guidebook chronicled the history of bolting in the context of route development there, emphasizing that there have been no new routes developed without at least one bolt being installed since the 1980s, that bolting is something that should be left to experts and done sparingly, and that alterations to existing routes should not be made without permission from the individuals who first established the route (Barnes, 2006). This history has not prevented other climbers from challenging those conventions and practices, but it has left them in a minority position with respect to their views on bolting, whether it be retrobolting without permission or bolt chopping.

Bolt chopping, which is both an aesthetic and ethical statement, can also be an issue of climbing safety. If a climber expects a bolt to exist on a route they are climbing, only to discover that it is gone, that climber may be placed in a position where they face possible groundfall, insecure anchorage, or other compromises to their safety. Whether a bolt should or should not exist, current conventions and practices notwithstanding, is not as cut-and-dried as the opposing positions of "there should be a bolt" and "there should not be a bolt" seem on the surface. Making these kinds of changes to routes without the knowledge of other climbers has the potential to lead to serious injury or death.

Ultimately, however, the debate over bolts among insiders is a management issue. If one group of insiders is placing bolts and another group of insiders is opposed to those bolts, it is critical that at least one person in the management unit understand that historically the issue of bolting is nuanced and complex both at Seneca Rocks and in American climbing in general. If future situations should require management intervention, it is important that management be 
able to address this issue with a full understanding of its complexity. Because management at Seneca Rocks has allowed climbers to make decisions about what bolting is and is not appropriate, generally without much conflict between climbers, stepping in suddenly to make a unilateral decision will likely be met with opposition regardless of what SKSR's management decision is. At this juncture the individuals who place bolts have little trust in the USFS, whereas the individuals who object to bolts are trying to work closely with the USFS, so SKSR management is currently only hearing part of the debate. The majority membership of both of the groups who hold strong positions on what bolting is or is not appropriate are special use permittees, but because of the laissez-faire treatment of climbing management to this point, these permittees have also become de facto land managers.

While bolting is a subject of debate between two diametrically opposed groups of insiders, the issue is not on the radar of the tourists and many of the regulars at Seneca Rocks. They appeared to be happy when a new route was established, bolts or no, because it was something new to climb. Nobody in those two social worlds discussed retrobolting. Every climber I talked to came to Seneca Rocks to climb on gear and liked the place because they could climb on gear there. How many bolts it took for them to be able to climb on gear on a particular route was not, however, something worth mentioning. It was just part of the route. Bolts were upsetting to the small group of insiders who opposed bolting on principle but did not appear to detract from the traditional climbing experiences people were having at Seneca. Sport climbers (who clip only fixed protection) had stronger opposition to new routes - which unlike traditional climbs at Seneca Rocks are protected entirely by bolts - if they had learned to climb in a gym (Borrie \& Harding, 2002). Half of the Seneca climbers I interviewed had learned to 
climb in a gym, but only a small number of insiders had developed a strong position about bolts on traditional climbs. It appears that where an individual learned to climb has less effect on traditional climbers' attitudes about bolting at Seneca Rocks than the subworlds to which they belong.

In his followup to "Tricksters and Traditionalists" (Higgins, 1984), Tom Higgins (2006) suggested that all climbing areas with conflicts about style needed to have some sort of sitting committee to determine which bolts are appropriate and which are not, and that appropriate first ascent styles be determined by the same, then published in guidebooks, on climbing web sites, and in other area literature. In fact, such committees seem to be in use only where climbing occurs on private property, in areas where there is conflict about overbolting (grid bolting, where there is no defined route per se, but large numbers of bolts placed close together allowing climbers to choose any line they like as opposed to climbing a pre-established route), where bolting has occurred next to cracks, or where there are a large number of new routes available for first ascents (Higgins, 2006), none of which are issues at Seneca Rocks. At Seneca Rocks accepted first ascent styles have been established over time, with de facto committees made up of the climbers for whom style issues were a concern, and published in the Seneca Rocks guidebooks (Barnes, 2006). Further, trailhead signs at Seneca Rocks admonish climbers to "think twice before bolting," although there is some question whether climbers were thinking at all about bolting routes before bolting was brought to their attention by this sign.

\section{Enforcing conventions and practices}

Climbers enforced conventions and practices at Seneca Rocks in three ways: through narrative discourses, through direct interventions with other climbers, and through reliance on 
more experienced climbers' knowledges. All three social subworlds engaged in these practices, although the most consistently reliable safety information was shared by regulars and insiders. Although there was some evidence of Foucault's (1980) assertion that those with the greatest power (in this case insiders) attempted to control the types of knowledges available to those in positions of less power, this issue only arose in the debate over bolting and was limited to the very small number of individuals attempting to control the narrative with respect to their personal positions on this particular issue. Overall these same individuals were generous with technical advice, sometimes to their own economic detriment, and actively engaged in participation in climber narratives that enforced other conventions and practices that were generally accepted among climbers at Seneca Rocks.

Most conventions and practices among climbers at Seneca Rocks were enforced through narratives shared at climber hangouts, including climbing guide services and campgrounds. Fine and Holyfield (1996) found a similar information sharing structure among mushroom collectors, where the lack of information about what mushrooms are poisonous made the activity hazardous to novice collectors. These discourses tended to be framed around "the other guy" but may also reference the individual who is telling the story. They may involve dangerous chains of events, issues of simple efficiency, or a situation from which an individual extricated him or herself. From these narratives, discussions followed about how to improve upon a particular situation in order to avoid similar incidents in the future. In these scenarios climbers benefitted from the collective knowledges of those around them and were vicariously exposed to risky situations without having to undertake the actual risk described in these shared narratives. 
Climbers will intervene directly with someone else while they are climbing if there is a risk of serious injury or death, but choose to let others learn from their mistakes if it is perceived that there is no imminent danger to self or others. The exception to this practice is a small number of insiders who "just leave" when they see potentially dangerous activity. These insiders attributed this behavior to "PTSD" from rescuing injured climbers in the past.

\section{How climbers integrate SKSR management into their social worlds}

Overall, climbers do not integrate SKSR management into their social worlds. Tourists were generally unaware of what agency managed Seneca Rocks and sometimes confused the USFS with West Virginia State Parks or the NPS. Regulars were more likely to be aware that the USFS managed Seneca Rocks. Neither of these groups had much direct interaction with the USFS unless they stopped by the Discovery Center, something few of the climbers I interviewed chose to do. Neither group had seen USFS personnel in the climbing areas at Seneca Rocks. On the other hand, neither group had any particular interest in seeing USFS personnel there, with the exception of a climber who thought that a climbing ranger like those in Yosemite or Rocky Mountain National Parks would be an acceptable person to encounter. Those tourists and regulars who did know that the USFS managed Seneca Rocks thought that the USFS was not knowledgeable about climbing and therefore should not intervene in climbing management.

All of the insiders I interviewed were aware that the USFS managed Seneca Rocks, but their views of the USFS were colored by their personal experiences with SKSR management over time and their attitudes toward Federal agencies in general. The divisions within this group related to whether members perceived the USFS as a reliable partner or a barrier to accomplishing personal goals. Individuals in the former group were attempting to develop a 
partnership with SKSR management. Members of the latter group had seen more staff turnover at SKSR, leading them to the impression that SKSR was just a stop on a promotional ladder rather than a place that individuals worked because of any personal attachments. They were less inclined to believe that the USFS took what they had to say seriously, and were opposed to climbing-related policies the USFS had made at the national level based on misinformation about climbing. The latter group's cynicism toward the USFS has left them inclined to keep SKSR management at arm's length.

Although the insiders at Seneca Rocks were aware of the existence of a climbing management plan they were unaware of its contents. Regulars and tourists, with the exception of one outdoor educator and another informant tied to the recreation industry, were unaware that such a plan existed.

\section{Improvements}

The climbers I interviewed did not identify any needed improvements to the climbing area at Seneca Rocks proper, although a small number of insiders expressed interest in access to Champe Rocks. Trail conditions were mentioned by only one of the climbers I interviewed; that climber was involved in the trailwork performed this summer at the Lower Slabs area. In general, climbers appear to be content with the current physical conditions at Seneca Rocks.

\section{Group regulations}

Overall there appear to be few issues with group sizes for either guided or unguided climbing; the greater concern appears to be with the knowledge level of inexperienced climbers, something the USFS cannot manage. One outdoor educator who occasionally guides at Seneca Rocks suggested the previous changes to permitted guide-to-client ratio was appropriate. A guide 
service owner suggested that splitting the permitted guide-to-client ratio depending on whether clients would be toproping or multipitch climbing could be considered. There are no hard and fast rules about guide-to-client ratios across climbing areas or managing agencies; these ratios vary depending on the climbing area in question and sometimes between guide services in those areas. A few regulars and insiders expressed concern about people toproping at Seneca Rocks, but their issue was with toproping behaviors that fell outside the conventions and practices typically employed at Seneca rather than the actual number of people who were toproping.

\section{Implications and Recommendations}

This study expands the recreation social worlds literature through an in-depth examination of rock climbers at Seneca Rocks. The results of this study supported Scott and Godbey's (1994) finding that recreation subworlds are defined by participants' choices and preferences rather than by a continuum of specialization (Bryan, 1977). There has been some recreation research examining the intersections and divergences of the social worlds and specialization constructs; recent studies have also indicated that Bryan's (1977) original conceptualization of specialization theory may not be reflective of the realities of contemporary recreation participation (see, e.g., Gahwiler \& Havitz, 1998; Kuentzel \& Heberlein, 2006; Scott \& Godbey, 1994; Scott \& Shafer, 2001). The results of this study support these prior findings.

While members of each subworld described in this study operated at different overall levels of area knowledge and traditional climbing expertise informants expressed little interest in “migrating" to a different subworld over time (see also Buchanan, 1985; Ditton et al., 1992; Green \& Chalip, 1998; Sean \& Chick, 2004). Regulars and insiders were more closely integrated socially than tourists, who tended to socialize solely within their own personal social groups, and 
had a greater commitment to Seneca Rocks as a whole, in keeping with Gahwiler and Havitz (1998).

For an activity like traditional climbing lack of interest in social worlds outside one's own has potential hazards. Regulars and insiders shared technical information with each other that was likely to improve upon each other's skills. These individuals also tended to have the greatest amount of experience climbing at Seneca Rocks and with traditional climbing in general. While one group of tourists whom I both interviewed and observed had a member who was an extremely experienced all-around climber acting as an advisor to less experienced traditional climbers, college and university clubs tended to have a lower overall level of experience with respect both to traditional climbing and to Seneca Rocks itself. Some of this can be attributed to the relative ages of the different groups. The social group of friends ranged in age from their early 40s to mid-60s and had been climbing periodically at Seneca Rocks for between eight and 20 years. The majority of the students had only recently begun climbing outdoors and tended to be making a transition from the built to the natural environment, although some of them had been climbing indoors since childhood.

Between the tourists, regulars, and insiders, tourists were the least likely to take advice from climbers with whom they were unfamiliar, to intervene in potentially dangerous climbing situations, or to socialize with climbers outside of the social group with which they travelled. All but one of the tourists I interviewed was a self-described beginner or intermediate traditional climber, meaning that this group's information and skill level was low relative to the regulars and insiders at Seneca. Information at Seneca Rocks tends to travel between insiders and regulars 
through socialization and word-of-mouth. Because tourists tended to operate within a closed social network they are likely to be the most difficult to reach with any new or important information about Seneca Rocks, whether from management or from climbing insiders.

How an individual learned to climb had less bearing on their social world membership than their commitment to the activity of traditional climbing and to Seneca Rocks as a place. Individuals who participated predominantly in traditional climbing over other types of climbing activities were situated socially as regulars or insiders, whereas those individuals who participated more equally in various forms of climbing like sport climbing or bouldering made up the tourists who came to Seneca Rocks. There was some concern among more experienced climbers on the influence of indoor climbing on beginners' attitudes toward safety practices and self-awareness and -assessment. Indoor climbing gyms are increasing in number and in popularity (Outdoor Industry Foundation, 2006). Over time, then, it will remain important not just to monitor the existence or ubiquity of such facilities but to track the types of instruction they provide for climbers wishing to make the transition to outdoor climbing, particularly traditional climbing.

Beginning outdoor climbers, whether they had learned to climb indoors or not, tended to rely on the individuals with whom they were climbing for information and instruction. They had little ability to assess the knowledge or skill of those individuals (or themselves) and tended to disregard advice from individuals they did not know because they did not think they could safely assess the accuracy of the advice given them. At the same time beginners were more likely to socialize within a small network, usually a club or a group of friends, and showed little interest 
in expanding that social network. One climber attributed this attitude to the "cliquish" nature of the regulars and insiders at Seneca Rocks, indicating that there is a perception of gatekeeping at least among some beginning climbers. Whether accurate or not, this perception may prevent inexperienced climbers from reaching out to obtain information that could improve their overall skill level.

There is an opportunity here for the guide services, who have seen decreasing revenues during the current economic downturn. By directly marketing to college and university climbing clubs it may be possible for them to alleviate the challenges of transitioning from the indoor to the outdoor climbing environments, thereby reducing the likelihood of beginning climbers making serious mistakes due to lack of skill and knowledge. Private indoor climbing gyms are another potential target market. Partnering with these businesses may help guides attract new clients as well as to increase overall climber knowledge and safety at Seneca Rocks. For the transitioning climbers, meeting some of the guides from Seneca may also increase their familiarity with individuals outside of their own social circles who can be relied upon for advice and information (see Kruger \& Dunning, 1999). It would also be advisable for SKSR management to provide an online list of permitted outfitter-guides at Seneca Rocks to ensure that unpermitted individuals cannot claim to offer climbing instruction at SKSR.

Climbing is a potentially dangerous activity. Participants accept its hazards willingly and, for the most part, knowingly. There have been concerns about climber safety at Seneca Rocks because of two recent fatalities there although it appears these two accidents were out-of-theordinary occurrences. The climbers I interviewed were conscientious about safety, although 
beginners and individuals who climbed at Seneca infrequently were less likely to be highly skilled than those who climbed at Seneca regularly. Seneca climbers self-police for safety, although what is perceived to be an appropriate intervention among climbers is an intervention that is not seen to limit the personal freedom climbers see as inherent to the activity. Seneca climbers are interested in preventing serious injury and fatality to themselves and other climbers, but otherwise practice nonintervention as a way for less experienced climbers to learn from their mistakes. To an outsider this behavior may seem strange, but it is important for resource managers to understand this practice in order to develop stronger relationships with rock climbers in general.

The proportion of serious accidents to climbing visitation at Seneca Rocks is unknown, although it appears minimal intervention is needed with respect to climbers' safety. Interviews with insiders indicated that there has been approximately one major accident requiring a victim extraction per year for the past nine years. While searching for details on these accidents I was able to find information on five incidents in the past 13 years. Three of the 349 United States climbing fatalities between 1996 and 2009 occurred at Seneca Rocks, fewer than 1\% of overall American climbing fatalities in that time period. Overall it does not appear that there have been any changes in recent years in the number of climbing accidents at Seneca Rocks; there appears, in fact, to be little pattern to these accidents. The two climbers who died at Seneca Rocks were experienced climbers; one injury accident occurred because of rockfall, which is a natural process; another possibly occurred because of defective equipment; and the last was the result of an inexperienced leader making poor decisions. While such accidents may appear sensational to nonclimbers, they also appear to be few and far between. 
An issue that has been raised to SKSR management in recent years is that of when it is appropriate to add or remove bolts. It appears that management is hearing only one position on the issue, as the individuals who are opposed to new bolts are making efforts to partner with SKSR management and the individuals who sometimes place new bolts express disaffection with the USFS in general. Insiders at Seneca Rocks hold multiple and varied positions on the appropriateness of including bolts on routes that take removable gear, ranging from opposition to any bolting for any reason to bolting for safety and environmental purposes. Regulars and tourists, on the other hand, tend not to have given the issue of bolting at Seneca Rocks much thought. In order to develop a fuller understanding of the issue and to make management decisions based on a wide range of available information it is critical that the USFS make efforts to develop meaningful relationships with all parties involved in this or any other disagreement about appropriate use of the resource. Because the individuals who place and replace bolts at Seneca Rocks are skeptical of the sincerity of USFS personnel this may need to be a long-term effort aimed initially at developing trust.

The challenging part of this complex issue is making sure that that Seneca Rocks remains a traditional climbing area - the preference of the individuals who climb there - without generating the perception of overregulation or of impinging on climbing safety. Understanding the current conventions and practices as described in the most recent Seneca Rocks guidebook would be a good place to start (Barnes, 2006). No climber I interviewed supported retrobolting without the permission of the first ascentionist, although there was some confusion among a small number of informants as to whether that was occurring. My overall impression was that it was not. For the USFS, tracking this sort of behavior would require an extreme level of 
micromanagement, something that climbers are opposed to as well as something that is not feasible from a management standpoint. Keeping an inventory of all the routes, what bolts are where, who climbed the route, their contact information, and files of documents giving permission to retrobolt would do little but generate an enormous amount of unnecessary paperwork, particularly when this information is already tracked in Barnes's (2006) guidebook. It would also tie liability for faulty fixed protection to the USFS, something that has been avoided by allowing climbers to take responsibility for any bolting that occurs at Seneca Rocks.

Rather than take an unnecessary step like this, it appears that leaving such decisions to the climbers who are concerned about such issues continues to be the most appropriate approach. Previous conflicts have reached an impasse, meaning that retaliatory action is no longer being taken on either extreme of the argument. The most recent conflict over bolting was six years ago, over the anchors on The Burn, and has seen no action since 2004. Should such conflicts arise in the future in a way that requires SKSR management to mediate, however, it is important that they have the trust of and input from all individuals who are in conflict over what constitutes appropriate bolting, and that management have the technical understanding of the bolting issue to make appropriate decisions in that regard. To this end, ensuring that at least one individual on the SKSR staff has familiarity with traditional climbing at Seneca Rocks could help inform internal decision-making about future climbing policy when necessary as well as to increase trust and awareness of the USFS among Seneca climbers in general.

Overall, the findings about bolting in this study show how a problem that may seem simple on its surface (i.e. bolts or no bolts in a climbing area) may be nuanced and informed by 
multiple understandings, particularly among people considered to be experts at a particular activity. In the past the USFS has made climbing related decisions based on a limited understanding of the issues involved. Ensuring that land management agencies understand the complexity of issues among an activity's practitioners prior to issuing a decision is critical to ensuring that relationships to user groups are not strained, particularly when it comes to obtaining expert advice for future decisions.

With respect to group sizes at Seneca Rocks, current levels of both guided and unguided appear to be acceptable to the climbers there. Prior to management decision-making about future climbing outfitter-guide permit allocations, managers should engage current permit holders and the American Mountain Guides’ Association regarding recommended numbers for toprope versus multipitch climbing, as the current guide-to-client ratios are set identically for both scenarios. According to the guide service owners, however, climbing visitation has been relatively low for several years, coinciding with the economic downturn. Future monitoring of group sizes will be necessary as visitation levels fluctuate.

Although group sizes on the whole were not a concern among climbers at Seneca Rocks, there was some concern about toproping behavior among less experienced climbers. Current practice at Seneca Rocks, established over time, is that individuals who are toproping a route yield the right-of-way for lead climbers. Apparently some climbers are carrying the first-comefirst-served indoor climbing practice to Seneca Rocks, leading to conflict between lead climbers and some topropers. Indoor climbing gyms who encourage members to transition from indoor to outdoor climbing should impress upon these members the importance of learning and engaging 
in practices considered appropriate at the outdoor sites where they choose to climb. As climbers who engage in this practice are most likely tourists, finding ways to reach out to these individuals is a particular challenge. In general including more detailed information about rock climbing at Seneca Rocks on the USFS Web site may be a way to reach climbers who separate themselves socially from the regulars and insiders there and otherwise miss out on word-ofmouth learning opportunities.

While partnerships are beneficial to both the USFS and its partners, there is some concern that partnering with a single faction may lead to low-level agency capture (see, e.g., Sabatier, 1975), in which that faction becomes the main source of advice on a particular issue to the agency. This type of situation leads to other advocates for a particular issue becoming disenfranchised and to the agency unwittingly promoting a particular faction's views as its own. It is critical that the USFS reach out to other potential partners, especially those who hold differing views from current partners, in order to expand the range of information they are receiving about controversial issues among user groups. In some cases these partnerships will have to start small, with trust building, before they can move on to stronger relationships between the insider organizations and the USFS.

\section{Future Research}

The popularity of rock climbing has increased recently but the academic literature is outof-date and contains considerable gaps (Nelb \& Schuster, 2008). There are many opportunities for research on this particular topic. At Seneca Rocks a split was evident between climbers who were stylistic generalists - people who participated in bouldering, sport climbing, traditional climbing, and indoor climbing without a particular commitment to a single style - and those who 
focused primarily on traditional climbing. The generalists, or tourists, were less likely to associate with climbers in other social worlds, meaning they were losing out on a wealth of technical information that could improve their traditional climbing skill levels. Whether this is the case in other climbing areas is unknown, as are the greater implications of this social divide for national level climbing management policies regarding climbing safety decisions and communication with climbing stakeholders.

A question that related to that of generalist climbers is the phenomenon of the transition from one style of climbing to another, whether that be from sport to traditional or from climbing in the built environment to climbing in the outdoor environment. Half of the climbers I interviewed learned to climb in an indoor climbing gym but a small number of climbers at Seneca Rocks appeared to be taking indoor gym conventions and practices with them to outdoor climbing scenarios, where the conventions and practices differ. As more of these built recreation opportunities present themselves, whether with climbing, whitewater rafting, or other activities which can be hazardous as practiced outdoors, it follows that individuals may eventually choose to participate in the same activities in an outdoor setting. In order to help the owners of such recreation venues with their clients' safe and informed transitions to outdoor activities, future research on this transition will be beneficial. This information will also be useful to recreation managers, as they will need to ensure that the information they provide the recreationists in their areas is appropriate to the knowledges and skill levels of their participants.

Although one of the foci of this study was on that of safety practices, it remains difficult to determine the ratio of accidents to participants without an accurate count of users who climb at 
a particular area or an accurate record of what types of accidents, if any, are occurring. Counting climbers is a challenge in other recreation areas, as well, as climbing areas can have multiple access points and/or be spread out over a large area. Further confounding the issue, trails that climbers use are shared by individuals participating in other activities. Developing reliable, affordable methods of counting climbers is critical to ensuring an accurate assessment of both use and accident rates. The second variable in this equation is accurate tracking of local accidents, something that requires buy-in from area climbers and an understanding with the managing agency that this count will be used to pinpoint any patterns that indicate a need for improved communication and education rather than a tool used to limit access to climbing areas.

While communication of conventions and practices is well established among insiders and regulars at Seneca Rocks, such communication is limited with respect to tourists. Further research into how to communicate with individuals with low overall commitment to an activity, like the tourists at Seneca Rocks, may help extend the knowledge of those conventions and practices, thereby reducing the potential for conflicts between different subworlds. It also may help individuals with low skill and low information improve their skills, reducing the likelihood that poor decision-making contributes to accidents.

Although current guide-client ratios do not appear to be generating conflict at Seneca Rocks there was some indication that having different guide-to-client ratios for toproping and lead climbing might be an option worth considering for future outfitter-guide permits. In some climbing areas this practice is already in place. What is missing from this discussion is information on what appropriate guide-to-client ratios are in general. Research on appropriate 
guide-to-client ratios for optimal client learning experience and safety as well as to ensure a positive experience for unguided individuals around them should be investigated, perhaps in tandem with the American Mountain Guide Association, who certify climbing guides in the United States, and guide service owners and guides around the country.

Another issue in need of examination is that of the economic downturn. This downturn is affecting the amount of business guide services can bring in and the number of guides they can hire. It is affecting the number of trips that unguided individuals can take in a given year. Decreases in participation, while most immediately affecting small businesses dependent on recreationists for their survival and the ability of recreationists themselves to participate in their activities of choice, spill over to Federal agencies' future budget allocations, which may be reduced due to decreases in visitation. This, in turn, could lead to budgetary shortfalls when visitation levels begin to increase again, as well as a shortage of outfitter-guides who may not in the short run be able to meet increased demand. Strategies to weather the current economic climate need to be developed by both small business owners and federal agencies in tandem with experts on budgeting and development, in order to protect these small businesses and for federal agencies to prepare for increased visitation with a decreased budget.

One possibility in this regard would be to examine the possibility of partnerships with the USFS extending in a different direction than they currently do. While climbing related organizations at Seneca Rocks work with the USFS to provide labor for trail maintenance, it may be worth considering for the USFS to expand its partnerships program to include more small business development, marketing support, computer access, and other opportunities which will 
increase small, recreation-related businesses' ability to stay afloat during difficult economic times. Some attempts have been made at SKSR in this regard, but the development of a pilot program that involves a longitudinal study assessing the successes and failures of such a program could help provide greater insight on how to implement such a program on the national level.

Self-reports from longtime volunteer rescuers indicated that there were negative personal impacts over time to participating in these rescues. Research directly related to PTSD and guides' participation in rescues is limited to a single study in Europe (Sommer et al., 2004); this study's findings contradict the results of other studies of volunteer rescuers (e.g., Johnsen et al., 2006; Mitchell et al., 2004). No studies have been carried out in the context of guides as rescuers in the United States. Further investigation is necessary to determine the whether PTSD is a widespread issue for American climbing guides who participate voluntarily in rescues, to ensure that individuals reporting residual negative emotional effects from participating in these rescues receive any help that they need in coping with the aftermath of climbing accidents, and to better understand the psychological ramifications of long-term participation in volunteer search-andrescue.

The Dunning-Kruger effect was established in studies of academic performance (Kruger \& Dunning, 1999). It has also been examined in the contexts of computer science (e.g., Compeau \& Higgins, 1995; Gravill, Compeau, \& Marcolin, 2006), medicine (e.g., Davis, Mazmanian, Fordis, Van Harrison, Thorpe, \& Perrier, 2006; Eva \& Regehr, 2005; Hodges, Regehr, \& Martin, 2001), and business (e.g., Jaramillo, Carrillat, \& Locander, 2005; Santos-Pinto, 2008). I could find no studies related to the Dunning-Kruger effect or metacognition in general that related to 
the field of outdoor recreation research. As honest self-assessment is crucial to safe participation in recreational activities ranging from hiking to BASE jumping, it follows that studies in this area would be fruitful for outdoor education, resource management, and other entities that provide information to recreationists entering situations with varying levels of potential personal risk.

\section{Summary}

The purpose of this study was to provide SKSR management with an understanding of the social worlds of rock climbers at Seneca Rocks, to ascertain any management interventions that can improve access to climbing areas at Seneca Rocks, and to determine how permitted group sizes among guided and/or unguided climbers would affect the social worlds of climbers at Seneca Rocks. Among the three major social worlds of tourists, regulars, and insiders as established by Unruh (1980), tourists and insiders were found to be the most socially fragmented. In the case of the tourists, fragmentation occurred because of personal social preference and, in one case, a sense that other social worlds were unwelcoming to new members. These climbers were least likely to interact with other climbers and were also the lowest-skilled climbers, meaning that their social isolation led to fewer opportunities to expand their climbing skills. Insiders' social worlds were fragmented over personal beliefs about bolting practices and the utility of SKSR management. Fragmentation in this social world has led to the USFS hearing only one side of the debate over what types of bolting are appropriate at Seneca Rocks, which is most strongly contested among this group of climbers.

While all climbers I interviewed were concerned about safety, poor skills assessment abilities among tourist climbers led them to mistrust advice from more experienced climbers 
with whom they were unfamiliar (Kruger \& Dunning, 1999). Such interventions from experienced climbers were situational in nature. Climbers preferred to intervene in other climbers' practices only when there was a perception of imminent injury or death. Otherwise, conventions and practices at Seneca Rocks were enforced in a non-climbing setting, through narrative discourses in social groups.

Across social worlds there was a sense of reliance on the two full-time guide services to effect rescues when there was a climbing accident. The guides had accepted this role, citing their strong skill sets, knowledge of the area, and physical fitness to undertake such rescues. Longtime guides, however, asserted that they experienced post-traumatic stress from participating in rescues over time.

Current guide-to-client ratios appeared to be satisfactory among all informants, although there was some indication that climbing related visitation to Seneca Rocks is currently low. One guide suggested dividing the number of permitted clients based on the type of climbing being undertaken; that is, if guides were toproping with clients a greater number of clients per guide be permitted than if guides were lead climbing with clients. There was also little concern about group sizes among unguided climbers. Rather, the issue appeared to be with individuals who violated the "leader gets priority" convention at Seneca Rocks. This issue was generally attributed to climbers taking acceptable practices in an indoor environment into an outdoor environment where such practices were not acceptable. 
Although half of my informants learned to climb in a built environment there was varying concern expressed about the effects of indoor climbing gyms on climbing behaviors and knowledges at Seneca Rocks. Of the five major non-fatality accidents on which I was able to find information, two of them were attributed by insiders to lack of traditional climbing knowledge and overconfidence engendered by climbing indoors. There was also concern about accepted indoor practices being transferred to Seneca Rocks, where such practices were not considered acceptable. The fragmentation of social worlds, particularly of the tourists, presented a challenge in enforcing these particular practices, as the tourists are least likely to interact with groups outside of their own small social units.

There was no interest expressed in USFS interventions to improve access to climbing areas at Seneca Rocks proper. Among some insiders, however, there was interest in opening access to Champe Rocks. Overall, the laissez-faire approach the USFS had taken toward climbing at Seneca Rocks resulted in the insiders there becoming the de facto managers of the climbing area. Some insiders had chosen to partner with the USFS, while others expressed a sense of futility toward working with the agency due to the high turnover there. Regulars and insiders correctly identified the USFS as the managing agency at Seneca Rocks, while tourists tended to confuse the USFS with West Virginia State Parks and the NPS.

SKSR management should investigate ways to build trust with the disenfranchised insiders, as their insights into climbing-related issues sometimes differ from those of the partnering insiders. The knowledge they gain from the former group would help illuminate the complexity of issues that appear superficially to be cut-and-dried. If guide-to-client ratios are to 
be reassessed involving all insiders (as well as the American Mountain Guides Association) will be necessary to the success of any changes. It is also necessary to find effective ways to communicate with tourist climbers, who are, overall, the lowest skilled and least committed participants in climbing at Seneca Rocks. In tandem with this effort, guide services may find that there are opportunities to partner with indoor climbing gyms to help inform indoor climbers wishing to make a safe transition to climbing at Seneca Rocks and to educate them about conventions and practices at Seneca Rocks prior to their arrival there. 


\section{REFERENCES}

Accident at Seneca 4/15. (2006). Rockclimbing.com forum discussion. Retrieved June 12, 2010, from the rockclimbing.com Web site: http:/Www.rockclimbing.com/cgibin/forum/gforum.cgi?post=1357613

Accident on East Face Seneca 10/25. (2009). Rockclimbing.com forum discussion. Retrieved June 12, 2010, from the rockclimbing.com Web site: http://www.rockclimbing.com/cgibin/forum/gforum.cgi?post=2229053

Adventure Schools Rock Climbing. (2010). Adventure programs. Retrieved from Thursday, August 19, 2010, from the Adventure Schools Rock Climbing Web site: http://www.adventureschool.com/programs.php

Allman, T. L., Mittelstaedt, R. D., Martin, B., \& Goldenberg, M. (2009). Exploring the motivations of BASE jumpers: Extreme sport enthusiasts. Journal of Sport and Tourism, 14(4), 229-247.

Ament, P. (2002). A History of Free Climbing in America: Wizards of Rock. Berkeley, CA: Wilderness Press.

American Alpine Club. (1997). Accidents in North American Mountaineering: 1997. Golden, CO: The American Alpine Club.

American Alpine Club. (2009). Accidents in North American Mountaineering: 2009. Golden, CO: The American Alpine Club.

Anderson, L. (2006). Analytic ethnography. Journal of Contemporary Ethnography, 35(4), 373395.

Atlantic Climbing School. (2010). Courses. Retrieved Thursday, August 19, 2010, from the Atlantic Climbing School Web site: http://www.climbacadia.com/courses_overview.htm 
Attarian, A. (2002). Rock climbers' self-perceptions of first aid, safety, and rescue skills. Wilderness Environmental Medicine, 13(4), 238-244.

Axelrod, R. (1986). An evolutionary approach to norms. American Political Science Review, 80(4), 1095-1111.

Barnes, T. (2006). Seneca: The Climber's Guide (2 ${ }^{\text {nd }}$ ed.). Chapel Hill, NC: Earthbound Sports, LLC.

Becker, H. S. (1958). Problems of inference and proof in participant observation. American Sociological Review, 23(6), 652-660.

Beeston Today. (2009). Ian Shevill: Beeston Rock Climber Dies After Fall. Beeston Today (online edition). Retrieved June 12, 2010, from the Beeston Today Web site: http://www.beestontoday.co.uk/4272/Ian-Shevill-Beeston-rock-...1

Blumer, H. (1969). Symbolic Interactionism: Perspective and Method. Englewood Cliffs, NJ: Prentice-Hall, Inc.

Borrie, W. T., \& Harding, J. A. (2002). Effective recreation visitor communication strategies: Rock climbers in the Bitterroot Valley, Montana. USDA Forest Service Research Note RMRS-RN-15. Fort Collins, CO: Rocky Mountain Research Station.

Buchanan, T. (1985). Commitment and leisure behavior: A theoretical perspective. Leisure Sciences, 7(4), 401-420.

Charmaz, K. (2005). Constructing Grounded Theory: A Practical Guide Through Qualitative Analysis. Thousand Oaks, CA: Sage.

Chen, S. X., et al. (2006). Reexamining personal, social, and cultural influences on compliance behavior in the United States, Poland, and Hong Kong. The Journal of Social Psychology, 146(2), 223-244. 
Christensen, A., Needham, M. D., \& Rowe, S. (2008). Whale watchers' past experience, value orientations, and awareness of consequences of actions on the marine environment. Tourism in Marine Environments, 5(4), 271-285.

Christensen, P. N., Rothgerber, H., Wood, W., \& Matz, D. C. (2004). Social norms and identity relevance: A motivational approach to normative behavior. Personality and Social Psychology Bulletin, 30(10), 1295-1309.

Clarke, A. E. (2005). Situational Analysis: Grounded Theory After the Postmodern Turn. Thousand Oaks, CA: Sage Publications.

Cloke, P., \& Perkins, H. C. (1998). "Cracking the canyon with the awesome foursome:” Representations of adventure tourism in New Zealand. Environment and Planning D, $16(2), 185-218$

Colton, C. W., \& Morrione, T. J. (1973). Outdoor recreation behavior viewed from a symbolic interactionism perspective. Paper presented at the Annual Meeting of the Rural Sociological Society, College Park, MD, August 26, 1973.

Compeau, D. R., \& Higgins, C. A. (1995). Computer self-efficacy: Development of a measure and initial test. MIS Quarterly, 19(2), 189-211.

Cottrell, S. P., \& Graefe, A. R. (1997). Testing a conceptual framework of responsible environmental behavior. Journal of Environmental Education, 29(1), 17-27.

Culp, R. H. (1998). Adolescent girls and outdoor recreation: A case study examining constraints and effective programming. Journal of Leisure Research, 30(3), 356-379.

Davis, D. A., Mazmanian, P. E., Fordis, M., Van Harrison, R., Thorpe, K. E., \& Perrier, L. (2006). Accuracy of physician self-assessment compared with observed measures of 
competence: A systematic review. Journal of the American Medical Association, 296(9), 1094-1102.

Denzin, N. K. (1974). The methodological implications of symbolic interactionism for the study of deviance. The British Journal of Sociology, 25(3), 269-282.

Dieser, R. B. (2005). Genealogy of the United States therapeutic recreation certification framework. Leisure Studies, 24(1), 61-79.

Ditton, R. B., Loomis, D. K., \& Choi, S. (1992). Recreation specialization: Re-conceptualization from a social worlds perspective. Journal of Leisure Research, 24(1), 33-51.

Donnelly, M. (2006). Studying extreme sports: Beyond the core participants. Journal of Sport and Social Issues, 30(2), 219-224.

Donnelly, M. P., Vaske, J. J., Whittaker, D., \& Shelby, B. (2000). Toward an understanding of norm prevalence: A comparative analysis of 20 years of research. Environmental Management, 25(4), 403-414.

Donnelly, P. (1982). Four fallacies - IV: Climbing leads people to form close friendships. Mountain, 83, 45-49.

Downing, K. B., \& Clark, R. N. (1985). Methodology for studying recreation choice behavior with emphasis on grounded inquiry. USDA Forest Service General Technical Report INT-GTR-184.

Dupuis, S. L. (1999). Naked truths: Towards a reflexive methodology in leisure research. Leisure Sciences, 21, 43-64.

Eva, K. W., \& Regehr, G. (2005). Self-assessment in the health professions: A reformulation and research agenda. Academic Medicine, 80(10), S46-S54. 
Fine, G. A., \& Holyfield, L. (1996). Secrecy, trust, and dangerous leisure: Generating group cohesion in voluntary organizations. Social Psychology Quarterly, 59(1), 22-38.

Foucault, M. (1973). The Order of Things: An Archaeology of the Human Sciences. New York: Random House.

Foucault, M. (1980). Power/Knowledge: Selected Interviews and Other Writings, 1972-1977. New York: Harvester Wheatsheaf.

Fuller, S. (2003). Creating and contesting boundaries: Exploring dynamics of conflict and classification. Sociological Forum, 18(1), 3-30.

Gahwiler, P., \& Havitz, M. E. (1998). Toward a relational understanding of leisure social worlds, involvement, psychological commitment, and behavioral loyalty. Leisure Sciences, 20(1), 1-23.

Gerdes, E. M., Hafner, J. W., \& Aldag, J. C. (2006). Injury patterns and safety practices of rock climbers. The Journal of TRAUMA Injury, Infection, and Critical Care, 61(6), 15171525.

Giddens, A. (1979). Central Problems in Social Theory: Action, Structure, and Contradiction in Social Analysis. London: MacMillan.

Glaser, B. G. (1978). Theoretical Sensitivity: Advances in the Methodology of Grounded Theory. Mill Valley, CA: Sociology Press.

Glaser, B. G., \& Strauss, A. L. (1967). The Discovery of Grounded Theory: Strategies for Qualitative Research. Chicago: Aldine.

Goffman, E. (1959). The Presentation of Self in Everyday Life. New York: Anchor Books.

Gravill, J. I., Compeau, D. R., \& Marcolin, B. L. (2006). Experience effects on the accuracy of self-assessed user competence. Information \& Management, 43(3), 378-394. 
Graydon, D., \& Hanson, H., eds. (1997). Mountaineering: The Freedom of the Hills $\left(6^{\text {th }}\right.$ ed.). Seattle: The Mountaineers.

Green, B. C., \& Chalip, L. (1998). Sport tourism as the celebration of subculture. Annals of Tourism Research, 25(2), 275-291.

Grijalva, T. C., \& Berrens, R. P. (2003). A question of standing: Institutional change and rock climbing in Wilderness areas. Society and Natural Resources, 16, 239-247.

Guo, Y., Chen, C., Lu, M., Tan, H., Lee, H., \& Wang, T. (2004). Posttraumatic stress disorder among professional and non-professional rescuers involved in an earthquake in Taiwan. Psychiatry Research, 127(1), 35-41.

Gurman, S., \& Simonich, M. (2008). North Hills doctor dies in rock climbing accident. Pittsburgh Post-Gazette (online edition). Retrieved June 10, 2010, from the Pittsburgh Post-Gazette Web site: http://www.post-gazette.com/pg/08288/919761-54.stm.

Hall, P. M. (1987). Interactionism and the study of social organization. The Sociological Quarterly, 28(1), 1-22.

Harrer, H. (1959/1998). The White Spider: The Classic Account of the Ascent of the Eiger. (H. Merrick, trans.). New York: Putnam.

Heinbach, D. (2004). Shaving the bull's horns. Alpinist, 8, online edition. Retrieved Monday, June 7, 2010, from the Alpinist Web site: http://www.alpinist.com/doc/ALP08/Letters.

Henderson, K. A., Presley, J., \& Bialicheski, M. D. (1994). Theory in recreation and leisure research: Reflections from the editors. Leisure Sciences, 26(4), 411-425.

Heywood, J. L. (2002). The cognitive and emotional components of behavior norms in outdoor recreation. Leisure Sciences, 24, 271-281. 
Heywood, J. L., \& Murdock, W. E. (2002). Social norms in outdoor recreation: Searching for the behavior-condition link. Leisure Sciences, 24, 283-295.

Higgins, T. (1984). Tricksters and traditionalists: A look at conflicting climbing styles. Retrieved Wednesday, May 26, 2010, from Tom Higgins.net: http://www.tomhiggins.net/index.php?option=com_content\&task=view\&id=13\&Itemid= 19

Higgins, T. (2006). Tricksters and traditionalists revisited: 2006. Retrieved Wednesday, May 26, 2010, from Tom Higgins.net: http://www.tomhiggins.net/index.php?option=com_content\&task=view\&id=33\&Itemid= 19

High Plains Outdoor Institute. (2010). Climbing classes. Retrieved Thursday, August 19, 2010, from the High Plains Outdoor Institute Web site: http://www.hpoiadventure.com/rockclimbing-class.htm

High Xposure Adventures. (2010). The school. Retrieved Thursday, August 19, 2010, from the High Xposure Adventures Web site: http://www.high-xposure.com/school/index.html.

Hodges, B., Regehr, G., \& Martin, D. (2001). Difficulties in recognizing one's own incompetence: Novice physicians who are unskilled and unaware of it. Academic Medicine, 76(10), S87-S89.

Hogg, M. A., \& Reid, S. A. (2006). Social identity, self-characterization, and the communication of group norms. Communication Theory, 16, 7-30.

Horst, E. J. (2001). Rock Climbing: Virginia, West Virginia, and Maryland. Guilford, CT: Falcon. 
Hunt, L. M., Lemelin, R. H., \& Saunders, K. C. (2009). Managing forest road access on public lands: A conceptual model of conflict. Society and Natural Resources, 22(2), 128-142.

James, W. R. (2009). Built Adventure Recreation Environments: Users, Uses, and the Adventure Recreation Model. Unpublished M.S. thesis. Raleigh, NC: North Carolina State University.

Jaramillo, F., Carillat, F. A., \& Locander, W. B. (2005). A meta-analytic comparison of managerial ratings and self-evaluations. Journal of Personal Selling and Sales Management, 25(4), 315-328.

Johnsen, B. H., Eid, J., Løstad, T., \& Michelsen, L. T. (2006). Posttraumatic stress symptoms in nonexposed, victims, and spontaneous rescuers after an avalanche. Journal of Traumatic Stress, 10(1), 133-140.

Kruger, J., \& Dunning, D. (1999). Unskilled and unaware of it: How difficulties in recognizing one's own incompetence lead to inflated self-assessments. Journal of Personality and Social Psychology, 77(6), 1121-1134.

Kuentzel, W. F., \& Heberlein, T. A. (2006). From novice to expert: A panel study of specialization progression and change. Journal of Leisure Research, 38(4), 496-512.

Kyle, G., \& Chick, G. (2002). The social nature of leisure involvement. Journal of Leisure Research, 34(4), 426-448.

Latour, B. (1999). We Have Never Been Modern. Cambridge, MA: Harvard University Press. Laurendeau, J. (1996) “He didn’t go in doing a skydive:" Sustaining the illusion of control in edgework activity. Sociological Perspectives, 49(4), 583-605.

Lee, J. (1999). The utility of a strategic postmodernism. Sociological Perspectives, 42(4), 739753. 
Little, D. E. (2002). Women and adventure recreation: Reconstructing leisure constraints and adventure experiences to negotiate continuing participation. Journal of Leisure Research, $34(2), 157-177$

Long, J., \& Luebben, C. (1997). Advanced Rock Climbing. Guilford, CT: Falcon Press.

Lyng, S. (1990). Edgework: A social psychological analysis of voluntary risk taking. The American Journal of Sociology, 95(4), 851-886.

Manning, R. E. (1999). Studies in Outdoor Recreation: Search and Research for Satisfaction $\left(2^{\text {nd }}\right.$ ed.). Corvallis, OR: Oregon State University Press.

Manning, R. E., Freimund, W. A., Lime, D. W., \& Pitt, D. G. (1996). Crowding norms at frontcountry sites: A visual approach to standards of quality. Leisure Sciences, 18(1), 3959.

Manzenreiter, W. (2007). Moving mountains: Order and change in a sports world. Chapter 4 in: Kelly, W. W. \& Sugimoto, A., eds. This Sporting Life: Sports and Body Culture in Modern Japan. New Haven, CT: Yale University Press.Marx, M., \& Chavez, D. J. (2002). Conflict and coalitions: An examination of outdoor recreation magazines. Environmental Management, 29(2), 207-216.

Mills, J., Bonner, A., \& Francis, K. (2006). The development of constructivist grounded theory. International Journal of Qualitative Methods, 5(1), 1-10.

Mitchell, M. Y., Force, J. E., Carroll, M. S., \& McLaughlin, W. J. (1993). Forest places of the heart. Journal of Forestry, 91(4), 32-37.

Mitchell, T. L., Griffin, K., Stewart, S. H., \& Loba, P. (2004). 'We will never ever forget ...': The Swissair Flight 111 disaster and its impact on volunteers and communities. Journal of Health Physiology, 9(2), 245-262. 
Mountain Madness. (2010). Rock climbing: Nevada. Retrieved Thursday, August 19, 2010, from the Mountain Madness Web site: http://www.mountainmadness.com/schools/schl_rc_nv.cfm

Nelson, N. G., \& McKenzie, L. B. (2009). Rock climbing injuries treated in emergency departments in the U.S., 1990-2007. American Journal of Preventative Medicine, 37(3), 195-200.

Nelb, S., \& Schuster, R. M. (2008). Questioning the continuum: Specialization in rock climbing. Pp. 204-209 in: Leblanc, C., \& Vogt, C., comps. Proceedings of the 2007 Northeastern Recreation Research Symposium, April 15-17, 2007, Bolton Landing, NY. USDA Forest Service General Technical Report GTR-NRS-P-23. Newtown Square, PA: Northern Research Station.

Northwest Mountain School. (2010). Leavenworth rock climbing guides and instruction. Retrieved Thursday, August 19, 2010, from the Northwest Mountain School Web site: http://www.mountainschool.com/content/main/leavenworth-rock-climbing-guidesinstruction/

Outdoor Industry Foundation. (2006). Outdoor recreation participation study: Climbing - natural rock, artificial wall, ice. Retrieved July 11, 2006, from the Outdoor Industry Foundation Web site: http://www.outdoorindustryfoundation.org.

Outdoor Wilderness Leadership School. (2010). Rock climbing in Virginia. Retrieved Thursday, August 19, 2010, from the Outdoor Wilderness Leadership School Web site: http://www.owlsadventures.com/adventure/apRC.html

Patton, M. Q. (2002). Qualitative Research and Evaluation Methods ( $3^{\text {rd }}$ ed.). Thousand Oaks, CA: Sage Publications. 
Peck, D. F., Robertson, A., \& Zeffert, S. (1996). Psychological sequelae of mountain accidents: A preliminary study. Journal of Psychosomatic Research, 41(1), 55-63.

Philipp, S. F. (1999). Are we welcome? African American racial acceptance in leisure activities and the importance given to children's leisure. Journal of Leisure Research, 31(4), 385403.

Piana, P. (1983). Touch the Sky: The Needles in the Black Hills of South Dakota. New York: American Alpine Club.

Porter, R., \& Tarrant, M. A. (2005). Determining acceptable carrying capacities for recreation use as identified by key stakeholders: A focus group process. pp. 304-309 in: Bricker, K., \& Millington, S. J., comps. Proceedings of the 2004 Northeastern Recreation Research Symposium. March 31-April 2, 2004, Bolton Landing, NY. USDA Forest Service Northeastern Research Station General Technical Report GTR-NE-326.

Puchan, H. (2004). Living 'extreme': Adventure sports, media, and commercialization. Journal of Communication Management, 9(2), 171-178.

Rockfall at Seneca Rocks WV. (2005). Rockclimbing.com forum discussion. Retrieved from the Web June 12, 2010: http://www.rockclimbing.com/cgibin/forum/gforum.cgi?post $=1181458$

Rossiter, P. (2007). Rock climbing: On nature, culture, and other nonhumans. Space and Culture, 10(2), 292-305 (abstract only).

Roper, S. (1994). Camp 4: Recollections of a Yosemite Rockclimber. Seattle, WA: The Mountaineers Press.

Rowe, D. (2006). Coming to terms with leisure and globalization. Leisure Studies, 25(4), 423436. 
Sabatier, P. (1975). Social movements and regulatory politics: Toward a more accurate theory of “clientele capture.” Policy Sciences, 6, 310-342.

Santos-Pinto, L. (2008). Positive self-image and incentives in organizations. The Economic Journal, 118(531), 1315-1332.

Seneca Accident on Front C. (2007). Rockclimbing.com forum discussion. Retrieved from the Web June 12, 2010: http://www.rockclimbing.com/cgibin/forum/gforum.cgi?post=1684994

Schneider, T. A., Butryn, T. M., Furst, D. M., \& Masucci, M. A. (2007). A qualitative examination of risk among elite adventure racers. Journal of Sport Behavior, 30(3), 330357.

Schuster, R. M., Thompson, J. G., \& Hammitt, W. E. (2001). Rock climbers' attitudes toward management of climbing and the use of bolts. Environmental Management, 28(3), 403412.

Scott, D., \& Godbey, G. (1994). Recreation specialization in the world of contract bridge. Journal of Leisure Research, 26(3), p. 275-295.

Smith-Sebasto, N. J., \& Walker, L. M. (2005). Toward a grounded theory for residential environmental education: A case study of the New Jersey School of Conservation. The Journal of Environmental Education, 37(1), 27-42.

Sommer, I., Ehlert, U., Cary, P., \& Soraya, S. (2004). Adjustment to trauma exposure: Prevalence and predictors of posttraumatic stress disorder symptoms in mountain guides. Journal of Psychomatic Research, 57(4), 329-338.

Strauss, A. L. (1959). Mirrors and Masks. Glencoe, IL: Free Press. 
Strauss, A. L., \& Corbin, J. (1998). The Basics of Qualitative Analysis: Grounded Theory Procedures and Techniques ( $2^{\text {nd }}$ ed). Thousand Oaks, CA: Sage Publications.

Tuler, S., \& Webler, T. (1999). Voices from the forest: What participants expect of a public participation process. Society and Natural Resources, 12(5), 437-453.

US Forest Service. (2008). Forest Service manual 2700: Special uses management. Retrieved July 27, 2009, from the US Forest Service Web site: http://www.fs.fed.us

Uprising Adventure Guides. (2010). Rock 101 - 1 day - Beginner. Retrieved Thursday, August 19, 2010, from Uprising Adventure Guides Web site: http://www.uprising.com/courses.php

Watts, A. (1992). Climber's Guide to Smith Rock. Guilford, CT: Falcon.

Weber, K. (2001). Outdoor adventure tourism: A review of research approaches. Annals of Tourism Research, 28(2), 360-377.

Wells, C. (2002). Warren Harding. The Independent (online edition), March 4, 2002. Retrieved Friday, September 17, 2010, from The Independent Web site: http://www.independent.co.uk/news/obituaries/warren-harding-729796.html.

Weinstein, M. (2008). TAMS Analyzer [computer software]. Kent, OH: Open source. West Virginia Department of Commerce. (2010). Why West Virginia. Retrieved Friday, September 17, 2010, from the West Virginia Department of Commerce Web site: http://www.wvcommerce.org/business/whywestvirginia/default.aspx.

Wright, D. J., Duncan, S. L., \& Lach, D. (2009). Social power and GIS technology: A review and assessment of approaches for natural resource management. Annals of the Association of American Geographers, 99(2), 254-272. 


\section{APPENDIX A: DEFINITIONS AND GLOSSARY OF CLIMBING TERMS}

active protection: equipment with moving parts that can be placed in and removed from crack systems, used to shorten the distance of a fall

aid climbing: climbing using protection as the means of ascent (as opposed to free climbing)

anchor: a site where climbers secure themselves at the top or bottom of a pitch, usually made up of several pieces of removable or fixed protection

belay: to protect a lead climber by feeding out rope and arresting falls; also, the site from which a person belays

belay plate: a friction device designed to arrest a falling climber and to slow the descent on a rappel.

Also called a belay device

beta: information about a particular route

bolt chopping: the act of removing a bolt without permission, often without repairing the site from which the bolt was removed

bouldering: unroped, gymnastic form of climbing

cam: a spring-loaded camming device (SLCD) placed in a crack to shorten the distance of a fall crag: a climbing area

crux: the most physically or mentally difficult part of a climb

exposure: a sense of the distance between the climber and the ground; a feeling that one is up very high first ascent: the first time a route is climbed. Also called an FA.

first ascentionist: the first person to climb a route; this person also names the route and suggests a grade for it 
fisherman's knot: a knot used to tie two ropes together with minimal slippage or to back up another knot; sometimes called a barrel knot

fixed protection: equipment permanently placed in rock to shorten the distance of a fall or provide a belay or rappel anchor

free climbing: climbing using natural features of the rock as the means of ascent

free solo: to climb alone, without protection

gear: see removable protection

grade: the subjective difficulty rating of a route, on a scale between $5.0-5.9$, then broken down to $5.10 \mathrm{a}-.5 .10 \mathrm{~d}, 5.11 \mathrm{a}-5.11 \mathrm{~d}$, and so on to 5.15 . Grades differ between crags because of their subjective nature.

groundfall: a fall resulting in a landing

hangdog: to hang repeatedly during the ascent of a route in order to learn a particular sequence of moves

headpointing: rehearsing a difficult route on toprope until a climber can do all of the moves in sequence, then climbing it on lead

hex: a hexagonally-shaped wedge placed in a crack to shorten the distance of a fall

human agency: the idea that individuals can act of their own free will outside of the constraints of social structures

lead climbing: climbing from the ground up, placing protection as the climber ascends multipitch: more than one rope length nut: a metal wedge placed in a crack to shorten the distance of a fall objective hazards: hazards that a climber cannot control, generally natural processes onsight: to climb a route with no prior information about that route 
passive protection: equipment without moving parts that can be placed in and removed from crack systems, used to shorten the distance of a fall

pinkpointing: redpointing a route with preplaced gear

pitch: approximately one rope length

piton: removable protection hammered into and out of cracks

pro: protection

rap bolting: placing bolts on rappel (as opposed to on lead)

rappel: to slide down a rope, usually to return to the ground after a climb is completed. Also called a rap.

rappel station: a set of anchors dedicated to rappelling only. Also called a rap station

redpointing: climbing a route with no falls from start to finish after more than one try, usually by rehearsing the moves on lead

removable protection: climbing equipment that can be placed in and removed from crack systems, used to shorten the distance of a fall. See also: nut, cam, hex, tricam

retrobolting: placing bolts after the first ascent, retroactively

routefinding: the ability to determine where a route goes

send: ascend, ascent

shuts: a type of bolts used for fixed anchors

splitter: cracks that are the same width from top to bottom

sport climbing: climbing that involves clipping fixed protection to shorten the distance of a fall

subjective hazards: potential hazards that a climber can control

tat: one-inch tubular webbing

teleological theories: theories that are universal or all-encompassing 
toprope: a configuration in which the climbing rope passes through a set of anchors and down to the individual climbing, lessening the risk involved in the climb in question. Sometimes called a slingshot belay.

traditional climbing: climbing that involves the placement of removable protection to shorten the distance of a fall. Also called trad climbing.

tricam: a piece of climbing protection that can be used passively or actively depending on the direction in which it is placed in the crack

water knot: a knot used to tie two pieces or ends of tubular webbing together with minimal slippage 


\title{
APPENDIX B: CURRICULUM VITAE
}

\section{KATHERINE A. THOMPSON}

\author{
706 Brunswick $\mathrm{Ct}$ \\ Morgantown WV 26508 \\ 304-276-5870 (cell) \\ recdoctor@gmail.com
}

\section{EDUCATION}

Ph. D. Candidate, Forest Resources/Recreation, Parks, and Tourism Resources, West Virginia University (expected graduation date: December 2010)

Dissertation title: Social Worlds of Rock Climbers at Seneca Rocks, West Virginia

Emphases: Outdoor recreation planning and management, collaborative planning methods, human dimensions of natural resource management, qualitative research methods, higher education instructional theory and practice

M. S., Recreation, Parks, and Tourism Resources, West Virginia University, 2007

Thesis: Management Perceptions of Off-Highway Vehicles on National Forest System Lands in Appalachia

B. A., Theatre Arts, University of Oregon, 1993

\section{PUBLICATIONS}

\section{Refereed publications}

Selin, S., Hunt, F., Blanche, C. \& Thompson, K. (2009). Outdoor Recreation Research and Education for the $21^{\text {st }}$ Century: Defining National Direction and Building Capacity. Journal of Forestry, 107(7), 346-349.

Thompson, K. A., Pierskalla, C. D., \& Schuett, M. A. (in review). Management perceptions of off-highway vehicle use on national forest system lands in Appalachia. Journal of Park and Recreation Administration.

\section{Peer-reviewed conference proceedings}

Thompson, K. A., Pierskalla, C. D., \& Schuett, M. A. (2008). Management perceptions of offhighway vehicle use on national forest system lands in Appalachia. pp. 300-305 in: Leblanc, C., Vogt, C., comps. Proceedings of the 2007 Northeastern Recreation Research Symposium, April 15-17, 2007. Bolton Landing, NY. USDA Forest Service General Technical Report GTR-NRS-P-23. Newtown Square, PA: USDA Forest Service, 
Northern Research Station.

Thompson, K. A., Pierskalla, C. D., \& Selin, S. W. (2007). Stakeholders' relationships with the USDA Forest Service at the Spruce Knob-Seneca Rocks National Recreation Area, West Virginia. pp. 176-179 in: Burns, R.; Robinson, K., comps. Proceedings of the 2006 Northeastern Recreation Research Symposium; 2006 April 9-11; Bolton Landing, NY. Gen. Tech. Rep. NRS-P-14. Newtown Square, PA: U.S. Department of Agriculture, Forest Service, Northern Research Station.

\section{Peer-reviewed published abstracts}

Thompson, K. A., Pierkalla, C. D., Selin, S. W., \& Smaldone, D. A. (2010). Social worlds of rock climbers at Seneca Rocks, West Virginia: Implications for Recreation Planning and Management. International Symposium on Society and Resource Management, June 6-10 2010, Corpus Christi, TX.

Thompson, K. A., Selin, S. W., \& Kruger, L. E. (2008). Amenity-based development at the New River Gorge National River: Dynamics of integrated park-community planning. International Symposium on Society and Resource Management, June 10-14, 2008, Burlington, VT.

Selin, S. W., Kruger, L. E., \& Thompson, K. A. (2008). Amenity-based development and America's forests: Addressing challenges through integrated science/policy systems. International Symposium on Society and Resource Management, June 10-14, 2008, Burlington, VT.

Thompson, K. A., \& Pierskalla, C. D. (2007). Off-highway vehicle use on national forest system lands in Appalachia: Management perceptions. International Symposium on Society and Resource Management, June 17-21, 2007, Park City, UT.

\section{CONFERENCE PRESENTATIONS}

\section{Invited papers}

Kruger, L. E., Selin, S. W., \& Thompson, K. A. (2008). Affinity to place, serious leisure, and community resilience in amenity communities. Understanding and Managing AmenityLed Migration in Mountain Regions, Banff Mountain Festival, May 15-19, 2008, Banff, Alberta, Canada.

\section{Paper presentations}

Thompson, K. A., Selin, S. W., \& Kruger, L. E. (2008). Amenity-based development at the New River Gorge National River: Dynamics of integrated park-community planning. International Symposium on Society and Resource Management, June 10-14, 2008, Burlington, VT.

Selin, S. W., Kruger, L. E., \& Thompson, K. A. (2008). Amenity-based development and America's forests: Addressing challenges through integrated science/policy systems. International Symposium on Society and Resource Management, June 10-14, 2008, Burlington, VT. 
Thompson, K. A., \& Pierskalla, C. D. (2007). Off-highway vehicle use on national forest system lands in Appalachia: Management perceptions. International Symposium on Society and Resource Management, June 17-21, 2007, Park City, Utah.

Thompson, K. A., Pierskalla, C. D., \& Schuett, M. A. (2007). Management perceptions of offhighway vehicle use on national forest system lands in Appalachia. Northeastern Recreation Research Symposium, April 15-17, 2007, Bolton Landing, NY.

\section{Poster presentations}

Thompson, K. A., Pierkalla, C. D., Selin, S. W., \& Smaldone, D. A. (2010). Social worlds of rock climbers at Seneca Rocks, West Virginia: Implications for Recreation Planning and Management. International Symposium on Society and Resource Management, June 6-10 2010, Corpus Christi, TX.

Thompson, K. A., Pierskalla, C. D., \& Selin, S. W. (2006). Stakeholders' relationships with the USDA Forest Service at the Spruce Knob-Seneca Rocks National Recreation Area, West Virginia (poster presentation). Northeastern Recreation Research Symposium, April 9-11, 2006, Bolton Landing, NY.

\section{TEACHING EXPERIENCE}

2008-2009 Instructor, Recreation, Parks, and Tourism Resources Program, Division of Forestry, West Virginia University

RPTR 142 Introduction to Recreation, Parks, and Tourism Resources ( 2 credits; Fall 2008, 2009)

Developed and instructed course designed to introduce new and potential majors to broad overview of the field of outdoor recreation management, including history, philosophy, current issues, career and service opportunities, professionalism, and the Recreation, Parks, and Tourism Resources (RPTR) program, using varied learning opportunities including guest speakers, service learning, field-based assignments, and group discussion. Planned and developed exams, lectures, discussions, and exercises for the course.

2007-2009 Teaching Assistant, Department of Recreation, Parks, and Tourism Resources, West Virginia University

FOR 670 Human Dimensions of Natural Resources (3 credits; Spring 2009)

Assisted in developing research project and leading discussions in an issue-based graduate-level course. Taught an overview of qualitative research methods to help students develop their final class project, which involved developing solutions for depreciative behavior at a popular recreation area on private property in Preston County, West Virginia. This course used a problem-based learning method to encourage systems-level thinking about issues related to human dimensions of natural resources. 
RPTR 142 Introduction to Recreation, Parks, and Tourism Resources ( 2 credits; Fall 2007) Assisted in developing and grading assignments for course designed to introduce new and potential majors to broad overview of the field of outdoor recreation management. Developed and led class lectures and discussions as needed. (Note: when I taught this class in 2008 and 2009 I redesigned the course based on RPTR faculty and student feedback about background knowledge needs for subsequent courses in the RPTR major course sequence.)

2007- Guest Lecturer, Division of Forestry, West Virginia University

2008

FOR 421 Natural Resource Policy and Governance (Fall 2008)

Led a discussion about ethics issues faced by natural resource professionals in a course for senior-level Forest Resource Management, Wildlife and Fisheries Management, and Recreation, Parks, and Tourism Resources students.

RPTR 433 Recreation Resource Management (Spring 2007)

Led a discussion about planning and management of recreation areas that provide offhighway vehicle use, including OHV-related management issues and trail design in a course for senior Recreation, Parks, and Tourism Resources and Forest Resource Management students.

2002 Instructor, Kitchener-Waterloo Arts Association, Kitchener, Ontario, Canada (Summer 2002)

Developed and taught acting and screenwriting for a summer program designed to develop basic work skills in at-risk youth aged 14-23. Facilitated discussions and managed conflict between participants. Project documentary available on request (VHS).

2001

Lead Instructor, Wilfrid Laurier University, Waterloo, Ontario, Canada (Summer 2001)

Led summer drama camp for 8-12-year-olds. Responsible for direct supervision of and hiring recommendations for two undergraduate instructors, classroom management, direction of final production, co-instruction of stage combat, research and development of program notes, and stage management of final production. Also stage managed production by concurrent summer drama camp designed for severely disabled youth and adults.

1989-1991 Pedagogue, Department of Theatre Arts, University of Oregon

The University of Oregon Department of Theatre pedagogy program was a forcredit program designed to give undergraduate theatre majors classroom experience in order to prepare them for graduate school and other teaching opportunities.

1991 Acting IV (3 credits, Winter 1991)

Co-taught vocal technique and dialect work under supervision of faculty. Coached individual students on class performance projects. Developed and led lectures and discussions as requested. Provided input on final grades. 
1989 Acting III (3 credits, Spring 1990)

Coached individual students on class performance projects, including selecting and performing appropriate audition materials. Developed and led class session on auditioning for musical theatre and vocal technique. Participated in roleplaying for simulated audition situations. Provided input on final grades.

1989 Acting I (3 credits, Fall 1989)

Graded written assignments. Coached individual students on class performance projects. Led daily class physical and vocal warm-ups. Developed and led two class sessions on performing final monologue. Provided input on final grades.

\section{COMMUNITY SERVICE}

Outdoor Recreation Research and Education Steering Committee, USDA Cooperative State Research, Education, and Extension Service, May 2007

Tyro (student Editor), JUPTRR: Journal of Unusual Parks, Tourism and Recreation Research, 2006-2009

Interpretive Sign Design, Seneca Rocks Discovery Center, Monongahela National Forest, West Virginia, 2007

\section{PROFESSIONAL AFFILIATIONS}

Student member, International Association for Society and Natural Resources

Member, American Alpine Club

\section{OTHER EMPLOYMENT}

2003-2004 Locator/data entry clerk, TIPCO (through Express Personnel Services), Salem, Oregon

Using property surveys, located properties on county plat maps. Adjusted property lines on plat maps when necessary. Entered property title data.

2001-2003 Managing director, Paradox Theatre Company, Kitchener, Ontario, Canada

Responsible for all business operations of small semiprofessional repertory theatre company. Managed budget, kept books, sold advertising, rented rehearsal and performance space, hired all technical personnel (stage managers, designers, crew members), ran PR campaigns, designed and distributed promotional materials. Also directed, acted, designed sound, and stage managed as needed. 
2000-2001 Senior Quality Assurance Analyst, Research In Motion, Waterloo, Ontario, Canada

Supervised nine simultaneous quality assurance projects with three direct reports. Hired translators and coordinated testing for all Spanish-localized software. Coordinated directly with senior developers to resolve bug reports. Developed and executed test plans. Assisted in interviewing and hiring co-op students.

1998-2000 Senior Quality Assurance Analyst, International Product Engineering, Symantec Corporation, Toronto, Ontario, Canada

Led Korean localization team for WinFax Pro 9.0. Developed disk images with internationally localized operating systems and software, including Korean, Japanese, Chinese Traditional, Chinese Simplified, Spanish, French, and German. Coordinated directly with senior developers to resolve bug reports. Developed and executed test plans. Worked in English-language quality assurance as needed. Assisted in interviewing and hiring co-op students.

1997

Technical Writer (internal co-op position), Symantec Corporation, Toronto, Ontario, Canada

Developed online help systems. Wrote a chapter for the WinFax Pro 9.0 user manual on using ACT! And WinFax Pro together. Copyedited software documentation.

1996-1997 Senior Technical Editor, Symantec Corporation, Toronto, Ontario, Canada Member of design and development team for online technical support decision tree software. Created content for decision tree using HTML (hand-coding). Developed style guide for technical support knowledge base. Edited technical support knowledge base to conform to in-house style guide standards using Lotus Notes.

1994-1996 Senior Technical Support Analyst, Symantec Corporation, Eugene, Oregon, and Toronto, Ontario, Canada

Provided online technical support for a variety of software on Windows, DOS, $\mathrm{OS} / 2$, and Macintosh platforms via in-house BBS, CompuServe, and America OnLine. Designated responder to irate online customers. Provided telephone technical support for ACT! for Windows, DOS, and Macintosh, ACT! for Networks (DOS) and ACT! MobileLink for Windows.

1993-1994 Customer Service Representative, Symantec Corporation, Eugene, Oregon Processed software upgrade purchases and software returns via telephone.

1993

Fulfillment Services Coordinator, Symantec Corporation, Eugene, Oregon

Acted as liaison between outsourced call center in Denver, Colorado, and customer service operations in Eugene, Oregon. Resolved disputes with irate customers. Proofread marketing materials to ensure compliance with in-house promotional code standards.

\footnotetext{
John H. HOOU $\begin{aligned} & \text { ou=Acquisitions Department, } \\ & \text { email=John. Hagen@mail.wvu.edu } \\ & \mathrm{c}=\text { US } \\ & \text { Date: 2010.12.13 15:01:33 -05'00' }\end{aligned}$
} 